\title{
ECONOMICS
}

\section{QUALITY, QUANTITY, SPENDING AND PRICES}

by

Kenneth W Clements

and

\author{
Grace Gao
}

Business School

The University of Western Australia 
June 2011

\title{
QUALITY, QUANTITY, SPENDING AND PRICES
}

\author{
by \\ Kenneth W Clements \\ and \\ Grace Gao* \\ Business School \\ The University of Western Australia
}

DISCUSSION PAPER 11.12

\begin{abstract}
$\underline{\text { Abstract }}$
One measure of the change in the "quality" of consumption is the degree to which the consumption basket as a whole moves towards more luxurious goods, away from necessities. We introduce two related measures based on the luxury/necessity distinction. One is an index of the extent to which the prices of luxuries change as compared to necessities, while the second indexes the change in spending. These two measures are interpreted as the price of and spending on quality. The "volume" of quality is then spending deflated by its price. Using the recent International Comparison Program data for $100+$ countries, we find that on average quality increases with income, but at a slower rate; luxuries are relatively more expensive in richer countries, necessities cheaper; and approximately 80 percent of additional spending on quality flows into a volume component, with the remaining 20 percent accounted for by prices.
\end{abstract}

*Kenneth Clements is a Winthrop Professor of Economics and BHP Billiton Research Fellow, Business School, UWA. Grace Gao is a PhD student in the Business School, UWA. We would like to acknowledge the helpful comments of Ganesh Viswanath Natraj and Mei-Hsiu Chen. This research was supported in part by BHP Billiton and the ARC. 


\section{Introduction}

Consumption differs vastly over consumers, time and space. For example, if we use PPPs and set real per capita consumption in the US at 100, then in 2005 in the Democratic Republic of the Congo consumption is 0.4 , that is, only 0.4 percent that of the US. In addition to differences in scale, the pattern of consumption also exhibits large differences. Thus, while food absorbs only about 6 percent of the American consumption budget, the Congolese devote more than 60 percent to food. ${ }^{1}$ Much of this decline in the food share as income rises is a reflection of Engel's law that the income elasticity of food is less than unity. Of course, the type and/or quality of food purchased would be likely to differ in the two countries, as well as its volume. These sorts of quality differences are a general problem when making cross-country comparisons of consumption. It is for this reason that the main topic of this paper is the theory and measurement of the quality of consumption across countries. We also introduce new summary measures of consumption patterns in the world economy.

The most well-known way of dealing with quality is the hedonic regression approach in which the price of a product is related to its physical characteristics (Griliches, 1961). A popular example is the case of personal computers, which have been subject to rapid quality improvements regarding processing speed and storage capacity (see, e. g., Berndt and Rappaport, 2001). Regressing the price of various types of PCs on speed and storage gives the shadow prices of the characteristics. From these, the effect of the quality improvements can be stripped out of the observed prices to yield a constant-quality index of prices. Quality improvement lowers the constant-quality price, so when we use this to deflate expenditure on PCs, the implied volume of computing power is higher than if no adjustment were undertaken. Another straightforward case is improvements in crop yields due to biological advances: If seed for growing wheat now produces 5 percent more than before and its price remains unchanged, then in quality-adjusted terms its price has fallen by 5 percent.

But for several reasons, the hedonic approach is not perfect and continues to attract controversy. First, the number of goods that possess easily-identified physical characteristics is limited. Also, there is still scope for differing views regarding the appropriate characteristics (which characteristics should be included in the regression?). Second, there can be disputation about the very nature of a "quality-adjusted good". If there is no good currently in existence that possesses the baseline characteristics, in what sense can it be said that the price of this nonexistent good has declined? In other words, to benefit from the quality improvement, consumers have to purchase the new model whose nominal price (unadjusted for quality) may well have risen. It is for this reason that those on fixed incomes indexed to, say, the CPI tend to be hostile to hedonic adjustments as their perceived cost of living is understated. ${ }^{2}$ Third, many services (such as education, most types of medicine and, possibly, construction) are more difficult to decompose into their

\footnotetext{
${ }^{1}$ Details of these data are given later in the paper.

${ }^{2}$ For example, Annette Barbetti (2010), Federal President of the Superannuated Commonwealth Officers' Association in Australia, advocates the publication of a "shopping" CPI, which is the sum of the conventional CPI inflation rate and quality inflation, defined as the "increase in shelf prices that can be attributed to a perceived increase in quality or utility."
} 
core characteristics that are priced and thus not readily amenable to hedonics. ${ }^{3}$ This issue is especially difficult in high-income countries, where services tend to dominate the consumption basket. These problems possibly account for the reluctance of many statistical agencies to enthusiastically embrace the hedonic approach.

In this paper, we use a different approach to measuring quality that is due to Theil $(1975 / 76)$. Increased affluence leads to the consumption of luxuries (goods with income elasticities $>1$ ) growing faster than necessities (elasticties $<1$ ), so the basket moves in a direction that is more desirable. Thus, reverse engineering, if the basket has a tendency to become more intensive in goods (and services!) that are luxuries, less intensive in necessities, it has become more desirable and it can be said that quality has increased. In a sense, this is a revealed preference approach that relies only on observed behavior and makes no a priori judgments regarding what is really beneficial to the consumer. In this paper, we extend this approach to new measures of spending on quality and its price, as well as measures of uncertainty of quality.

There is substantial interest in comparing economies internationally and the associated rankings. Knowledge of the size of economies is important for purposes of economic policy (how did the rich countries become rich and what is keeping the poor poor?), international power politics (will China become larger than the US?), international migration (where are the enhanced job opportunities for me and my family?) and international marketing (where are the rapidly growing markets for my products?), to name some of the more prominent reasons. But it should be recognised that there are also substantial challenges in making reliable cross-country comparisons. This is essentially an issue of comparing like with like when we compare consumption in, say, New York City and Kinshasa, the capital of the DR of the Congo. Incomes, climate, language, culture and currency units all differ, as well as quality. Usually, it is only currency units that are standardised, but there is debate even here regarding which exchange rate to use (the market rate, purchasing power parity, the fundamental equilibrium rate, the Big Mac Index, etc.). While mindful of these important issues, as mentioned previously in this paper we deal with measuring quality differences across countries. The next two sections of the paper introduce the basic concepts, while Section 4 sets out formally the quality index and its extensions to spending and prices. Sections 5 and 6 deal with applications of the indexes to the $100+$ countries of the International Comparison Program (2008). This gives rise to a bilateral index that compare one country with another. These results are then summarised in Section 7 in multilateral form, whereby each country is compared with the world as a whole. In Section 8, we introduce new ways to analyse the underlying uncertainty of the measures of quality. Concluding comments are contained in Section 9.

\footnotetext{
${ }^{3}$ There is at least one major exception to this rule. House prices, the present value of future housing services, have long been subject to hedonic analysis.
} 


\section{Prices, Quantities and Budget Shares}

Let $\mathrm{p}_{\mathrm{i}}$ be the price of good $\mathrm{i}$ and $\mathrm{q}_{\mathrm{i}}$ be the corresponding quantity demanded. Then if there are $\mathrm{n}$ goods, $M=\sum_{i=1}^{n} p_{i} q_{i}$ is total expenditure ("income" for short), and $w_{i}=p_{i} q_{i} / M$ is the budget share of $i$, with $\sum_{\mathrm{i}=1}^{\mathrm{n}} \mathrm{w}_{\mathrm{i}}=1$. Using proportional changes, this share can be conveniently expressed as the sum of price, quantity and income components,

$$
\hat{\mathrm{w}}_{\mathrm{i}}=\hat{\mathrm{p}}_{\mathrm{i}}+\hat{\mathrm{q}}_{\mathrm{i}}-\hat{\mathrm{M}} \text {, }
$$

where a circumflex (“^”) denotes a proportional change (so that $\hat{x}=\mathrm{dx} / \mathrm{x}$, for $\mathrm{x}>0$ ). The differential of the budget constraint, $M=\sum_{i=1}^{n} p_{i} q_{i}$, is $d M=\sum_{i=1}^{n}\left(p_{i} d q_{i}+q_{i} d p_{i}\right)$, which if we divide both sides by $M$ and use the definition of the budget share, is equivalent to $\hat{M}=\sum_{i=1}^{n}\left(w_{i} \hat{q}_{i}+w_{i} \hat{p}_{i}\right)$, or

$$
\hat{\mathrm{M}}=\hat{\mathrm{Q}}+\hat{\mathrm{P}} \text {, with } \hat{\mathrm{Q}}=\sum_{\mathrm{i}=1}^{\mathrm{n}} \mathrm{w}_{\mathrm{i}} \hat{\mathrm{q}}_{\mathrm{i}} \text { and } \hat{\mathrm{P}}=\sum_{\mathrm{i}=1}^{\mathrm{n}} \mathrm{w}_{\mathrm{i}} \hat{\mathrm{p}}_{\mathrm{i}} \text {. }
$$

This shows that the change in nominal income, $\hat{M}$, can be decomposed into the sum of volume and price indexes, $\hat{\mathrm{Q}}$ and $\hat{\mathrm{P}}$. These are budget-share weighted averages of the $\mathrm{n}$ quantity and price changes and are known as Divisia (1925) indexes. The volume index $\hat{Q}$ is a measure of the change in real income, while the price index $\hat{\mathrm{P}}$ is the change in the cost of living. It follows from equation (2) that the change in real income is the excess of the change in money income over the change in the cost-of-living index, $\hat{\mathrm{Q}}=\hat{\mathrm{M}}-\hat{\mathrm{P}}$. Deflation is usually a matter of dividing by a price index, but division becomes subtraction when proportional changes are used.

The budget share $\mathrm{w}_{\mathrm{i}}$ is a dimensionless pure number, independent of currency units. But the same is not true for the prices $\mathrm{p}_{\mathrm{i}}$ and income $\mathrm{M}$, which is inconvenient for comparisons involving countries with different currencies (or different time periods in which the value of the currency changes due to inflation/deflation). Currency units disappear when the budget share is expressed in change form, as in equation (1), but $\hat{\mathrm{p}}_{\mathrm{i}}$ and $\hat{\mathrm{M}}$ are still both nominal variables, so that, for example, they would take larger values in times of higher inflation. We thus convert from nominal to real by subtracting and adding the price index $\hat{P}$ from the right-hand side of equation (1) to yield $\hat{\mathrm{w}}_{\mathrm{i}}=\left(\hat{\mathrm{p}}_{\mathrm{i}}-\hat{\mathrm{P}}\right)+\hat{\mathrm{q}}_{\mathrm{i}}-(\hat{\mathrm{M}}-\hat{\mathrm{P}})$, or

$$
\hat{\mathrm{w}}_{\mathrm{i}}=\frac{\widehat{\mathrm{p}_{\mathrm{i}}}}{\mathrm{P}}+\hat{\mathrm{q}}_{\mathrm{i}}-\hat{\mathrm{Q}}
$$

This expresses the change in the share as the sum of three components, (i) the change in the relative price, $\widehat{\mathrm{p}_{\mathrm{i}} / \mathrm{P}}$; (ii) the change in the quantity consumed, $\hat{\mathrm{q}}_{\mathrm{i}}$; and (iii) the change in real income, $\hat{\mathrm{Q}}$. Each of these three components is now a pure number suitable for cross-country comparisons. 


\section{Luxuries and Necessities}

Suppose for simplicity the relative price remains unchanged. Then, the first term on the right-hand side of equation (3) vanishes and we have

$\left(3^{\prime}\right) \quad \hat{\mathrm{W}}_{\mathrm{i}}=\hat{\mathrm{q}}_{\mathrm{i}}-\hat{\mathrm{Q}}$.

Consider the effect of income growth $(\hat{\mathrm{Q}}>0)$ on the budget share. This has a direct effect of causing the share to fall by $-\hat{Q}$, as well as an indirect effect due to the dependence of the quantity consumed $q_{i}$ on income. To analyse the latter effect, write the demand function for good i as $q_{i}=q_{i}(Q)$, so that

$$
\hat{\mathrm{q}}_{\mathrm{i}}=\eta_{\mathrm{i}} \hat{\mathrm{Q}}, \quad \text { with } \eta_{\mathrm{i}}=\frac{\mathrm{d}\left(\log \mathrm{q}_{\mathrm{i}}\right)}{\mathrm{d}(\log \mathrm{Q})}
$$

the income elasticity of demand for i. Luxuries have income elasticities greater than unity, as their consumption grows proportionately faster than income, while necessities $\left(\eta_{i}<1\right)$ grow slower. Consider the $\mathrm{n}$ income elasticites, $\eta_{1}, \ldots, \eta_{\mathrm{n}}$. It follows from the budget constraint that the budget-share weighted mean of these elasticities is unity, $\sum_{\mathrm{i}=1}^{\mathrm{n}} \mathrm{w}_{\mathrm{i}} \eta_{\mathrm{i}}=1$, so that not all goods can be either luxuries or necessities; the average income elasticity is unity. ${ }^{4}$

Combining equations (3') and (4), we have

$$
\hat{\mathrm{w}}_{\mathrm{i}}=\left(\eta_{\mathrm{i}}-1\right) \hat{\mathrm{Q}} \text {, }
$$

which reveals that the budget shares of luxuries increase with income, while those of necessities fall under the condition that the relative price of the good remains unchanged.

\section{Three Indexes Involving Income Elasticities}

In this section we consider three summary measures of the consumer's budget that deal with quality, the structure of prices and spending. These measures take the form of indexes that involve income elasticities.

\section{The Quality Index}

Suppose real income grows. The consumption of those goods that are luxuries grow faster than income, while necessities grow more slowly. The effect of this growth is for the consumer to spend relatively more on luxuries, less on necessities, as indicated by equation (4'). In this sense, luxuries are more desirable than necessities. If there is a systematic tendency for the consumption basket to move in the direction of luxuries, away from necessities, then we could say that the "quality" of consumption has increased. This is the basic idea of Theil's (1975/76, Sec. 11.3) index of quality, details of which follow.

\footnotetext{
${ }^{4}$ Above, we showed that the budget constraint in change form is $\hat{M}=\sum_{i=1}^{n}\left(w_{i} \hat{q}_{i}+w_{i} \hat{p}_{i}\right)$. Dividing both sides by $\hat{M}$, holding prices constant and using $\hat{\mathrm{q}}_{\mathrm{i}} / \hat{\mathrm{M}}=\eta_{\mathrm{i}}$, we obtain $\sum_{\mathrm{i}=1}^{\mathrm{n}} \mathrm{w}_{\mathrm{i}} \eta_{\mathrm{i}}=1$.
} 
Consider the deviation of the income elasticity from its weighted mean, $\eta_{i}-1$. A weighted average over all goods of these deviations is zero, $\sum_{i=1}^{n} w_{i}\left(\eta_{i}-1\right)=0$. A similar relationship also holds for the quantities consumed: As $\hat{\mathrm{Q}}=\sum_{\mathrm{i}=1}^{\mathrm{n}} \mathrm{W}_{\mathrm{i}} \hat{\mathrm{q}}_{\mathrm{i}}$, relative consumption, in change form, is $\hat{\mathrm{q}}_{\mathrm{i}}-\hat{\mathrm{Q}}$, which satisfies $\sum_{\mathrm{i}=1}^{\mathrm{n}} \mathrm{W}_{\mathrm{i}}\left(\hat{\mathrm{q}}_{\mathrm{i}}-\hat{\mathrm{Q}}\right)=0$. Suppose as a result of income growth, the consumption of good $\mathrm{i}$ grows faster than average, so that $\hat{\mathrm{q}}_{\mathrm{i}}-\hat{\mathrm{Q}}>0$. If this good is a luxury, $\eta_{\mathrm{i}}-1>0$ and $\left(\eta_{\mathrm{i}}-1\right)\left(\hat{\mathrm{q}}_{\mathrm{i}}-\hat{\mathrm{Q}}\right)>0$. On the other hand, if $\mathrm{i}$ is a necessity and grows slower than average, then $\left(\eta_{i}-1\right)\left(\hat{\mathrm{q}}_{\mathrm{i}}-\hat{\mathrm{Q}}\right)>0$. Thus, if relative consumption, $\hat{\mathrm{q}}_{\mathrm{i}}-\hat{\mathrm{Q}}$, is weighted by the excess of the good's income elasticity over unity, we obtain some useful information about the nature of this part of the consumption basket. In particular, a positive value of this product represents a movement towards a more desirable good, or away from a less desirable one, so there is an improvement in the quality of this part of the basket. On the other hand, quality diminishes when $\left(\eta_{\mathrm{i}}-1\right)\left(\hat{\mathrm{q}}_{\mathrm{i}}-\hat{\mathrm{Q}}\right)<0$. This is an objective measure of quality, based on the revealed preference of the consumer. Theil's quality index is a budget-share weighted average of the n products $\left(\eta_{i}-1\right)\left(\hat{\mathrm{q}}_{\mathrm{i}}-\hat{\mathrm{Q}}\right)$,

$$
\mathrm{y}_{\eta q}=\sum_{\mathrm{i}=1}^{\mathrm{n}} \mathrm{w}_{\mathrm{i}}\left(\eta_{\mathrm{i}}-1\right)\left(\hat{\mathrm{q}}_{\mathrm{i}}-\hat{\mathrm{Q}}\right)
$$

If $y_{\eta q}$ is positive (negative), then on average consumption of luxuries grows faster (slower) than average and that of necessities grows slower (faster) and the quality of the consumption basket has increased (decreased). The final thing to note about index (5) is that it also is a weighted covariance between the $\mathrm{n}$ income elasticities, $\eta_{1}, \ldots, \eta_{n}$, and the $n$ quantity changes, $\hat{\mathrm{q}}_{1}, \ldots, \hat{\mathrm{q}}_{\mathrm{n}}$, meaning that when the two variables are positively correlated, quality improves.

\section{The Structure-of-Prices Index}

Prices are usually taken as exogenous variables in the analysis of consumer demand, but there is no good reason why we should feel constrained by this convention. It is interesting to analyse systematic patterns in prices and an obvious starting point is again the luxury/necessity distinction.

The change in the relative price of good $i$ is $\hat{p}_{i}-\hat{P}$. The $n$ relative prices satisfy $\sum_{i=1}^{n} w_{i}\left(\hat{p}_{i}-\hat{P}\right)=0$. Suppose that the relative price of $\mathrm{i}$ increases and this good is a luxury, so that $\left(\eta_{\mathrm{i}}-1\right)\left(\hat{\mathrm{p}}_{\mathrm{i}}-\hat{\mathrm{P}}\right)>0$. Alternatively, if $i$ is a necessity and its relative price falls, then again we have $\left(\eta_{i}-1\right)\left(\hat{\mathrm{p}}_{\mathrm{i}}-\hat{\mathrm{P}}\right)>0$. Accordingly, a budget-share weighted-average of all such terms

$$
\mathrm{y}_{\eta p}=\sum_{\mathrm{i}=1}^{\mathrm{n}} \mathrm{w}_{\mathrm{i}}\left(\eta_{\mathrm{i}}-1\right)\left(\hat{\mathrm{p}}_{\mathrm{i}}-\hat{\mathrm{P}}\right)
$$


is positive when, on average, luxuries become relatively more expensive and necessities cheaper. A negative value means the opposite. Accordingly, we shall refer to (6) as an index of the structure of prices. Finally, like index (5), $\mathrm{y}_{\eta p}$ is a weighted covariance between the income elasticities and the relative price changes.

Relative to the poor, the rich spend a larger fraction of their income on luxuries and a smaller fraction on necessities. The value of $y_{\eta p}$ thus provides information regarding the distributional impact of changes in the structure of prices. When $\mathrm{y}_{\eta p}>0$, price changes have a progressive impact on the distribution of real income; and they are regressive when $\mathrm{y}_{\eta \mathrm{p}}<0$.

\section{The Allocation Index}

A convenient way to describe the allocation of income to the $\mathrm{n}$ goods is by the budget shares, $\mathrm{w}_{1}, \ldots, \mathrm{w}_{\mathrm{n}}$, or by their changes, $\mathrm{dw}_{1}, \ldots, \mathrm{dw}_{\mathrm{n}}$. By definition, $\sum_{\mathrm{i}=1}^{\mathrm{n}} \mathrm{w}_{\mathrm{i}}=1$, so that $\sum_{\mathrm{i}=1}^{\mathrm{n}} \mathrm{dw}_{\mathrm{i}}=0$. This implies that a budget-share weighted-average of the proportionate changes is zero, $\sum_{i=1}^{n} \mathrm{w}_{i} \hat{\mathrm{w}}_{\mathrm{i}}=0$, and the weighted covariance between the income elasticities and the budget share changes is

$$
\mathrm{y}_{\eta \mathrm{w}}=\sum_{\mathrm{i}=1}^{\mathrm{n}} \mathrm{w}_{\mathrm{i}}\left(\eta_{\mathrm{i}}-1\right) \hat{\mathrm{w}}_{\mathrm{i}} .
$$

This $\mathrm{y}_{\eta \mathrm{w}}$ is positive (negative) when, on average, the shares of luxuries increase (decrease) and those of necessities decrease (increase). As the budget shares summarise the allocation of the budget, we call expression (7) the allocation index.

Index (7) is obviously related to several of the above concepts. From equations (3), (5), (6) and (7), we have

$$
\mathrm{y}_{\eta \mathrm{w}}=\mathrm{y}_{\eta q}+\mathrm{y}_{\eta \mathrm{p}} \cdot
$$

In words, the allocation index is the sum of the quality and the structure of prices indexes. Suppose, for example, $\mathrm{y}_{\eta q}=0.05, \mathrm{y}_{\eta \mathrm{w}}=0.07$ and $\mathrm{y}_{\eta \mathrm{p}}=0.02$. Thus, a 5 percent-increase in quality is made up of the difference between 7 and 2 percent, so that quality is obtained by deflating a nominal variable by a price index. This establishes that $\mathrm{y}_{\eta \mathrm{w}}$ can be interpreted as expenditure on quality and $\mathrm{y}_{\eta \mathrm{p}}$ its cost, where both are expressed in terms of relative changes. This result is just like the deflation of money income to yield real income. Another way of seeing the spending interpretation of $y_{\eta w}$ is to use equation (1) in the form $\hat{w}_{i}=\widehat{p_{i} q_{i}}-\hat{M}$, and then substitute into (7) to yield $y_{\eta w}=\sum_{i=1}^{n} w_{i}\left(\eta_{i}-1\right)\left(\widehat{p_{i} q_{i}}-\hat{M}\right)$, which is a weighted covariance between the income elasticities and the change in expenditures.

\section{The Previous Literature}

We conclude this section with some brief notes on the literature. As mentioned above, the quality index (5) is due to Theil (1975/76, Sec. 11.3). For applications of this index, see Clements and Theil (1979), Finke (1983), Theil (1975/76, Sec 14.1), Theil and Chen (1996) and Theil and Suhm (1981, Chap. 5). Theil 
(1975/76, Sec. 11.3) also discusses alternative ways of measuring quality, including the hedonic approach of regressing product prices on an objective set of characteristics and the use of average prices paid for certain commodities on the basis that higher quality items are usually more expensive (Houthakker, 1952, Theil, 1952). Theil (1975/76, p. 173) briefly mentions the structure-of-prices index (6), but does not pursue it further to link it with the quality index as we do in equation (8). The impact of changing relative prices on the distribution of income has been studied in the literature (see, e. g., Broda and Romalis, 2009, Muellbauer, 1974, Nicholas et al., 2010, and Pendakur, 2002) and the structure-of-prices index (6) could be usefully applied in future research in this area.

When prices are held constant, equation $\left(4^{\prime}\right)$ gives the relationship between the change in the budget share and income. The reciprocal form of this relationship is $\hat{Q}=1 /\left(\eta_{i}-1\right) \cdot \hat{w}_{i}$, so that inferences can be made regarding income from information on the income elasticity and the budget share, provided $\eta_{\mathrm{i}} \neq 1$. Such an approach may be valuable when estimates of income are less reliable than those of budget shares, or when income is only published with a substantial lag (three years in the case of the most recent rendition of the World Bank's International Comparison Project, 2008, for example). Clements and Chen (2010) use this approach for food, the dominant commodity in the budget in many poor countries, for which there is considerable information available about its income elasticity. Thus, a falling food share is interpreted as reflecting rising income. As this idea deals with a single commodity, it is a bit different to the quality index, whereby higher quality is defined as a movement of the overall budget towards luxuries, away from necessities. Some combination of elements of the two approaches is possible, however. From equations $\left(3^{\prime}\right)$ and $\left(4^{\prime}\right)$, we have $\hat{\mathrm{q}}_{\mathrm{i}}-\hat{\mathrm{Q}}=\left(\eta_{\mathrm{i}}-1\right) \hat{\mathrm{Q}}$, so that the quality index (5) can be expressed as $\mathrm{y}_{\eta q}=\gamma \hat{\mathrm{Q}}$, where $\gamma=\sum_{\mathrm{i}=1}^{\mathrm{n}} \mathrm{w}_{\mathrm{i}}\left(\eta_{\mathrm{i}}-1\right)^{2}$ is the income elasticity of quality. As the budget-share weighted mean of the $\mathrm{n}$ income elasticities is unity, this $\gamma$ is a weighted variance of these elasticities; thus, $\gamma=0$ when each $\eta_{i}=1$, as then the composition of the consumption basket is unchanged with income growth. For broad aggregates, inferior goods are unlikely, as are goods so luxurious that their income elasticities exceed 2. It seems likely that the $\eta_{i}$ fall in the range $[0,2]$, which implies that $\gamma$ is a positive fraction. Thus, quality rises with income, but not as fast.

\section{Cross-Country Application}

The International Comparison Program (2008) presents data for 12 commodities in 146 countries. Clements and Chen (2010) use 132 of those countries, which are listed in Table 1 and ranked in terms of real income per capita. ${ }^{5}$ As can be seen, there is wide variation in income per capita, which ranges from 100 in the US, the richest country, to 0.4 in the Democratic Republic of Congo, the poorest. Additionally, the food budget share rises noticeably as income falls, from 6 percent of income in the US, to more than 60 percent in

\footnotetext{
${ }^{5}$ The 146-132=14 countries are not considered due to missing data or because of problems with outliers; see Clements and Chen (2010).
} 
the Congo, which is a reflection of Engel's law. In what follows, we use these 132-country data. Before turning to these results, however, we discuss some necessary adjustments to deal with finite-change data, as well as the source of the income elasticities.

\section{Discrete Countries}

The application of the quality index equation (5) to cross-country data involves the comparison of country $\mathrm{c}$ with country $\mathrm{d}$. Thus, the relative change in the consumption of good $i, \hat{\mathrm{q}}_{\mathrm{i}}$, is interpreted as $\hat{\mathrm{q}}_{\mathrm{i}}^{\mathrm{cd}}=\log \left(\mathrm{q}_{\mathrm{i}}^{\mathrm{c}} / \mathrm{q}_{\mathrm{i}}^{\mathrm{d}}\right)$, the change in income, $\hat{\mathrm{Q}}, \hat{\mathrm{Q}}^{\mathrm{cd}}=\sum_{\mathrm{i}=1}^{12} \mathrm{w}_{\mathrm{i}}^{\mathrm{cd}} \hat{\mathrm{q}}_{\mathrm{i}}^{\mathrm{cd}}$, the share, $\mathrm{w}_{\mathrm{i}}$, as $\mathrm{w}_{\mathrm{i}}^{\mathrm{cd}}=\left(\mathrm{w}_{\mathrm{i}}^{\mathrm{c}}+\mathrm{w}_{\mathrm{i}}^{\mathrm{d}}\right) / 2$, the average in the two countries, and the income elasticity, $\eta_{i}$, as $\eta_{i}^{\text {cd }}$, the elasticity corresponding to $w_{i}^{\text {cd }}$. Averaging over the two countries in this manner strikes a neutral balance that treats both symmetrically. We use exactly the same approach to apply the structure of prices index and the allocation index, equations (6) and (7). The three indexes now take the form

$$
\text { (9) } y_{\eta q}^{c d}=\sum_{i=1}^{12} w_{i}^{c d}\left(\eta_{i}^{c d}-1\right)\left(\hat{\mathrm{q}}_{i}^{c d}-\hat{Q}^{c d}\right), \quad y_{\eta p}^{c d}=\sum_{i=1}^{12} w_{i}^{c d}\left(\eta_{i}^{c d}-1\right)\left(\hat{p}_{i}^{c d}-\hat{P}^{c d}\right), \quad y_{\eta w}^{c d}=\sum_{i=1}^{12} w_{i}^{c d}\left(\eta_{i}^{c d}-1\right) \hat{w}_{i}^{c d} \text {. }
$$

These indexes now compare discretely-separated countries, so the changes are no longer infinitesimal. This implies that constraint (8), which refers to infinitesimal changes, holds only approximately in the finitechange case:

(10) $\quad y_{\eta w}^{c d} \approx y_{\eta q}^{c d}+y_{\eta p}^{c d}$.

\section{The Income Elasticities}

Application of the above indexes requires numerical values of the 12 income elasticities $\eta_{\mathrm{i}}$. We use the elasticities implied by the estimates of a demand system, the Florida model, from Clements and Chen (2010), given in Table 2. ${ }^{6}$ The last column of this table contains the income elasticities, evaluated at means. These show that food is a strong necessity, while the other goods are luxuries or nearly neutral. It must be emphasised, however, the income elasticities are not constant across countries in this model, as is illustrated for the case of food in Table 1. While these elasticties are all less than one, they are substantially higher in poorer countries. Below, we use the income elasticities for each country that are implied by the estimates of this model.

\section{The Three Indexes in 132 Countries}

With countries ranked according to decreasing income per capita, so that for country $\mathrm{c}<\mathrm{d}$, $\mathrm{c}$ is richer than $d$, the index $y_{\eta q}^{c d}$ in (9) involves a comparison of the quality of consumption in a richer country with a poorer one. Thus, as we expect quality to increase with income, when countries are ordered in this manner, the quality index is likely to be mostly positive. If, for example, $y_{\eta q}^{c d}=0.05$, then the quality of the

\footnotetext{
${ }^{6}$ On the Florida model, see Theil et al. (1989); and for a recent application, see Seale and Regmi (2006).
} 
consumption basket in the richer country c is 5 percent above that in the poorer country d. Similarly, as increased affluence leads to a tendency for the budget shares of luxuries to increase and those of necessities to decrease, the allocation index $y_{\eta w}^{c d}$ is also likely to be positive for rich:poor comparisons. How relative prices might change with income, is not clear, however. The effect of income growth is usually for wages to be higher and if services are labour intensive, their relative prices would tend to be higher also. Under the additional condition that services are luxuries, we would observe luxuries to be more expensive in rich countries, necessities cheaper. ${ }^{7}$ In this situation, the price-structure index $y_{\eta p}^{c d}>0$. But, in general, it is not possible to unambiguously sign $\mathrm{y}_{\eta \mathrm{p}}^{\mathrm{cd}}$. However, if $\mathrm{y}_{\eta \mathrm{w}}^{\mathrm{cd}}$ and $\mathrm{y}_{\eta q}^{\mathrm{cd}}$ are both positive and $\mathrm{y}_{\eta \mathrm{p}}^{\mathrm{cd}}<0$, approximation (10) implies that the price index cannot be too negative; that is, as an approximation, $y_{\eta p}^{\mathrm{cd}}>-\mathrm{y}_{\eta \mathrm{q}}^{\mathrm{cd}}$.

For the $\mathrm{c}=1, \ldots, 132$ countries, there are $132 \times 131 / 2=8,646$ distinct pairs for which $\mathrm{c}$ is richer than $\mathrm{d}$ $(c<d)$. Figure 1 contains histograms of the three indexes for these 8,646 cases. As can be seen, the quality and allocation indexes are indeed positive on average, while the price-structure index is smaller but still positive on average. In moving from a poorer to richer country, on average quality increases by about 8.9 percent, which is (approximately) made up of 10.3 percent additional spending on quality (the increase in the allocation index) less a 1.4-percent increase in its price (the structure of prices index).

For all pairs of countries $c, d=1, \ldots, 132$, the quality index can be arranged in the form of a $132 \times 132$ matrix $\left[y_{\eta q}^{c d}\right]$. The diagonals of this matrix refer to the own-country comparisons, which are all zero, and the upper triangle contains the quality index for country c (the row label) as compared to a poorer country $\mathrm{d}$ (the column), that is for $\mathrm{c}<\mathrm{d}$; this upper triangle contains the 8,646 elements considered above. The elements in the lower triangle are the negative of those in the upper triangle, reflecting the consistency requirement that if, for example, quality in c is 5 percent above that in $\mathrm{d}$, then d's quality is 5 percent below c's. Thus, $\left[\mathrm{y}_{\eta \mathrm{q}}^{\mathrm{cd}}\right]$ is a skew-symmetric matrix. Table 3 compares quality in each country relative to the US $(d=1)$ by presenting the first column of $\left[y_{\eta q}^{c d}\right]$, together with the corresponding measures for prices and spending. Thus, we see that while quality in Luxembourg is only about 1.7 percent less than that in the US, it is 33 percent lower in the Congo. With only a few exceptions, $y_{\eta q}^{c 1}<0$, so quality falls with income, as does its price (but at a slower rate) and expenditure. Roughly speaking there is an 80:20 rule, whereby 80 percent of the change in expenditure flows directly into the volume of quality, with the remaining 20 percent accounted for by prices. Figure 2, which plots the three indexes against the corresponding income differences, clearly show how these increase with affluence. Figure 3 shows that the errors associated with approximation (10) are quite modest, so the approximation is satisfactory.

\footnotetext{
${ }^{7}$ This is essentially the Balassa (1964)-Samuelson (1964) argument.
} 


\section{A Multilateral Formulation}

The above comparisons are all relative to the US. This is subject to two objections. First, although the US has the largest economy in the world, using this country as the base is still asymmetric as it singles it out for unnatural, special attention. A more neutral approach that treats all countries symmetrically would be appealing. The second problem when we compare one country with the US is that as this comparison is based on just one observation, it may be unreliable due to chance factors. A more robust measure would use observations on all relevant countries, which would decrease the role of chance. With these considerations in mind, in this section we formulate a summary measure of the pairwise comparisons, so we move from a bilateral index of quality involving pairs of countries to a multilateral version that compares each country with the mean. ${ }^{8} \mathrm{We}$ commence at the individual-country level and then aggregate to groups of countries.

\section{Individual Countries}

We express the $132^{2}=17,424$ elements of the matrix $\left[y_{\eta q}^{c d}\right]$ in terms of a smaller number of parameters as follows:

$$
\mathrm{y}_{\eta \mathrm{q}}^{\mathrm{cd}}=\alpha_{\mathrm{c}}-\alpha_{\mathrm{d}}+\varepsilon_{\mathrm{cd}}, \quad \mathrm{c}, \mathrm{d}=1, \ldots, 132,
$$

where $\alpha_{\mathrm{c}}$ is a parameter that satisfies $\sum_{\mathrm{c}=1}^{132} \alpha_{\mathrm{c}}=0$, and $\varepsilon_{\mathrm{cd}}$ is a zero-mean disturbance term with $\mathrm{E}\left(\varepsilon_{\mathrm{cd}}^{2}\right)=\sigma^{2}$. Model (11) states that aside from random factors, the quality index for countries $\mathrm{c}$ and $\mathrm{d}$ is equal to the difference between a factor for $\mathrm{c}$ and one for $\mathrm{d}$, so that for all pairs $\mathrm{c}, \mathrm{d}=1, \ldots, 132$, the $17 \mathrm{k}+$ pairwise comparisons are reduced to 132-1 parameters. Thus, this model provides a summary in a parsimonious manner, which helps keep things manageable, but the cost is that it rules out specific interactions between countries or groups thereof. The zero-sum constraint implies that the mean of the parameters $\alpha_{1}, \ldots, \alpha_{132}$ is zero, or that their geometric mean in unity. This is an identifying constraint that is similar to employing an arbitrary base (such as 100) for any index of levels.

In $y_{\eta q}^{\text {cd }}$, country $c$ is compared to $d$, so c could be termed the comparator and $d$ the comparatee. Accordingly, the term $-\alpha_{d}$ in model (11) is interpreted as the "comparatee effect" and $y_{\eta q}^{c d}+\alpha_{d}$ is the quality index net of this effect. Model (11) then implies that $E\left(y_{\eta q}^{c d}+\alpha_{d}\right)=\alpha_{c}$, which shows that $\alpha_{c}$ is the expected value of quality in country c, independent of the comparatee country. Similarly, $-\alpha_{d}=E\left(y_{\eta q}^{c d}-\alpha_{c}\right)$ is quality in $\mathrm{d}$ independent of the comparator, while adjusting for both effects gives

\footnotetext{
${ }^{8}$ This amounts to applying the stochastic approach to index numbers to the quality indexes, so there are indexes of indexes. The stochastic approach (SA) recasts conventional index-number theory in an econometric framework in which randomness is made explicit and the focus moves from a single number (the index value) to its whole distribution. For reviews of the SA, see Clements et al. (2006) and Selvanathan and Rao (1994). In a recent overview of the whole area, Diewert (2008) classifies the SA as one of four major approaches to index number theory. The other three are the fixed basket, the test and the economic approaches.
} 
$\mathrm{E}\left(\mathrm{y}_{\eta \mathrm{q}}^{\mathrm{cd}}-\alpha_{\mathrm{c}}+\alpha_{\mathrm{d}}\right)=\mathrm{E}\left(\varepsilon_{\mathrm{cd}}\right)=0$. Interchanging the roles of the two countries in the comparison simply results in a change in sign of these measures, reflecting the (skew) symmetric nature of the comparisons. In view of the zero mean of the country parameters, another interpretation of $\alpha_{c}$ is the quality of consumption in country $\mathrm{c}$ as compared to the mean of all countries, so quality is higher than average in some countries, lower in others, balancing out to zero over all countries. To further interpret the model, for comparator country c, sum both sides of equation (11) over $d=1, \ldots, 132$ and use $\sum_{d=1}^{132} \alpha_{d}=0$ to give $\sum_{\mathrm{d}=1}^{132} \mathrm{y}_{\eta q}^{\mathrm{cd}}=132 \cdot \alpha_{\mathrm{c}}+\mathrm{E}_{\mathrm{c}}$, where $\mathrm{E}_{\mathrm{c}}=\sum_{\mathrm{d}=1}^{132} \varepsilon_{\mathrm{cd}}$ is the sum of the disturbances involving c. Thus, $\alpha_{c}=1 / 132 \cdot\left(\sum_{\mathrm{d}=1}^{132} \mathrm{y}_{\eta \mathrm{q}}^{\mathrm{cd}}-\mathrm{E}_{\mathrm{c}}\right)$, which is the corresponding row average with the random component excluded. In summary, model (11) allows us to make simple, one-dimensional comparisons of quality across countries. ${ }^{9}$

In Appendix A1, model (11) is formulated as a dummy-variable regression for all 132 countries simultaneously and it is shown that the least-squares estimates are

$$
\hat{\alpha}_{c}=\frac{1}{132} \sum_{d=1}^{132} y_{\eta q}^{c d}, \quad \text { with } \operatorname{var}\left(\hat{\alpha}_{c}\right)=\hat{\sigma}^{2} \cdot \frac{131}{2 \times 132^{2}}, c=1, \ldots, 132,
$$

where $\hat{\sigma}^{2}=1 /[132(132-1)+1] \cdot \sum_{\mathrm{c}=1}^{132} \sum_{\mathrm{d}=1}^{132} \hat{\varepsilon}_{\mathrm{cd}}^{2}$ is the estimated error variance and $\hat{\varepsilon}_{\mathrm{cd}}=\mathrm{y}_{\eta q}^{\mathrm{cd}}-\hat{\alpha}_{\mathrm{c}}+\hat{\alpha}_{\mathrm{d}}$ is the residual for the pair of countries [c,d]. According to expression (12), the estimate of the parameter $\alpha_{c}$ for country $\mathrm{c}$ is just the mean the quality index for all pairwise comparisons involving that country. The elements of the $c^{\text {th }}$ row of the matrix $\left[y_{\eta q}^{\text {cd }}\right], y_{\eta q}^{c, 1}, \ldots, y_{\eta q}^{c, 132}$, give the quality in country c relative to each of the 132 countries in the world. The estimate $\hat{\alpha}_{c}$ is the closest single number to these 132 values in a leastsquares sense. The above interpretation of $\alpha_{c}$ is $1 / 132 \cdot\left(\sum_{d=1}^{132} y_{\eta q}^{c d}-E_{c}\right)$, which is the same as (12) except for the zero-mean term $\mathrm{E}_{\mathrm{c}}$. When the quality index can be better approximated by model (11), the error variance $\hat{\sigma}_{c}$ is lower. Expression (12) thus reveals that in this case, the sampling variance of $\hat{\alpha}_{c}$ is lower. These results are intuitively appealing.

Columns 2, 6 and 10 of Table 4 contain the estimates of model (11). These show that the quality of consumption in the top $60+$ countries is mostly above the mean and the rest mostly below. Ignoring a couple of outlying cases, the range of quality is roughly $[-12,12]$ percent around the mean. Compared to the previous results for the bilateral comparisons involving the US, in general, the impact of the averaging over countries is to reduce the quality differences. There are a couple of anomalous figures, but in the context of 132 countries, these are of no great cause for concern. As indicated in the note to Table 4, the standard error of the estimates is small at about 0.5 percent. The two other sets of figures in Table 4 apply exactly the same stochastic index approach to the structure-of-prices and the spending indexes. These results roughly conform

\footnotetext{
${ }^{9}$ Model (11) was proposed by Theil (1967, Sec. 5.3). Our approach extends Theil's work by showing how this model leads to a stochastic index number and developing its econometric implications; see Appendix A1 for details.
} 
to the $80: 20$ rule of the previous section. Note also that these estimates satisfy $\alpha_{c}($ volume $) \approx \alpha_{c}$ (spending) $+\alpha_{c}$ (price), which is constraint (10) in stochastic-index form.

\section{Groups of Countries}

The above analysis compresses the large volume of numerical results into something more manageable. Still further economies can be had by aggregating countries into groups with similar incomes. A simple approach is to divide the 132 countries into 6 groups, each containing 22 members, as indicated by the grid lines of Table 4. If we denote these groups by $\mathbf{S}_{1}, \ldots, \mathbf{S}_{6}$, the "groupwise" version of model (11) is then

$$
\mathrm{y}_{\eta q}^{\mathrm{cd}}=\mathrm{A}_{\mathrm{g}}-\mathrm{A}_{\mathrm{h}}+\zeta_{\mathrm{cd}}, \quad \mathrm{c} \in \mathrm{S}_{\mathrm{g}}, \mathrm{d} \in \mathrm{S}_{\mathrm{h}}, \mathrm{g}, \mathrm{h}=1, \ldots, 6
$$

where $A_{g}$ is a parameter for group $g$ that satisfies $\Sigma_{g=1}^{6} A_{g}=0$. The role of each member country of the group is now the same in the sense that for $c \in \mathbf{S}_{g}, d \in \mathbf{S}_{h}, E\left(y_{\eta q}^{c d}+A_{h}\right)=A_{g}$ and $E\left(y_{\eta q}^{c d}-A_{g}\right)=-A_{h}$. Another way to visualise the workings of this model is to compare it to the individual country model: Model (11) under the constraint $\alpha_{\mathrm{c}}=\mathrm{A}_{\mathrm{g}}, \mathrm{c} \in \mathbf{S}_{\mathrm{g}}$, coincides with (13). Columns 2, 4 and 6 of Table 4 show that this constraint is not exactly satisfied, but because countries within a group have similar incomes, in the main the departures are not gross. As established in Appendix A1, the LS estimate of $A_{g}$ is $\hat{A}_{g}=1 / 22 \cdot \Sigma_{c \in \mathbf{S}_{g}} \hat{\alpha}_{c}$, where $\hat{\alpha}_{c}$ is the estimate of the parameter for country c defined in equation (12), so the estimates are consistent in aggregation.

The estimates for the quality index for country groups are given in column 2 of panel A of Table 5, while the other columns give the pairwise comparisons implied by model (13), $\hat{\mathrm{A}}_{\mathrm{g}}-\hat{\mathrm{A}}_{\mathrm{h}}, \mathrm{g}, \mathrm{h}=1, \ldots, 6$, and $\mathrm{g}<\mathrm{h}$. The first entry of column $2,11.89$, means that the quality of consumption in the richest 22 countries is about 12 percent above the average for the world, while according to the sixth entry, -11.03 , quality in the poorest countries is about 11 percent below average. Thus, quality in the richest, as compared to that in the poorest, is higher by $11.89+11.03=22.92$, or about 23 percent, as indicated by the first entry of column 7 . Moving down the first six elements of column 2, the largest jump is from "Medium Rich" to "Lower Rich" (group 2 to 3), whereby quality falls by more than 6 percentage points. These differences in quality still seem to be reasonably modest in view of the substantially larger income disparities. In other words, quality increases with income, but at a slower rate, which was foreshadowed at the end of Section 4 above. This difficulty in enhancing the quality of the consumption basket may be an explanation of the apparent lengths to which consumers in rich countries are prepared to go to in the pursuit of ever more elaborate ways to spend their incomes. ${ }^{10}$

\footnotetext{
${ }^{10}$ Fascination with, and the regulation of, spending patterns of the rich is a topic with a long history. For example, in Roman times, laws restricted certain types of expenditures, including the cost of funerals and memorials to the deceased, while in medieval Europe only royals were permitted to wear linen and lace (Frank, 1999, p. 199). Veblen (1899) points to the apparent
} 
Panels B and C of Table 5 apply the same country-group approach to prices and spending and the results are similar to before. In richer countries as compared to the poor, there is more spending on quality and luxuries are more expensive while necessities are cheaper. And the price effect is smaller than the spending effect. ${ }^{11}$

\section{Quality and Uncertainty}

The above measures of quality are based on income elasticties and the quantities consumed, which both have random components: The income elasticities are only estimates and are subject to estimation uncertainty, while the quantities are drawings from an underlying probability distribution. Accordingly, the quality indexes can be thought of as referring to expected values. In this section, we explicitly recognise randomness and introduce procedures to analyse the whole distribution of the quality index.

The Florida demand model of Table 2 can be written for the $n-1=11$ commodities as

$$
\mathbf{w}^{\mathrm{c}}=\mathbf{f}\left(\mathbf{x}^{\mathrm{c}}, \theta\right)+\varepsilon^{\mathrm{c}}
$$

where $\mathbf{w}^{c}$ and $\varepsilon^{c}$ are vectors of budget shares and disturbances for country $c, \mathbf{x}^{c}$ is a vector of income and prices, and $\theta$ is a vector of parameters. We simulate the budget vector for country c from equation (14) by (i) drawing $\varepsilon^{\mathrm{c}}$ from a multivariate normal distribution with mean vector zero and covariance matrix equal to its data-based maximum likelihood estimate; (ii) using for $\theta$ its data-based estimate; and (iii) using the observed values of $\mathbf{x}^{\mathrm{c}}$. Repeating this for each of the 132 countries leads to 132 values of the simulated budget vectors, $\mathbf{w}^{\mathrm{c}(\mathrm{s})}, \mathrm{c}=1, \ldots, 132$, which are used together with $\mathbf{x}^{\mathrm{c}}$ to reestimate the model by the same ML procedure to yield $\theta^{(s)}$. These simulated values are then used to reevaluate the income elasticties, quantities, and the quality index. Repeating this procedure 1,000 times yields the distribution of the quality index, which we summarise in the form of the stochastic index numbers for the six groups of countries. ${ }^{12}$

Figure 4 contains the results in the form of histograms that compare quality in one group of countries with that in another. There are several noteworthy patterns. First, the move from left to right along a given row involves comparing one group with successively poorer ones. As the distributions shift to the right with such a move, this means that quality becomes more different the greater are the income differences. Second, while the means are reasonably close to the values in panel A of Table 5, there is a systematic tendency for them to be lower, which is a reflection of Jenson's inequality. Third, for

excesses of consumption of the rich in the US Gilded Era, 1890-1915, and coined the term "conspicuous consumption". More recently, Frank (1999) documents a surge in luxury spending in the US during the boom of the 1990s; this surge surely extended up to the financial crisis of 2007 . He argues much of that spending was socially wasteful and cites colourful examples of $\$ 17,000$ watches, sales of luxury cars, bigger and better equipped houses, pleasure craft, professional home appliances and cosmetic surgery (Frank, 1999, pp. 16-27). This type of spending is indicative that it is not easy to enhance the effective quality of the consumption basket of the rich and the extraordinary "efforts" they have to incur to increase this quality. This suggests a low income sensitivity of quality.

${ }_{11}^{11}$ See Appendix A2 for an analysis of the income sensitivity of the volume of, price of and spending on quality.

${ }^{12}$ As the Florida model does not constrain the budget share to the [0,1] interval, in some trials the simulated share fell outside this range. In these instances, we disregarded the trial and draw a new one. If after repeating this approach three time, the [0,1] constraint is still violated, the share vector is set to its observed value. This implies that the simulation provides a lower bound to the true dispersion of the quality index. 
"neighbouring" country groups on the income scale, the standard deviations of the quality differences are of the order of 1 percent. Fourth, the dispersion of the quality distribution rises with the "income distance" between the groups being compared, which is reasonable. For example, comparing the very rich with the very poor, the average quality difference is about 18 precent with a standard deviation of 1.9 percent. All in all, it seems that the quality distribution is fairly compact.

Figure 5 plots the probability of quality differences against the "distance" between individual countries. As can be seen, this probability is much less than 1 for closely located countries, but rises rapidly and hits about 0.9 for a 30 -country distance. Thus, there is a high probability of quality differences for more distant countries on the income scale. Finally, rather than dealing with all the combined influence of all pairs of countries, Figure 6 provides some more detail by showing similar quality probabilities for individual pairs. Starting at the far right and moving towards the left, panel A of this figure plots the probably of US quality exceeding that in countries that become poorer and poorer. As for country 40 (Lithuania) this probability is about 0.9 , in about $(131-40) / 131 \approx 70$ percent of instances, quality in the US exceeds that in other countries with high probability. Panel B gives the corresponding probabilities for all pairs of counties. This panel is like a waterfall with the water level, which plays the role of the probability, falling by about one half, from 1 to something around 0.5 . The source of the water is concentrated where there is maximum contrast between countries, at the point that compares the Congo with the US (coordinates $\mathrm{c}=132, \mathrm{~d}=1$ ). The water flow then becomes wider and its level falls as countries become closer on the income scale, to end with comparisons of immediate neighbours (coordinates $\mathrm{c}=1, \ldots, 131, \mathrm{~d}=\mathrm{c}+1){ }^{13}$

\section{Concluding Comments}

As fillet steak costs more than twice rump steak, it is readily understood that it is a higher quality product. It is more nutritious, contains less fat and tastes better (at least to most meat-eaters), which is why consumers are willing to pay more for it. Similarly, flying business class rather than economy on long flights involves a better travel experience, with better service, better food and drink, and a higher chance of a more restful trip. But even in these nominally clear-cut cases, the comparison of the different varieties still entails considerable subjectivity - the quality difference is real, but mostly in the eye (mouth?) of the beholder. This issue becomes even more difficult for measuring the quality of the whole consumption basket that contains markedly diverse products: In what meaningful sense is it possible to compare the quality of restaurant meals and medical services, for example? In short, quality is a difficult concept and even more difficult to quantify.

Theil (1975/76) proposed the clever idea of measuring quality on the basis of the luxury/necessity distinction of goods. As more affluent consumers spend relatively more on luxuries, less on necessities, luxuries are more desirable than necessities. Quality thus increases when consumption moves towards

\footnotetext{
${ }^{13}$ Note that panel A of Figure 6 is the back right-hand "edge" of panel B. Note also that Figures 5 and 6 are from the simulations of the stochastic index approach. Results derived from the simulated quality index itself are very similar.
} 
luxuries, away from necessities. As it is based on the dimensionless concepts of income elasticities and rates of growth of consumption, this measure of quality has the advantage of being applicable to the whole consumption basket comprising diverse goods and services. When Scott Fitzgerald declared "The rich are different than you and me", Ernest Hemingway is said to have responded "Yes, they have more money". Hemingway could easily have added "And spend it on luxuries".

In this paper, we introduced a new approach to the price of and spending on quality, with Theil's measure of quality emerging as a volume index equal to spending deflated by price. To allow for the influence of estimation error and other sources of randomness, we also introduced measures of uncertainty of quality. Using the recent International Comparison Program data for $100+$ countries, we find that on average quality increases with income, but at a slower rate; luxuries are relatively more expensive in richer countries, necessities cheaper; and 80 percent of additional spending on quality flows into the volume component, with the remaining 20 percent accounted for by higher prices. 


\section{$\underline{\text { References }}$}

Balassa, B. (1964). "The Purchasing Power Parity Doctrine: A Reappraisal.” Journal of Political Economy 72: 584-96. Barbetti, A. (2010). "Adjustments to Prices for Technological Improvements and Quality Changes in Prices Indexes." Paper presented at Economics of (for) Price Indexes Conference, EPIC, Department of Economics, Melbourne University, June.

Berndt, E. R,. and N. J. Rappaport. (2001). "Price and Quality of Desktop and Mobile Personal Computers: A QuarterCentury Historical Overview." American Economic Review 91: 268-73.

Broda, C., and J. Romalis (2009). “The Welfare Implications of Rising Price Dispersion." Working Paper, Booth School of Business, The University of Chicago.

Clements, K. W., and D-L. Chen (2010). “Affluence and Food: A Simple Way to Infer Incomes.” American Journal of Agricultural Economics. 92: 909-26.

Clements, K. W., H. Y. Izan and E. A. Selvanathan (2006). "Stochastic Index Numbers: A Review." International Statistical Review 74: 235-70.

Clements, K. W., and H. Theil (1979). “A Cross-Country Analysis of Consumption Patterns.” Report 7924 of the Centre for Mathematical Studies in Business and Economics, The University of Chicago. In H. Theil Studies in Global Econometrics. Dordrecht: Kluwer Academic Publishers, 1996, pp. 95-108.

Diewert, W. E. (2008). "Index Numbers." In The New Palgrave Dictionary of Economics. Second Edition. Eds. S. N. Durlauf and L. E. Blume. Palgrave Macmillan. The New Palgrave Dictionary of Economics Online. Palgrave $\quad$ Macmillan. $\quad 01 \quad$ February 2011 $<$ http://www.dictionaryofeconomics.com/article?id=pde2008_I000053> doi:10.1057/9780230226203.0775

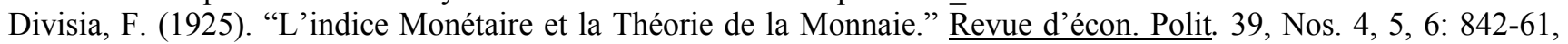
980-1008, 1121-51.

Finke, R. (1983). “A New Cross-Country Tabulation of the Quality Index of Consumption.” Economics Letters 13: 11-14.

Frank, R. H. (1999). Luxury Fever: Money and Happiness in an Era of Excess. Princeton and Oxford: Princeton University Press.

Griliches, Z. (1961). "Hedonic Price Indexes for Automobiles: An Econometric Analysis of Quality Change.” In The Price Statistics of the Federal Government, General Series No. 73, New York, NY: Columbia University Press. Pp. 137-96.

Houthakker, H. S. (1952). “Compensated Changes in Quantities and Qualities Consumed." Review of Economic Studies 19: 155-64.

International Comparison Program (2008). "Global Purchasing Power Parities and Real Expenditures." Washington, DC: The World Bank. Available at http://www.worldbank.org.

Muellbauer, J. (1974). "Prices and Inequality: The United Kingdom Experience.” Economic Journal 84: $32-55$.

Nicholas, A., R. Ray and R. Valenzuela (2010). "Evaluating the Distributional Implications of Price Movements: Methodology, Application and Australian Evidence.” Economic Record 86: 352-66.

Pendakur, K. (2002). "Taking Prices Seriously in the Measurement of Inequality." Journal of Public Economics 86: 47-69.

Samuelson, P. A. (1964). "Theoretical Notes on Trade Problems.” Review of Economics and Statistics 46: $145-54$.

Seale Jr., J., A. Regmi (2006). "Modeling International Consumption Patterns.” Review of Income and Wealth 52: 603-24.

Selvanathan, E. A., and D. S. Prasada Rao (1994). Index Numbers: A Stochastic Approach. London: Macmillan.

Theil, H. (1952). “Qualities, Prices and Budget Enquiries.” Review of Economic Studies 19: 129-47.

Theil, H. (1967). Economics and Information Theory. Amsterdam and Chicago: North-Holland and Rand McNally.

Theil, H. (1975/76). Theory and Measurement of Consumer Demand. Two volumes. Amsterdam: North-Holland.

Theil, H., and D-L. Chen (1996). "The Quality of Consumption in Rich and Poor Countries." In H. Theil Studies in Global Econometrics. Dordrecht: Kluwer Academic Publishers. Pp. 89-94.

Theil, H., C.-F. Chung and J. L. Seale Jr (1989). International Evidence on Consumption Patterns. Greenwich, Conn.: JAI Press.

Theil, H., and F. E. Suhm (1981). International Consumption Comparisons: A System-Wide Approach. Amsterdam: North-Holland.

Veblen, T. (1899). The Theory of the Leisure Class. New York: Modern Library. 
TABLE 1

REAL INCOMES, FOOD BUDGET SHARES AND INCOME ELASTICITIES, 132 COUNTRIES IN 2005

\begin{tabular}{|c|c|c|c|c|c|c|c|c|c|c|c|}
\hline \multirow[b]{2}{*}{ Country } & \multirow[b]{2}{*}{$\begin{array}{l}\text { Income } \\
\text { p.c. }\end{array}$} & \multicolumn{2}{|c|}{ Food } & \multirow[b]{2}{*}{ Country } & \multirow[b]{2}{*}{$\begin{array}{l}\text { Income } \\
\text { p.c. }\end{array}$} & \multicolumn{2}{|c|}{ Food } & \multirow[b]{2}{*}{ Country } & \multirow[b]{2}{*}{$\begin{array}{l}\text { Income } \\
\text { p.c. }\end{array}$} & \multicolumn{2}{|c|}{ Food } \\
\hline & & $\begin{array}{c}\text { Budget } \\
\text { share }\end{array}$ & $\begin{array}{r}\text { Income } \\
\text { elasticity }\end{array}$ & & & $\begin{array}{r}\begin{array}{r}\text { Budget } \\
\text { share }\end{array} \\
\end{array}$ & $\begin{array}{r}\text { Income } \\
\text { elasticity }\end{array}$ & & & $\begin{array}{r}\begin{array}{r}\text { Budget } \\
\text { share }\end{array}\end{array}$ & $\begin{array}{r}\text { Income } \\
\text { elasticity }\end{array}$ \\
\hline 1. United States & 100.0 & 6.2 & 0.09 & 45. Lebanon & 32.0 & 27.8 & 0.55 & 89. Cape Verde & 8.8 & 28.8 & 0.72 \\
\hline 2. Luxembourg & 92.2 & 6.9 & 0.15 & 46. Mexico & 28.7 & 22.0 & 0.57 & 90. Bhutan & 8.0 & 34.5 & 0.72 \\
\hline 3. Iceland & 80.7 & 8.9 & 0.24 & 47. Belarus & 27.3 & 34.7 & 0.58 & 91. Kyrgyz & 8.0 & 40.8 & 0.72 \\
\hline 4. Norway & 77.7 & 9.7 & 0.26 & 48. Kazakhstan & 26.5 & 18.6 & 0.59 & 92. Sri Lanka & 7.9 & 36.4 & 0.72 \\
\hline 5. United Kingdom & 76.9 & 7.1 & 0.26 & 49. Mauritius & 26.3 & 23.4 & 0.59 & 93. Iraq & 7.8 & 32.1 & 0.73 \\
\hline 6. Austria & 76.4 & 8.7 & 0.27 & 50. Russia & 26.3 & 25.5 & 0.59 & 94. Mongolia & 7.7 & 35.9 & 0.73 \\
\hline 7. Switzerland & 74.6 & 9.3 & 0.28 & 51. Bulgaria & 26.1 & 19.5 & 0.59 & 95. Philippines & 7.5 & 43.9 & 0.73 \\
\hline 8. Canada & 74.4 & 7.7 & 0.28 & 52. Iran & 25.2 & 23.4 & 0.60 & 96. Indonesia & 7.4 & 41.6 & 0.73 \\
\hline 9. Netherlands & 72.4 & 8.2 & 0.30 & 53. Romania & 24.4 & 25.0 & 0.60 & 97. Pakistan & 7.3 & 48.8 & 0.73 \\
\hline 10. Sweden & 72.0 & 8.3 & 0.30 & 54. Oman & 24.2 & 22.1 & 0.60 & 98. Morocco & 7.2 & 31.1 & 0.73 \\
\hline 11. France & 71.5 & 10.6 & 0.30 & 55. Argentina & 24.0 & 22.5 & 0.60 & 99. Lesotho & 7.1 & 35.5 & 0.73 \\
\hline 12. Australia & 70.6 & 8.5 & 0.31 & 56. Serbia & 23.7 & 25.6 & 0.61 & 100. China & 7.0 & 24.1 & 0.73 \\
\hline 13. Denmark & 69.8 & 8.1 & 0.31 & 57. Saudi Arabia & 23.6 & 18.5 & 0.61 & 101. Vietnam & 6.8 & 31.3 & 0.74 \\
\hline 14. Belgium & 68.4 & 10.3 & 0.32 & 58. Chile & 23.3 & 16.2 & 0.61 & 102. India & 5.5 & 33.7 & 0.75 \\
\hline 15. Germany & 67.5 & 9.1 & 0.33 & 59. Uruguay & 22.1 & 19.0 & 0.62 & 103. Cambodia & 5.3 & 47.2 & 0.75 \\
\hline 16. Hong Kong & 66.3 & 8.9 & 0.34 & 60. Bosnia Herz. & 21.9 & 28.5 & 0.62 & 104. Yemen & 5.2 & 41.1 & 0.75 \\
\hline 17. Ireland & 66.2 & 4.6 & 0.34 & 61. Macedonia & 20.5 & 30.9 & 0.63 & 105. Sudan & 4.5 & 55.6 & 0.76 \\
\hline 18. Japan & 66.0 & 12.3 & 0.34 & 62. Ukraine & 19.8 & 32.1 & 0.63 & 106. Lao & 4.4 & 47.3 & 0.76 \\
\hline 19. Taiwan & 64.5 & 14.8 & 0.35 & 63. South Africa & 19.3 & 17.6 & 0.64 & 107. Djibouti & 4.4 & 33.6 & 0.76 \\
\hline 20. Cyprus & 63.4 & 13.7 & 0.36 & 64. Malaysia & 19.3 & 17.3 & 0.64 & 108. Kenya & 4.3 & 33.3 & 0.76 \\
\hline 21. Finland & 63.0 & 9.3 & 0.36 & 65. Turkey & 18.9 & 23.1 & 0.64 & 109. Sao Tome & 4.3 & 53.7 & 0.76 \\
\hline 22. Spain & 61.9 & 11.8 & 0.37 & 66. Montenegro & 18.7 & 32.2 & 0.64 & 110. Congo, R. & 4.1 & 37.5 & 0.77 \\
\hline 23. Italy & 61.6 & 12.3 & 0.37 & 67. Brazil & 18.7 & 15.5 & 0.64 & 111. Cameroon & 4.0 & 43.4 & 0.77 \\
\hline 24. Greece & 59.4 & 13.8 & 0.38 & 68. Venezuela & 17.1 & 26.1 & 0.65 & 112. Nigeria & 4.0 & 56.7 & 0.77 \\
\hline 25. NZ & 57.7 & 11.5 & 0.39 & 69. Thailand & 16.1 & 15.9 & 0.66 & 113. Senegal & 3.9 & 48.9 & 0.77 \\
\hline 26. Israel & 54.7 & 12.9 & 0.41 & 70. Albania & 14.6 & 24.6 & 0.67 & 114. Chad & 3.5 & 55.0 & 0.78 \\
\hline 27. Malta & 54.3 & 13.9 & 0.41 & 71. Colombia & 14.5 & 24.3 & 0.67 & 115. Nepal & 3.4 & 48.7 & 0.78 \\
\hline 28. Singapore & 53.6 & 8.2 & 0.42 & 72. Ecuador & 13.7 & 25.9 & 0.68 & 116. Bangladesh & 3.3 & 49.9 & 0.78 \\
\hline 29. Qatar & 50.5 & 13.6 & 0.44 & 73. Jordan & 13.7 & 28.9 & 0.68 & 117. Benin & 3.3 & 43.6 & 0.78 \\
\hline 30. Slovenia & 50.0 & 11.9 & 0.44 & 74. Tunisia & 13.7 & 24.8 & 0.68 & 118. Ghana & 3.3 & 49.2 & 0.78 \\
\hline 31. Portugal & 49.0 & 13.1 & 0.45 & 75. Peru & 13.6 & 29.2 & 0.68 & 119. Cote d'Ivoire & 3.1 & 43.3 & 0.78 \\
\hline 32. Brunei & 48.7 & 18.4 & 0.45 & 76. Egypt & 13.5 & 41.6 & 0.68 & 120. S. Leone & 3.1 & 42.4 & 0.78 \\
\hline 33. Kuwait & 47.0 & 14.8 & 0.46 & 77. Moldova & 13.0 & 24.2 & 0.68 & 121. M'gascar & 3.0 & 57.0 & 0.78 \\
\hline 34. Czech Rep & 46.3 & 13.1 & 0.47 & 78. Maldives & 12.9 & 22.9 & 0.68 & 122. Togo & 2.7 & 48.6 & 0.79 \\
\hline 35. Hungary & 42.6 & 13.3 & 0.49 & 79. Gabon & 12.7 & 36.3 & 0.68 & 123. Burkina Faso & 2.5 & 42.0 & 0.79 \\
\hline 36. Bahrain & 41.6 & 19.0 & 0.49 & 80. Fiji & 12.6 & 26.3 & 0.68 & 124. Guinea & 2.4 & 44.0 & 0.79 \\
\hline 37. Korea & 40.4 & 13.7 & 0.50 & 81. Georgia & 12.1 & 36.7 & 0.69 & 125. Mali & 2.3 & 46.7 & 0.79 \\
\hline 38. Estonia & 39.4 & 15.4 & 0.51 & 82. Botswana & 11.9 & 21.9 & 0.69 & 126. Angola & 2.3 & 40.7 & 0.80 \\
\hline 39. Slovakia & 38.8 & 15.7 & 0.51 & 83. Namibia & 10.9 & 26.0 & 0.70 & 127. Rwanda & 2.1 & 42.7 & 0.80 \\
\hline 40. Lithuania & 38.3 & 22.9 & 0.51 & 84. Swaziland & 10.8 & 41.9 & 0.70 & 128. C. Africa & 1.9 & 56.8 & 0.80 \\
\hline 41. Poland & 36.7 & 17.8 & 0.52 & 85. Syria & 10.5 & 41.7 & 0.70 & 129. M'bique & 1.7 & 60.1 & 0.81 \\
\hline 42. Croatia & 36.1 & 19.3 & 0.53 & 86. Bolivia & 10.2 & 27.8 & 0.70 & 130. Niger & 1.3 & 46.4 & 0.82 \\
\hline 43. Macao & 36.1 & 13.3 & 0.53 & 87. Equat. Guinea & 10.1 & 39.5 & 0.71 & 131. G-Bissau & 1.2 & 52.3 & 0.82 \\
\hline 44. Latvia & 33.4 & 19.2 & 0.54 & 88. Paraguay & 9.9 & 32.3 & 0.71 & 132. Congo, D. R. & 0.4 & 62.2 & 0.85 \\
\hline
\end{tabular}

Notes: 1. Income is real total consumption expenditure per capita in United States dollars with United States=100.

2. Food shares are in percentage form.

3. See note 4 of Table 2 for details of the food income elasticities. 
TABLE 2

ESTIMATES OF DEMAND EQUATIONS, THE FLORIDA MODEL, 132 COUNTRIES IN 2005

$$
\begin{aligned}
\mathrm{w}_{\mathrm{i}}^{\mathrm{c}}= & \alpha_{\mathrm{i}}+\beta_{\mathrm{i}} \mathrm{q}^{\mathrm{c}}+\left(\alpha_{\mathrm{i}}+\beta_{\mathrm{i}} \mathrm{q}^{\mathrm{c}}\right)\left[\log \frac{\mathrm{p}_{\mathrm{i}}^{\mathrm{c}}}{\overline{\mathrm{p}}_{\mathrm{i}}}-\sum_{\mathrm{j}=1}^{12}\left(\alpha_{\mathrm{j}}+\beta_{\mathrm{j}} \mathrm{q}^{\mathrm{c}}\right) \log \frac{\mathrm{p}_{\mathrm{j}}^{\mathrm{c}}}{\overline{\mathrm{p}}_{\mathrm{j}}}\right] \\
& +\phi\left(\alpha_{\mathrm{i}}+\beta_{\mathrm{i}} \mathrm{q}^{{ }^{\mathrm{c}}}\right)\left[\log \frac{\mathrm{p}_{\mathrm{i}}^{\mathrm{c}}}{\overline{\mathrm{p}}_{\mathrm{i}}}-\sum_{\mathrm{j}=1}^{12}\left(\alpha_{\mathrm{j}}+\beta_{\mathrm{j}} \mathrm{q}^{*^{\mathrm{c}}}\right) \log \frac{\mathrm{p}_{\mathrm{j}}^{\mathrm{c}}}{\overline{\mathrm{p}}_{\mathrm{j}}}\right]+\varepsilon_{\mathrm{i}}^{\mathrm{c}}
\end{aligned}
$$

(Asymptotic standard errors in parentheses)

\begin{tabular}{lcccc}
\hline \hline \multicolumn{1}{c}{ Good } & Intercept $\alpha_{i}$ & Slope $\beta_{\mathrm{i}}$ & \multicolumn{2}{c}{ Mean } \\
\cline { 3 - 5 } 1. Food & $0.1007(0.0064)$ & $-0.0917(0.0034)$ & 0.2706 & 0.6612 \\
2. Alcohol \& tobacco & $0.0291(0.0028)$ & $-0.0023(0.0015)$ & 0.0334 & 0.9311 \\
3. Clothing & $0.0490(0.0028)$ & $-0.0019(0.0015)$ & 0.0525 & 0.9638 \\
4. Housing & $0.1590(0.0061)$ & $0.0064(0.0029)$ & 0.1471 & 1.0435 \\
5. Durables & $0.0590(0.0028)$ & $0.0036(0.0014)$ & 0.0523 & 1.0688 \\
6. Health & $0.0996(0.0033)$ & $0.0125(0.0019)$ & 0.0764 & 1.1635 \\
7. Transport & $0.1276(0.0044)$ & $0.0171(0.0021)$ & 0.0959 & 1.1783 \\
8. Communication & $0.0356(0.0019)$ & $0.0056(0.0008)$ & 0.0252 & 1.2220 \\
9. Recreation & $0.0815(0.0035)$ & $0.0177(0.0013)$ & 0.0487 & 1.3635 \\
10. Education & $0.0811(0.0049)$ & $-0.0008(0.0027)$ & 0.0826 & 0.9903 \\
11. Restaurants & $0.0676(0.0049)$ & $0.0126(0.0020)$ & 0.0442 & 1.2847 \\
12. Other & $0.1103(0.0048)$ & $0.0213(0.0021)$ & 0.0709 & 1.3004 \\
\hline Income flexibility $\phi$ & $-0.6782(0.0243)$ & & & \\
\hline
\end{tabular}

Notes: 1.The term $\mathrm{w}_{\mathrm{i}}^{\mathrm{c}}$ is the budget share of good $\mathrm{i}$ in country $\mathrm{c}, \mathrm{i}=1, \ldots, 12, \mathrm{c}=1, \ldots, 132 ; \alpha_{\mathrm{i}}$ and $\beta_{\mathrm{i}}$ are coefficients satisfying $\sum_{\mathrm{i}=1}^{\mathrm{n}} \alpha_{\mathrm{i}}=1, \sum_{\mathrm{i}=1}^{\mathrm{n}} \beta_{\mathrm{i}}=0 ; \mathrm{q}^{\mathrm{c}}=\log \mathrm{Q}^{\mathrm{c}}$ is the logarithm of real income per capita in country $\mathrm{c} ; \mathrm{q}^{*_{\mathrm{c}}}=1+\mathrm{q}^{\mathrm{c}}$; $\log p_{i}^{c}$ is the $\operatorname{logarithm}$ of the price of $\operatorname{good} i$ in $c$; $\log \bar{p}_{i}=(1 / 132) \sum_{c=1}^{132} \log p_{i}^{c}$ is the mean of the price of $i$, interpreted as the world price; $\varepsilon_{\mathrm{i}}^{\mathrm{c}}$ is a zero-mean disturbance term, drawn from a multivariate normal distribution with a covariance matrix that takes two values, one for the richest 69 countries and the other for the remaining 63 (to allow for heteroscedasticity).

2. The Florida model is a system of $n$ demand equations. The $i^{\text {th }}$ equation, given at the top of this table, expresses the budget share as the sum of four terms. The first is $\alpha_{i}+\beta_{i} q^{c}$, which deals with the effect of real income on the budget share with prices held constant. The second term is the "direct" effect of a change in the relative price of $i$ on its budget share, while the third term deals with the substitution effect of a change in this relative price (an "indirect" effect). The last term is the disturbance $\varepsilon_{i}^{\mathrm{c}}$ that deals with all other factors. The table gives the maximum likelihood estimates of the parameters of the Florida model for $n=12$ goods, obtained with data from the ICP (2008) as described in Clements and Chen (2010).

3. The second last column contains the cross-country mean budget shares $\overline{\mathrm{W}}_{\mathrm{i}}=(1 / 132) \sum_{\mathrm{c}=1}^{132} \mathrm{~W}_{\mathrm{i}}^{\mathrm{c}}$, while the last column contains the income elasticities at means $1+\hat{\beta}_{\mathrm{i}} / \overline{\mathrm{W}}_{\mathrm{i}}$, where $\hat{\beta}_{\mathrm{i}}$ is the estimated slope parameter for good $\mathrm{i}$.

4. The predicted budget share of $i$ in $c$ at world prices is $\hat{w}_{i}^{c}=\hat{\alpha}_{i}+\hat{\beta}_{i} q^{c}$, where $\hat{\alpha}_{i}$ is the estimated intercept. The income elasticity of $\mathrm{i}$ in $\mathrm{c}$ at world prices is then $1+\hat{\beta}_{\mathrm{i}} / \hat{\mathrm{w}}_{\mathrm{i}}^{\mathrm{c}}$. Table 1 contains the food income elasticities for each country. 
TABLE 3

BILATERAL QUALITY, PRICES AND ALLOCATION INDEXES, 131 COUNTRIES COMPARED TO US IN 2005

(Logarithmic changes $\times 100$ )

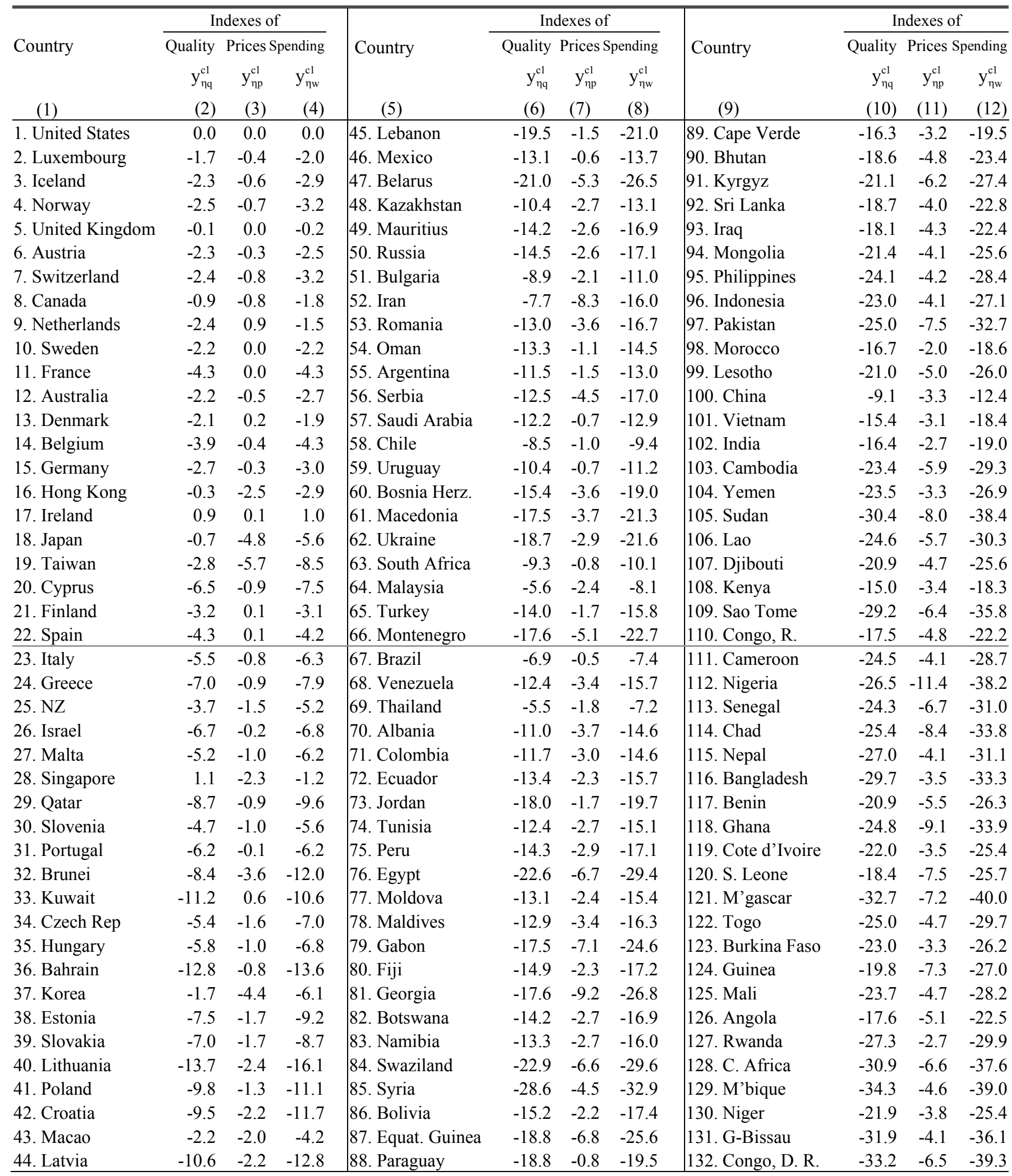


TABLE 4

MULTILATERAL INDEXES OF QUALITY, PRICES

AND SPENDING, 132 COUNTRIES IN 2005

(Logarithmic changes $\times 100$ )

\begin{tabular}{|c|c|c|c|c|c|c|c|c|c|c|c|}
\hline \multirow[b]{2}{*}{$\begin{array}{l}\text { Country } \\
\text { (1) }\end{array}$} & \multicolumn{3}{|c|}{ Index $\alpha_{c}$} & \multirow[b]{2}{*}{$\begin{array}{l}\text { Country } \\
\text { (5) }\end{array}$} & \multicolumn{3}{|c|}{ Index $\alpha_{c}$} & \multirow[b]{2}{*}{$\begin{array}{l}\text { Country } \\
\text { (9) }\end{array}$} & \multicolumn{3}{|c|}{ Index $\alpha_{c}$} \\
\hline & $\begin{array}{c}\text { Quality } \\
\text { (2) }\end{array}$ & $\begin{array}{l}\text { Prices } \\
\text { (3) }\end{array}$ & $\begin{array}{c}\text { Spending } \\
\text { (4) }\end{array}$ & & $\begin{array}{c}\text { Quality } \\
\text { (6) }\end{array}$ & $\begin{array}{c}\text { Prices } \\
(7)\end{array}$ & $\begin{array}{c}\text { Spending } \\
\text { (8) }\end{array}$ & & $\begin{array}{c}\text { Quality } \\
(10)\end{array}$ & $\begin{array}{r}\text { Prices } \\
(11)\end{array}$ & $\begin{array}{c}\text { Spending } \\
\text { (12) }\end{array}$ \\
\hline 1. United States & 13.9 & 3.1 & 17.1 & 45. Lebanon & -5.3 & 2.8 & -2.6 & 89. Cape Verde & -3.7 & -0.1 & -3.9 \\
\hline 2. Luxembourg & 12.3 & 2.2 & 14.5 & 46. Mexico & 0.8 & 2.2 & 3.0 & 90. Bhutan & -6.4 & -0.3 & -6.8 \\
\hline 3. Iceland & 12.0 & 1.7 & 13.7 & 47. Belarus & -5.6 & -0.6 & -6.2 & 91. Kyrgyz & -6.6 & -2.2 & -8.8 \\
\hline 4. Norway & 11.7 & 2.0 & 13.7 & 48. Kazakhstan & 1.4 & 0.4 & 1.8 & 92. Sri Lanka & -4.3 & -0.8 & -5.0 \\
\hline 5. United Kingdom & 14.7 & 2.2 & 16.9 & 49. Mauritius & -0.6 & 0.3 & -0.3 & 93. Iraq & -5.8 & -0.5 & -6.3 \\
\hline 6. Austria & 12.2 & 2.0 & 14.2 & 50. Russia & -0.5 & 0.8 & 0.3 & 94. Mongolia & -8.6 & -0.2 & -8.8 \\
\hline 7. Switzerland & 11.3 & 2.0 & 13.3 & 51. Bulgaria & 5.0 & 0.2 & 5.3 & 95. Philippines & -8.3 & -0.2 & -8.5 \\
\hline 8. Canada & 13.2 & 1.4 & 14.5 & 52. Iran & 5.3 & -5.1 & 0.1 & 96. Indonesia & -7.5 & -0.5 & -8.0 \\
\hline 9. Netherlands & 11.3 & 4.0 & 15.3 & 53. Romania & 0.6 & -0.3 & 0.2 & 97. Pakistan & -10.1 & -2.5 & -12.6 \\
\hline 10. Sweden & 11.5 & 2.7 & 14.2 & 54. Oman & -0.2 & 2.0 & 1.8 & 98. Morocco & -2.6 & 0.4 & -2.2 \\
\hline 11. France & 9.1 & 3.0 & 12.1 & 55. Argentina & 2.3 & 1.5 & 3.7 & 99. Lesotho & -8.6 & -1.2 & -9.7 \\
\hline 12. Australia & 11.7 & 1.8 & 13.5 & 56. Serbia & 0.9 & -1.1 & -0.2 & 100. China & 4.6 & -1.1 & 3.6 \\
\hline 13. Denmark & 11.7 & 2.8 & 14.5 & 57. Saudi Arabia & -0.4 & 2.3 & 1.9 & 101. Vietnam & -1.7 & -0.3 & -2.0 \\
\hline 14. Belgium & 9.3 & 2.6 & 11.9 & 58. Chile & 3.5 & 1.6 & 5.1 & 102. India & -3.2 & 0.6 & -2.6 \\
\hline 15. Germany & 10.5 & 2.5 & 13.1 & 59. Uruguay & 1.8 & 2.2 & 4.0 & 103. Cambodia & -8.9 & -1.3 & -10.2 \\
\hline 16. Hong Kong & 14.3 & -0.6 & 13.8 & 60. Bosnia Herz. & -1.0 & -0.1 & -1.2 & 104. Yemen & -10.0 & 0.7 & -9.3 \\
\hline 17. Ireland & 16.1 & 1.9 & 18.0 & 61. Macedonia & -3.3 & 0.2 & -3.1 & 105. Sudan & -14.2 & -3.5 & -17.5 \\
\hline 18. Japan & 13.6 & -2.5 & 11.1 & 62. Ukraine & -4.0 & 0.9 & -3.1 & 106. Lao & -9.7 & -1.6 & -11.3 \\
\hline 19. Taiwan & 11.8 & -3.0 & 8.7 & 63. South Africa & 2.9 & 1.7 & 4.6 & 107. Djibouti & -7.9 & -1.7 & -9.7 \\
\hline 20. Cyprus & 8.5 & 1.3 & 9.8 & 64. Malaysia & 8.4 & -0.7 & 7.7 & 108. Kenya & -0.8 & -0.9 & -1.7 \\
\hline 21. Finland & 10.4 & 2.7 & 13.1 & 65. Turkey & -0.8 & 0.9 & 0.0 & 109. Sao Tome & -13.5 & -2.0 & -15.5 \\
\hline 22. Spain & 10.4 & 2.6 & 13.1 & 66. Montenegro & -3.8 & -0.9 & -4.8 & 110. Congo, R. & -2.7 & -2.2 & -4.8 \\
\hline 23. Italy & 8.0 & 1.9 & 9.9 & 67. Brazil & 5.2 & 2.0 & 7.2 & 111. Cameroon & -9.2 & -1.0 & -10.1 \\
\hline 24. Greece & 7.7 & 1.6 & 9.3 & 68. Venezuela & 1.9 & -0.8 & 1.1 & 112. Nigeria & -11.2 & -6.4 & -17.6 \\
\hline 25. NZ & 10.3 & 0.8 & 11.1 & 69. Thailand & 9.1 & -0.7 & 8.4 & 113. Senegal & -9.4 & -2.8 & -12.2 \\
\hline 26. Israel & 6.5 & 2.6 & 9.1 & 70. Albania & 2.4 & -0.9 & 1.5 & 114. Chad & -8.1 & -4.1 & -12.1 \\
\hline 27. Malta & 9.8 & 1.3 & 11.1 & 71. Colombia & 1.5 & -0.4 & 1.1 & 115. Nepal & -13.8 & 0.6 & -13.1 \\
\hline 28. Singapore & 16.2 & -1.0 & 15.2 & 72. Ecuador & 0.2 & 0.3 & 0.5 & 116. Bangladesh & -15.6 & 0.8 & -14.7 \\
\hline 29. Qatar & 3.3 & 2.4 & 5.6 & 73. Jordan & -5.1 & 1.7 & -3.4 & 117. Benin & -5.3 & -2.4 & -7.7 \\
\hline 30. Slovenia & 8.8 & 1.3 & 10.2 & 74. Tunisia & 2.0 & -0.5 & 1.4 & 118. Ghana & -11.1 & -4.8 & -15.9 \\
\hline 31. Portugal & 7.3 & 2.6 & 10.0 & 75. Peru & 0.4 & 0.0 & 0.4 & 119. Cote & -7.3 & -0.5 & -7.7 \\
\hline 32. Brunei & 6.5 & -1.1 & 5.4 & 76. Egypt & -7.6 & -1.6 & -9.2 & 120. S. Leone & -5.3 & -3.4 & -8.8 \\
\hline 33. Kuwait & 1.1 & 3.7 & 4.8 & 77. Moldova & 0.1 & 0.1 & 0.2 & 121. M'gascar & -17.2 & -2.6 & -19.8 \\
\hline 34. Czech Rep & 8.1 & 0.9 & 9.0 & 78. Maldives & -1.9 & 0.1 & -1.9 & 122. Togo & -9.3 & -1.7 & -10.9 \\
\hline 35. Hungary & 7.4 & 1.5 & 8.9 & 79. Gabon & -3.4 & -2.9 & -6.3 & 123. Burkina & -7.9 & -0.2 & -8.0 \\
\hline 36. Bahrain & -0.4 & 2.9 & 2.5 & 80. Fiji & -2.7 & 0.9 & -1.8 & 124. Guinea & -2.7 & -6.2 & -8.7 \\
\hline 37. Korea & 12.9 & -2.8 & 10.1 & 81. Georgia & -3.5 & -5.1 & -8.6 & 125. Mali & -10.0 & -1.5 & -11.6 \\
\hline 38. Estonia & 6.0 & 0.8 & 6.8 & 82. Botswana & -1.9 & -0.7 & -2.6 & 126. Angola & -3.0 & -2.3 & -5.3 \\
\hline 39. Slovakia & 6.3 & 1.0 & 7.3 & 83. Namibia & -0.6 & 0.1 & -0.6 & 127. Rwanda & -14.5 & 0.7 & -13.8 \\
\hline 40. Lithuania & 0.4 & 1.2 & 1.5 & 84. Swaziland & -8.9 & -1.4 & -10.3 & 128. C. Africa & -15.4 & -2.8 & -18.3 \\
\hline 41. Poland & 3.1 & 1.9 & 5.1 & 85. Syria & -14.0 & 0.7 & -13.1 & 129. M'bique & -19.8 & -0.2 & -20.0 \\
\hline 42. Croatia & 4.5 & 0.6 & 5.1 & 86. Bolivia & -0.9 & 0.0 & -1.0 & 130. Niger & -6.2 & -1.0 & -7.1 \\
\hline 43. Мacao & 13.6 & -0.7 & 13.0 & 87. Equat. Guinea & -4.3 & -2.6 & -6.9 & 131. G-Bissau & -17.0 & -0.4 & -17.4 \\
\hline 44. Latvia & 2.9 & 0.7 & 3.6 & 88. Paraguay & -4.3 & 2.2 & -2.1 & 132. Congo, D.R & -23.5 & -0.5 & -24.1 \\
\hline
\end{tabular}

Note: The standard errors $(\times 100)$ of the indexes of quality, prices and spending are $0.48,0.23$ and 0.20 , respectively. 
TABLE 5

MULTILATERAL INDEXES FOR

SIX GROUPS OF COUNTRIES IN 2005

(Logarithmic changes $\times 100)$

\begin{tabular}{|c|c|c|c|c|c|c|}
\hline \multirow{2}{*}{$\begin{array}{l}\text { Country } \\
\text { group } \\
(1)\end{array}$} & \multirow[b]{2}{*}{$\begin{array}{c}\text { Index } \\
\mathrm{A}_{\mathrm{g}} \\
(2)\end{array}$} & \multicolumn{5}{|c|}{ Groupwise comparison $A_{g}-A_{h}$} \\
\hline & & $\begin{array}{l}\text { 2. Medium } \\
\text { rich } \\
(3)\end{array}$ & $\begin{array}{l}\text { 3. Lower } \\
\text { rich } \\
(4)\end{array}$ & $\begin{array}{l}\text { 4. Upper } \\
\text { poor } \\
(5)\end{array}$ & $\begin{array}{l}\text { 5. Medium } \\
\text { poor } \\
(6)\end{array}$ & $\begin{array}{l}\text { 6. Very } \\
\text { poor } \\
(7)\end{array}$ \\
\hline & & \multicolumn{5}{|c|}{ A. Quality } \\
\hline 1. Very rich & 11.89 & 5.05 & 11.55 & 13.54 & 18.27 & 22.92 \\
\hline 2. Medium rich & 6.84 & & 6.50 & 8.49 & 13.22 & 17.87 \\
\hline 3. Lower rich & 0.34 & & & 1.98 & 6.72 & 11.37 \\
\hline 4. Upper poor & -1.65 & & & & 4.73 & 9.38 \\
\hline 5. Medium poor & -6.38 & & & & & 4.65 \\
\hline \multirow[t]{2}{*}{ 6. Very poor } & -11.03 & & & & & \\
\hline & & \multicolumn{5}{|c|}{ B. Prices } \\
\hline 1. Very rich & 1.75 & 0.65 & 1.25 & 2.19 & 2.72 & 3.69 \\
\hline 2. Medium rich & 1.10 & & 0.60 & 1.54 & 2.07 & 3.04 \\
\hline 3. Lower rich & 0.50 & & & 0.94 & 1.47 & 2.44 \\
\hline 4. Upper poor & -0.44 & & & & 0.53 & 1.50 \\
\hline 5. Medium poor & -0.97 & & & & & 0.97 \\
\hline \multirow[t]{2}{*}{6. Very poor } & -1.94 & & & & & \\
\hline & \multicolumn{6}{|c|}{ C. Spending } \\
\hline 1. Very rich & 13.64 & 5.70 & 12.82 & 15.72 & 20.98 & 26.59 \\
\hline 2. Medium rich & 7.94 & & 7.12 & 10.02 & 15.28 & 20.89 \\
\hline 3. Lower rich & 0.82 & & & 2.90 & 8.17 & 13.77 \\
\hline 4. Upper poor & -2.09 & & & & 5.26 & 10.87 \\
\hline 5. Medium poor & -7.35 & & & & & 5.61 \\
\hline 6. Very poor & -12.96 & & & & & \\
\hline
\end{tabular}

Note: The standard errors $(\times 100)$ of the indexes of quality, prices and spending are $0.10,0.05$ and 0.08 , respectively. 
FIGURE 1

DISTRIBUTIONS OF THE THREE BILATERAL INDEXES, 132 COUNTRIES IN 2005

(Logarithmic changes $\times 100)$

A. Quality

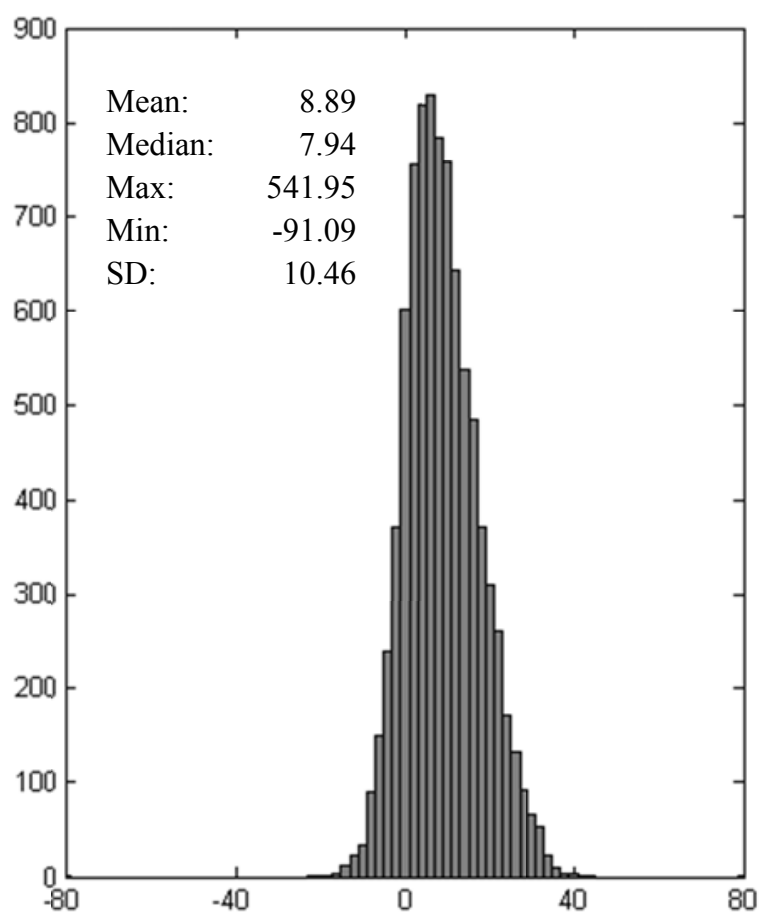

B. Allocation

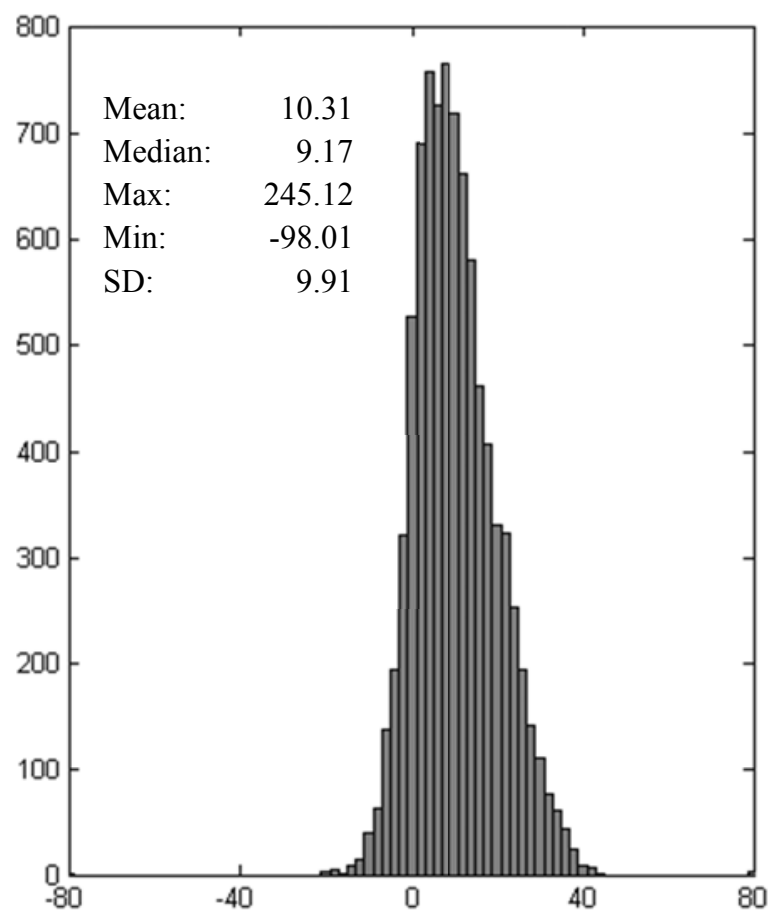

C. $\underline{\text { Prices }}$

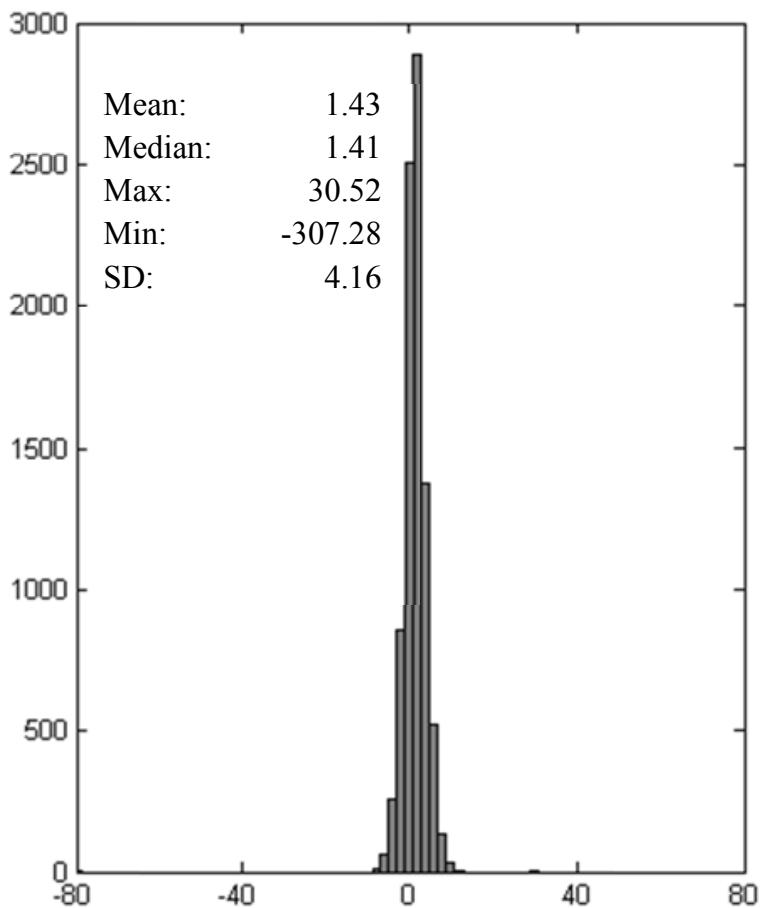

Note: To enhance clarity, observations falling outside the range $[-80,80]$ are excluded. 
FIGURE 2

SCATTER PLOTS OF THREE BILATERAL INDEXES AGAINST INCOME

A. Quality

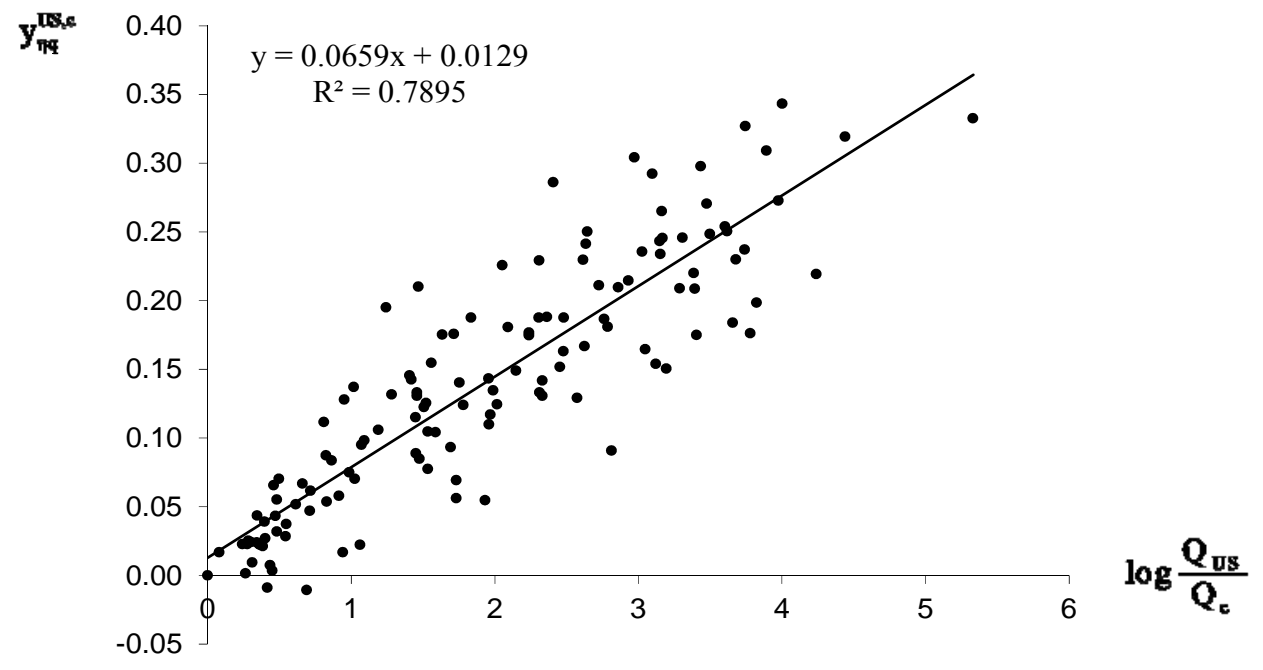

B. Prices

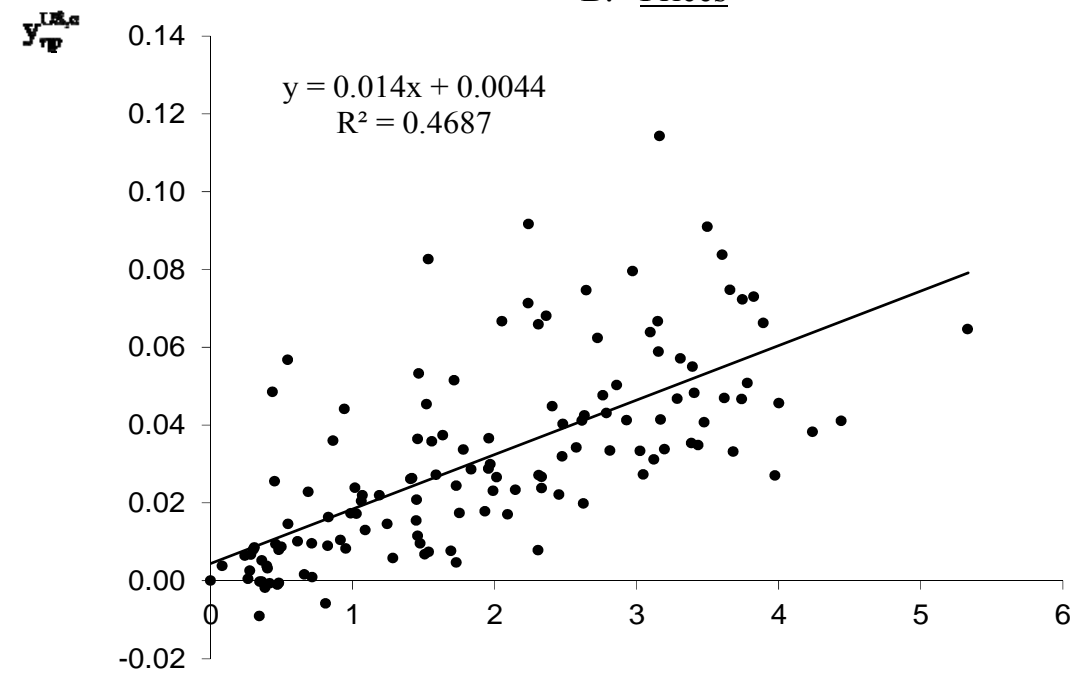

$\log \frac{Q_{\mathrm{us}}}{\mathbf{Q}_{\mathbf{c}}}$

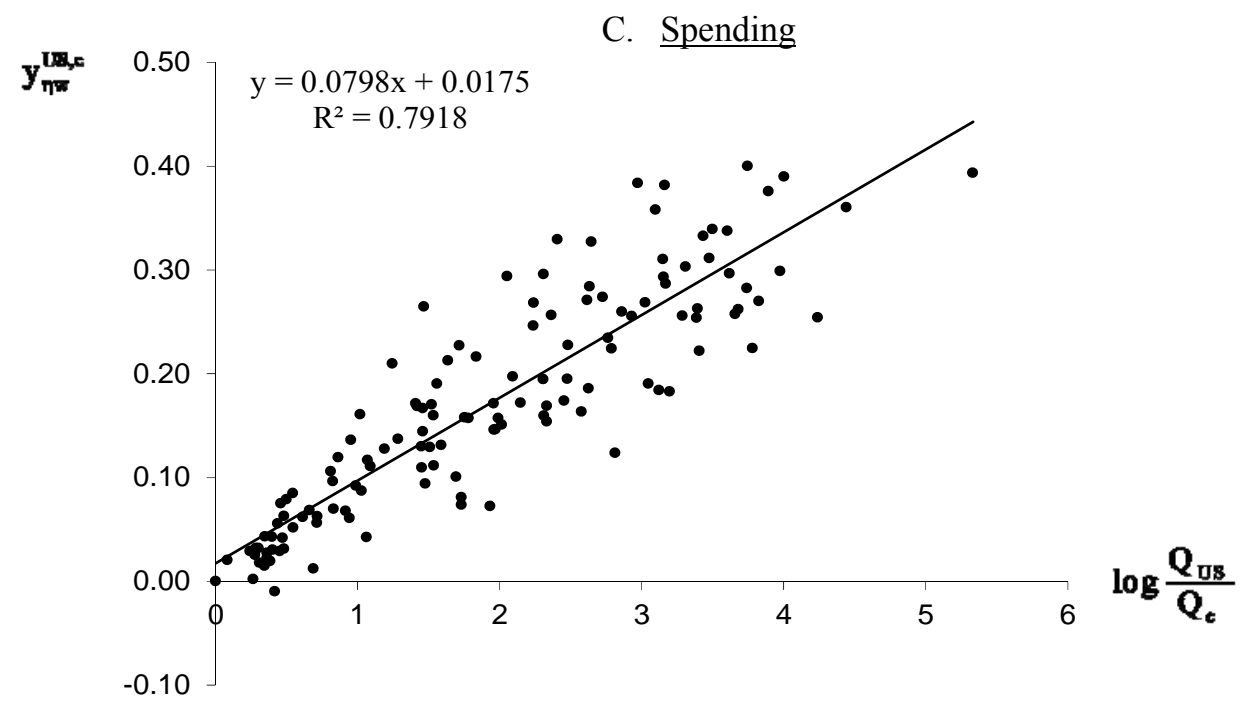


FIGURE 3

THE APPROXIMATION ERRORS

$\left(\mathrm{y}_{\eta \mathrm{w}}^{\mathrm{cd}}-\mathrm{y}_{\eta \mathrm{q}}^{\mathrm{cd}}-\mathrm{y}_{\eta \mathrm{p}}^{\mathrm{cd}}, \mathrm{c}<\mathrm{d}, \times 100\right)$

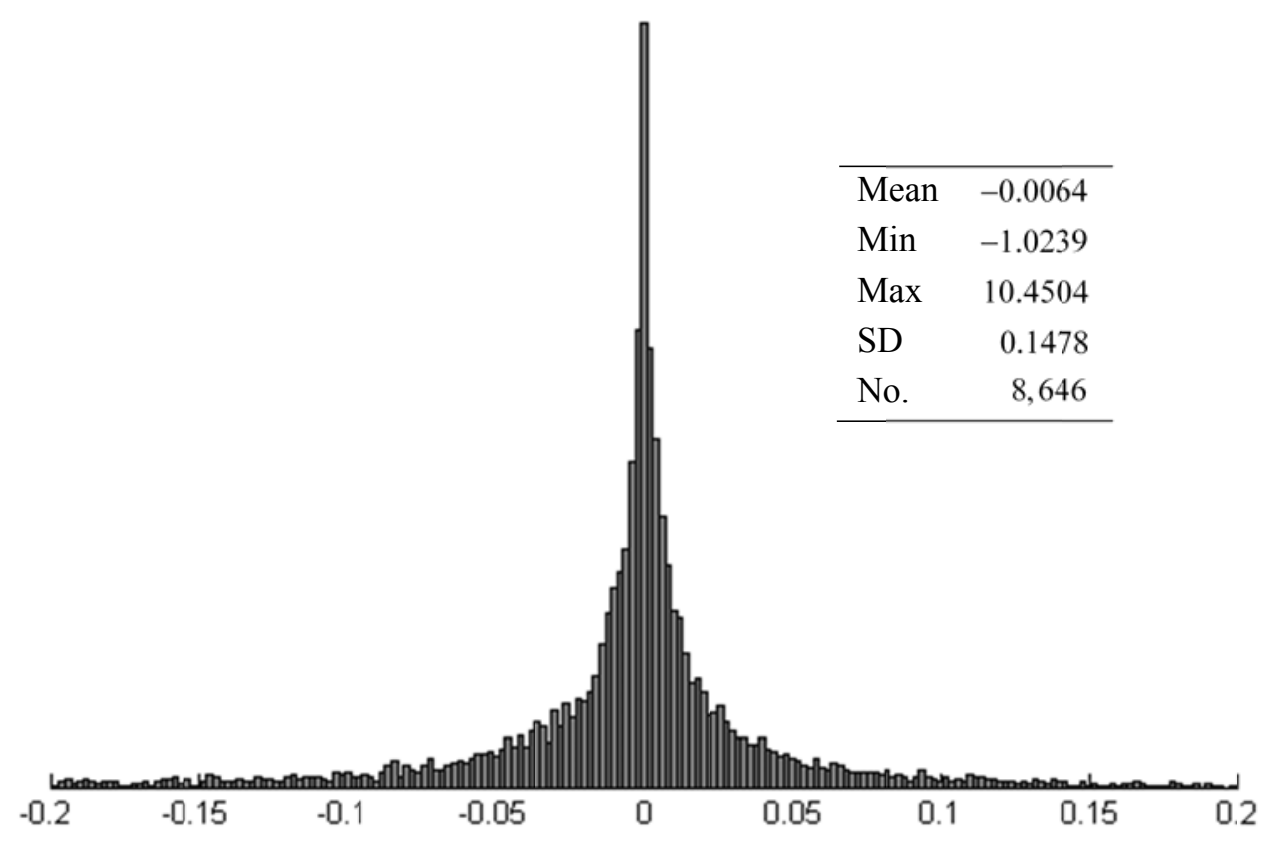


FIGURE 4

HISTOGRAMS OF SIMULATED MULTILATERAL QUALITY INDEXES FOR SIX COUNTRY GROUPS

$($ Logarithmic ratios $\times 100)$
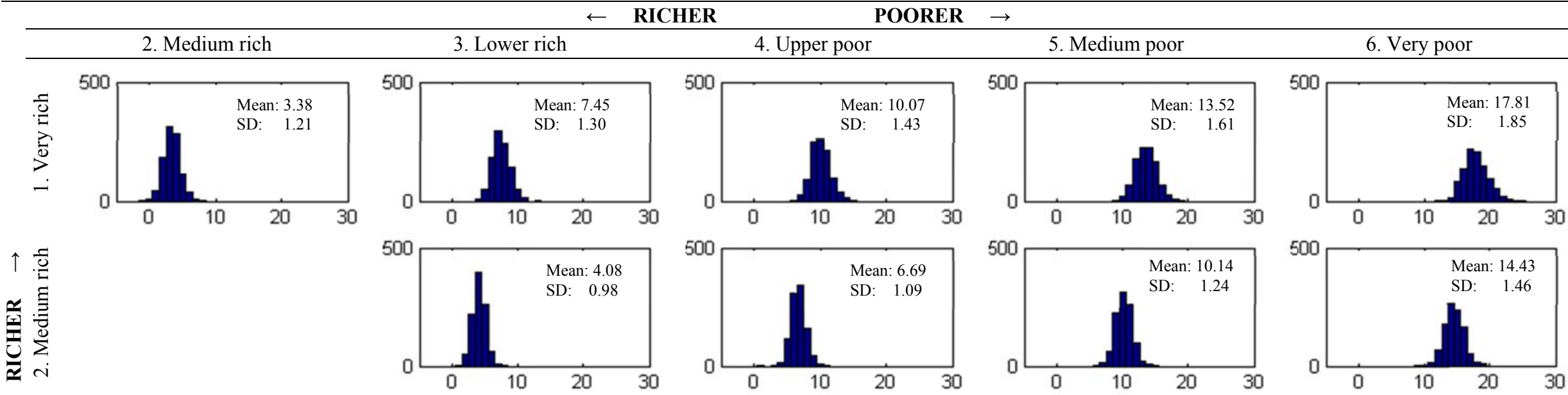

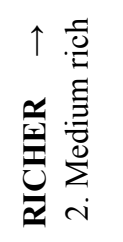
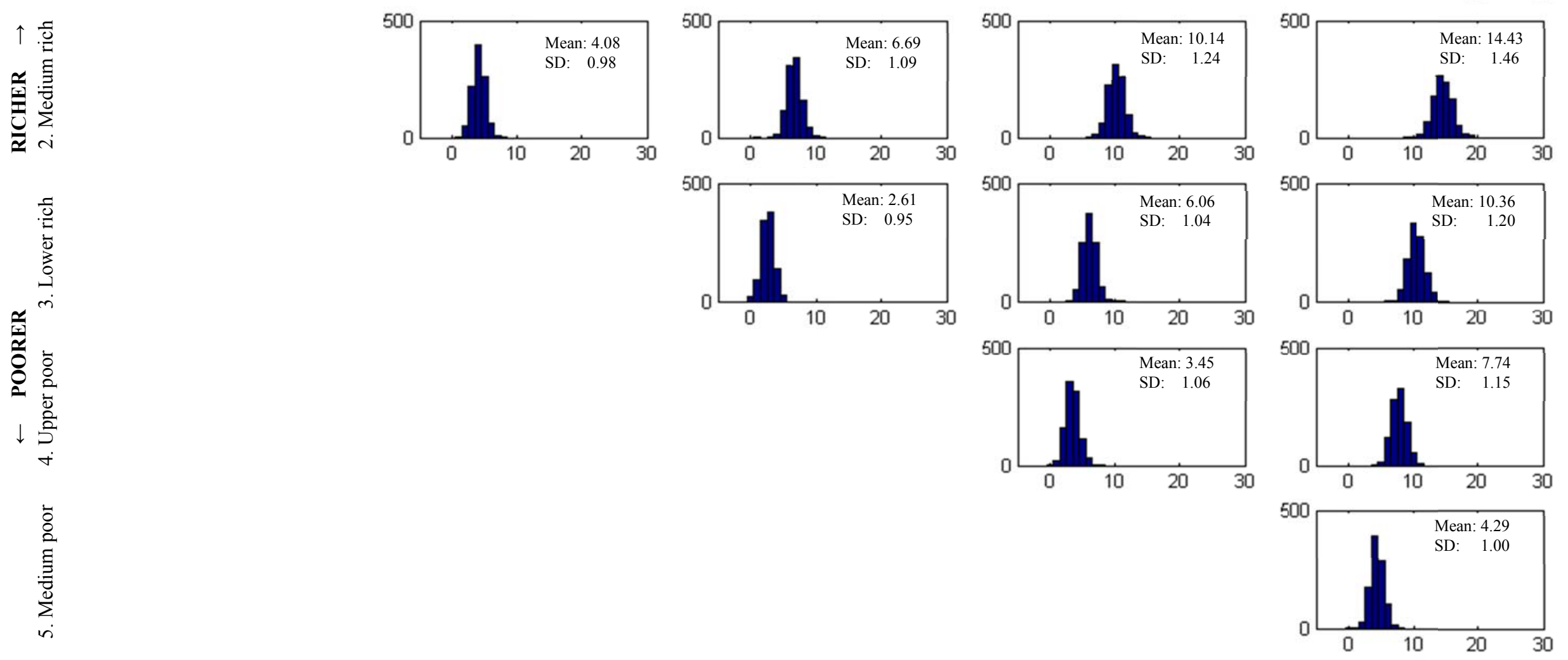

Note: The 132 countries are ranked by income per capita and then divided into 6 groups of 22 countries each. 
FIGURE 5

QUALITY DIFFERENCES AND DISTANCE BETWEEN COUNTRIES

$\mathrm{P}$ (quality in $\mathrm{c}>$ quality in $\mathrm{c}+\mathrm{x}$ )

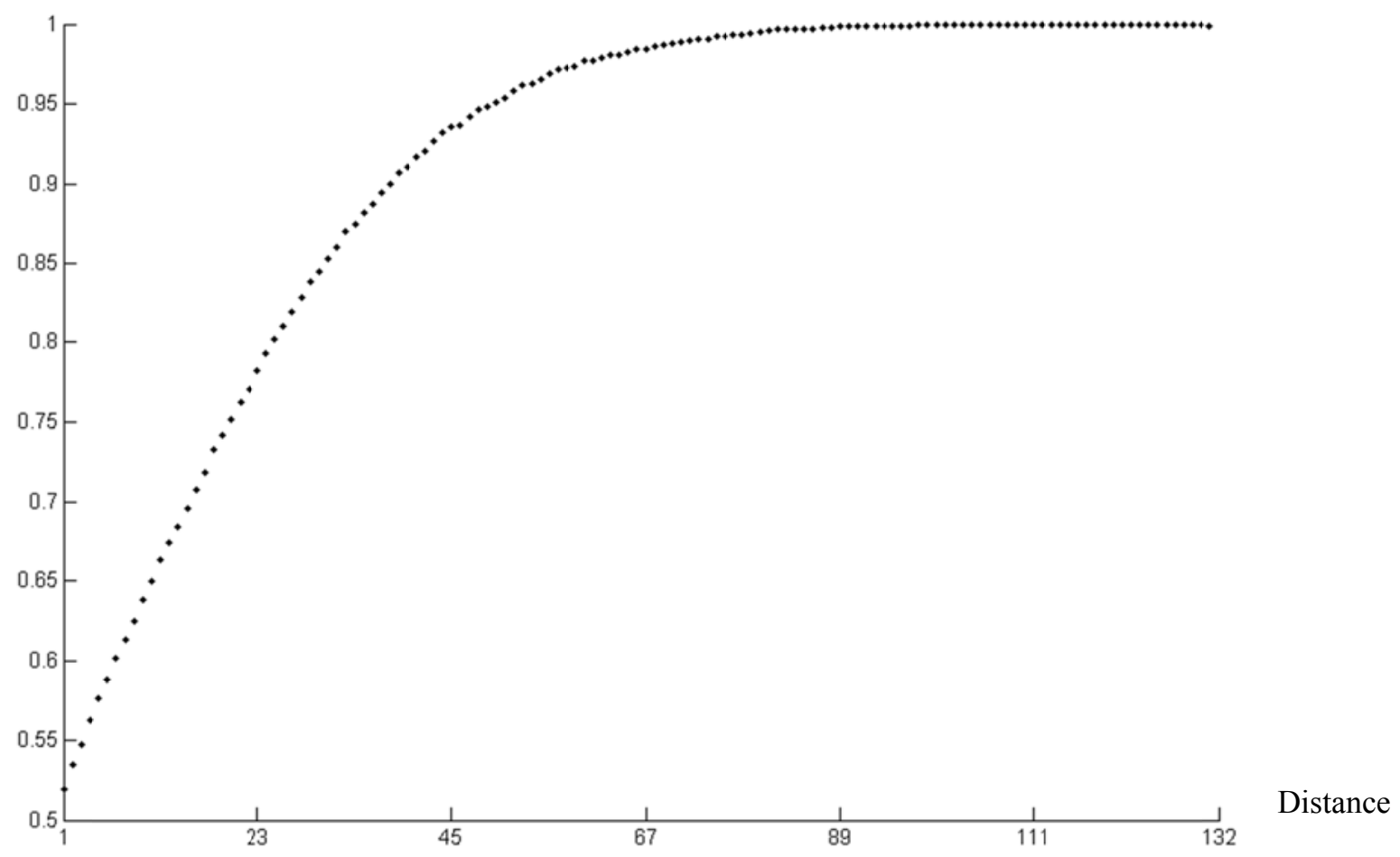

Notes: Countries are indexed by $\mathrm{c}=1, \ldots, 132$ and ranked in terms of decreasing per capita income. This figure gives the relative frequency that country $c$ consumes a higher quality basket than country $c+x(x \geq 1$, the "distance" between countries) for $\mathrm{c}=1, \ldots, 131$. 
FIGURE 6

PROBABILITY OF QUALITY DIFFERENCES,

132 COUNTRIES

\section{A. The US and others}

$\mathrm{P}$ (US quality $>$ quality elsewhere)

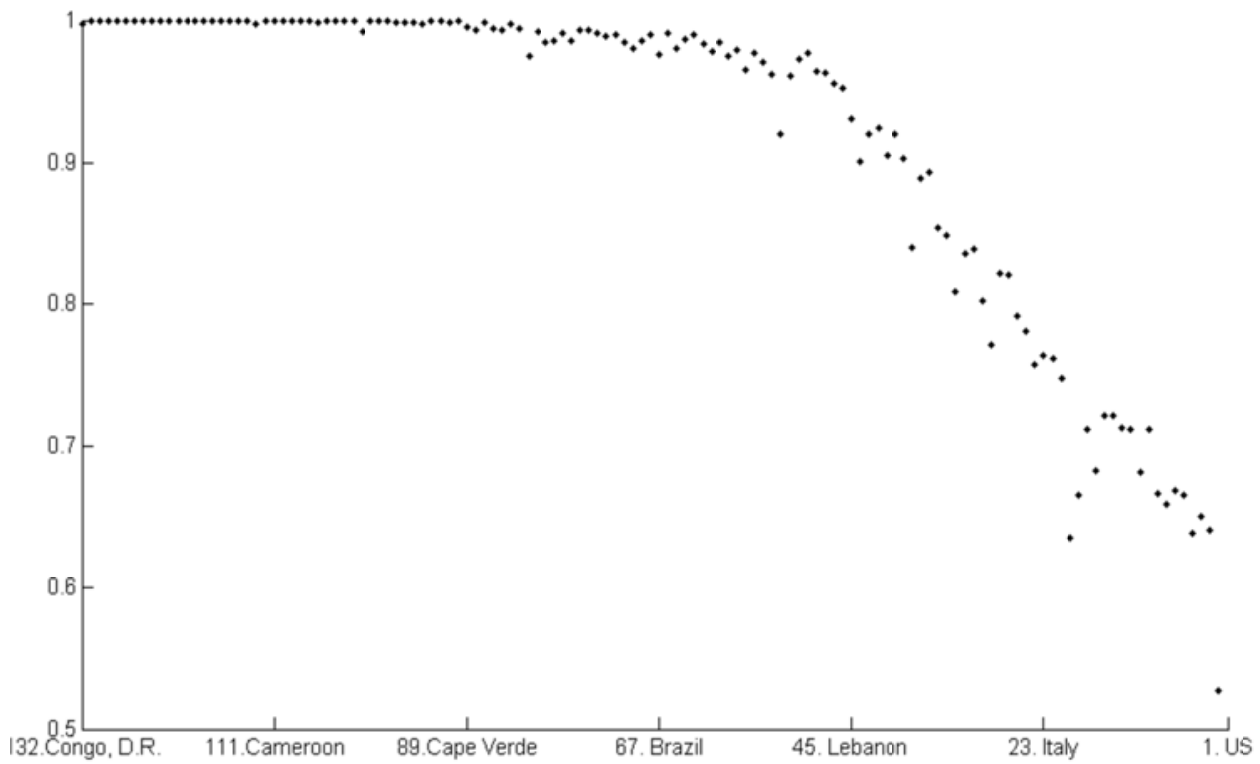

B. All pair-wise comparisons

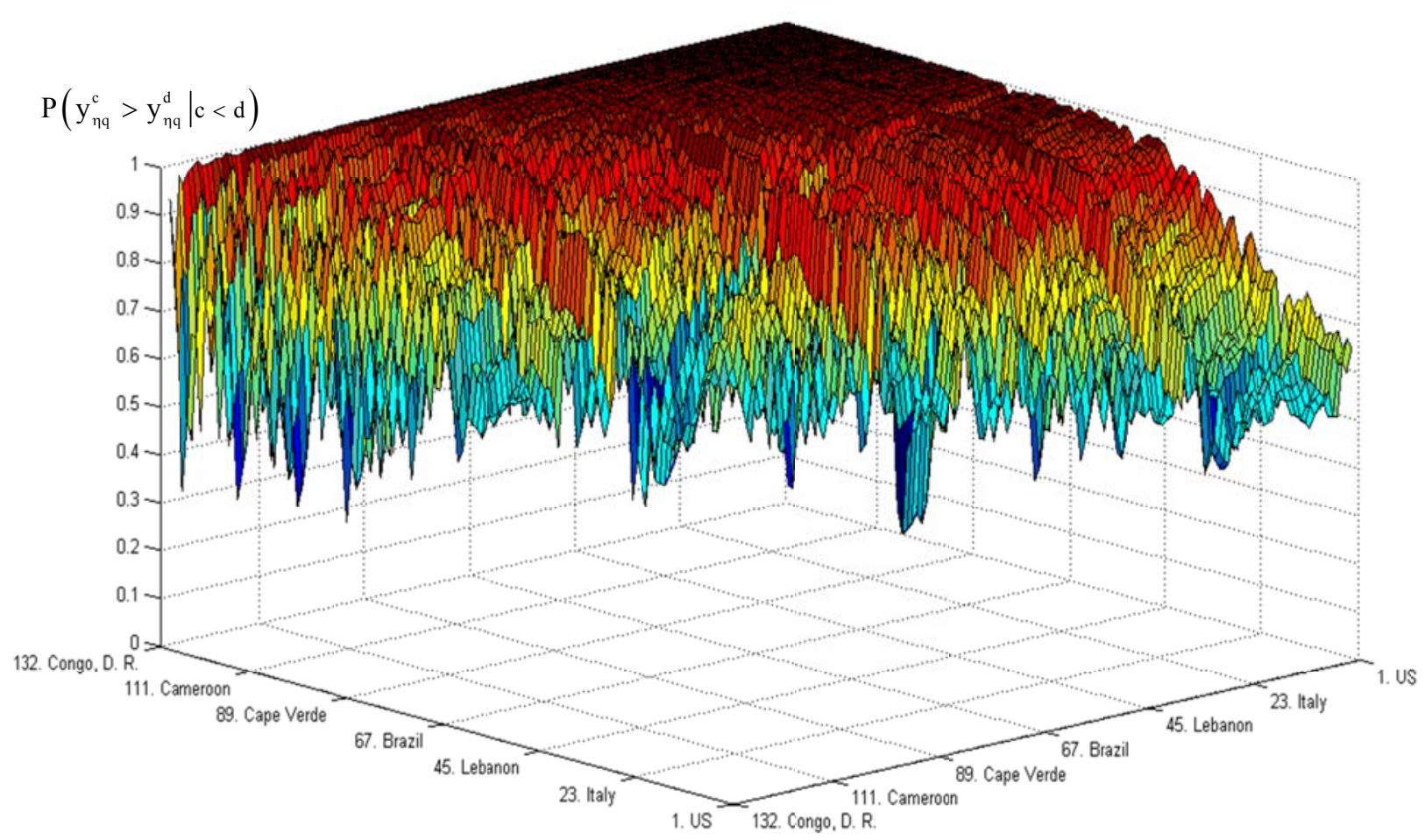




\section{Appendix A1}

\section{QUALITY AS A STOCHASTIC INDEX NUMBER}

This appendix contains the details of the multilateral measure of quality of Section 7 that involves a stochastic-index number approach. We commence with the case of individual countries and then proceed to groups of countries.

\section{A1.1 Matrix Formulation for One Country}

Model (11) expresses the quality index for countries c and $d$ as $y_{\eta q}^{c d}=\alpha_{c}-\alpha_{d}+\varepsilon_{c d}$. To simplify the notation, we omit the subscript $\eta q$ from $y_{\eta q}^{\mathrm{cd}}$ and write this model as

$$
\mathrm{y}_{\mathrm{cd}}=\alpha_{\mathrm{c}}-\alpha_{\mathrm{d}}+\varepsilon_{\mathrm{cd}}
$$

where $\alpha_{c}$ is a parameter that satisfies $\sum_{c=1}^{\mathrm{N}} \alpha_{\mathrm{c}}=0, \mathrm{~N}$ is the number of countries and $\varepsilon_{\mathrm{cd}}$ is a zero-mean disturbance term with $\mathrm{E}\left(\varepsilon_{\mathrm{cd}}^{2}\right)=\sigma^{2}, \mathrm{c}, \mathrm{d}=1, \ldots, \mathrm{N}$. Write the model in dummyvariable format as

$$
\mathrm{y}_{\mathrm{cd}}=\sum_{\mathrm{i}=1}^{\mathrm{N}} \alpha_{\mathrm{i}}\left(\delta_{\mathrm{ic}}-\delta_{\text {id }}\right)+\varepsilon_{\mathrm{cd}}
$$

where $\delta_{\mathrm{ij}}=1$ if $\mathrm{i}=\mathrm{j}, 0$ otherwise.

The above model can be expressed for the $\mathrm{c}^{\text {th }}$ country in vector form as

$$
\text { (A1.1) } \mathbf{y}_{\mathrm{c}}=\mathbf{X}_{\mathrm{c}} \boldsymbol{\alpha}+\boldsymbol{\varepsilon}_{\mathrm{c}}
$$

where $\mathbf{y}_{\mathrm{c}}, \quad \boldsymbol{\alpha}$ and $\boldsymbol{\varepsilon}_{\mathrm{c}}$ are $\mathrm{N} \times 1$ vectors with $\mathbf{y}_{\mathrm{c}}=\left[\mathrm{y}_{\mathrm{c} 1}, \ldots, \mathrm{y}_{\mathrm{cN}}\right]^{\prime}, \quad \boldsymbol{\alpha}=\left[\alpha_{1}, \ldots, \alpha_{\mathrm{N}}\right]^{\prime}$ and $\boldsymbol{\varepsilon}_{\mathrm{c}}=\left[\varepsilon_{\mathrm{cl}}, \ldots, \varepsilon_{\mathrm{cN}}\right]^{\prime}$, while $\mathbf{X}_{\mathrm{c}}$ is an $\mathrm{N} \times \mathrm{N}$ matrix defined as $-\mathbf{I}+\mathbf{u t}_{\mathrm{c}}^{\prime}$, where $\mathbf{I}$ is the $\mathrm{N} \times \mathrm{N}$ identity matrix, $\mathbf{l}$ is a unit column vector, and $\mathbf{l}_{\mathrm{c}}$ is a vector of $\mathrm{N}$ elements with the $\mathrm{c}^{\text {th }}$ element unity and zeros elsewhere. Thus,

$$
\mathbf{y}_{\mathrm{c}}=\left[\begin{array}{ccccccc}
1 & \cdots & \mathrm{c}-1 & \mathrm{c} & \mathrm{c}+1 & \cdots & \mathrm{N} \\
\mathrm{y}_{\mathrm{c}, \mathrm{c}-1} \\
\mathrm{y}_{\mathrm{cc}} \\
\mathrm{y}_{\mathrm{c}, \mathrm{c}+1} \\
\vdots \\
\mathrm{y}_{\mathrm{cN}}
\end{array}\right], \quad \mathbf{X}_{\mathrm{c}}=\left[\begin{array}{ccccccc}
-1 & & & 1 & & & \\
& \ddots & & \vdots & & & \\
& & -1 & 1 & & & \\
& & & -1+1 & & & \\
& & & 1 & -1 & & \\
& & & \vdots & & \ddots & \\
& & & 1 & & & -1
\end{array}\right] \begin{gathered}
\mathrm{c}-1 \\
\mathrm{c}+1 \\
\vdots \\
\end{gathered}
$$


The $\mathrm{i}^{\text {th }}$ row of $\mathbf{X}_{\mathrm{c}}$ refers to the comparison between country $\mathrm{c}$ and $\mathrm{i}$, so the $\mathrm{i}^{\text {th }}$ element is -1 and the $c^{\text {th }}$ element is 1 . The constraint $\sum_{\mathrm{i}=1}^{\mathrm{N}} \alpha_{\mathrm{i}}=0$ can be handled by substituting $-\sum_{\mathrm{i}=1}^{\mathrm{N}-1} \alpha_{\mathrm{i}}$ for $\alpha_{N}$, so the reduced model involving N-1 parameters becomes

(A1.2) $\mathbf{y}_{\mathrm{c}}=\mathbf{X}_{\mathrm{c}}^{*} \boldsymbol{\alpha}^{*}+\boldsymbol{\varepsilon}_{\mathrm{c}}$

where $\alpha^{*}=\left[\alpha_{1}, \ldots, \alpha_{\mathrm{N}-1}\right]$ is a $(\mathrm{N}-1) \times 1$ vector, and $\mathbf{X}_{\mathrm{c}}^{*}$ is a $\mathrm{N} \times(\mathrm{N}-1)$ matrix with the $\mathrm{i}^{\text {th }}$ column given by $\left(\mathbf{X}_{\mathrm{c}}^{*}\right)_{\mathrm{i}}=\left(\mathbf{X}_{\mathrm{c}}\right)_{\mathrm{i}}-\left(\mathbf{X}_{\mathrm{c}}\right)_{\mathrm{N}}, \mathrm{i}=1, \ldots, \mathrm{N}-1$, the corresponding column of $\mathbf{X}_{\mathrm{c}}$ minus the last column of $\mathbf{X}_{\mathrm{c}}$, where $(\cdot)_{\mathrm{i}}$ denotes the $\mathrm{i}^{\text {th }}$ column of matrix inside the brackets. That is,

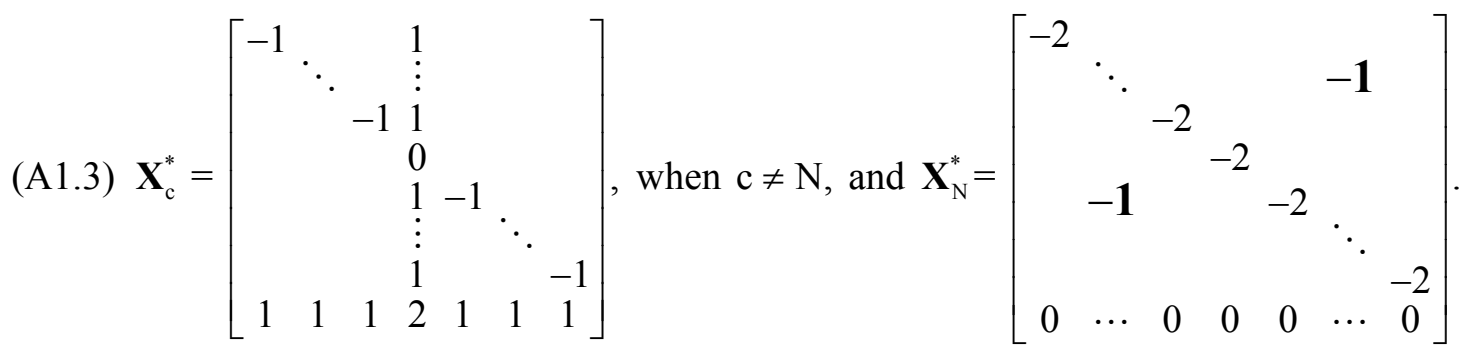

Accordingly, the $(\mathrm{N}-1) \times(\mathrm{N}-1)$ moment matrix is

(A1.4) $\mathbf{X}_{\mathrm{c}}^{* \prime} \mathbf{X}_{\mathrm{c}}^{*}=\mathbf{I}+\mathfrak{u}^{\prime}+\mathrm{N}_{\mathrm{c}} \mathfrak{\imath}_{\mathrm{c}}^{\prime}$ for $\mathrm{c} \neq \mathrm{N}$, and $\mathbf{X}_{\mathrm{N}}^{* \prime} \mathbf{X}_{\mathrm{N}}^{*}=\mathbf{I}+(\mathrm{N}+1) \mathfrak{\imath} \mathfrak{\imath}^{\prime}$

where $\mathbf{I}$ is the $(\mathrm{N}-1) \times(\mathrm{N}-1)$ identity matrix, $\mathbf{l}$ is an $(\mathrm{N}-1) \times 1$ unit vector, and $\mathbf{t}_{\mathrm{c}}$ is a vector of $\mathrm{N}-1$ elements with the $\mathrm{c}^{\text {th }}$ element unity and zeros elsewhere.

\section{A1.2 All Countries Combined}

Model (A1.2) refers to the pairwise comparisons involving country c. As the parameter vector $\alpha^{*}$ refers to all $\mathrm{N}-1$ countries, we combine (A1.2) for $\mathrm{c}=1, \ldots, \mathrm{N}$, as

$\mathbf{y}=\mathbf{X}^{*} \alpha^{*}+\varepsilon$

where $\mathbf{y}$ and $\boldsymbol{\varepsilon}$ are $\mathrm{N}^{2} \times 1$ vectors with $\mathbf{y}=\left[\mathbf{y}_{1}^{\prime}, \ldots, \mathbf{y}_{\mathrm{N}}^{\prime}\right]^{\prime}$ and $\boldsymbol{\varepsilon}=\left[\boldsymbol{\varepsilon}_{1}^{\prime}, \ldots, \boldsymbol{\varepsilon}_{\mathrm{N}}^{\prime}\right]^{\prime}$, and $\mathbf{X}^{*}=\left[\mathbf{X}_{1}^{* \prime}, \ldots, \mathbf{X}_{\mathrm{N}}^{* \prime}\right]^{\prime}$ is an $\mathrm{N}^{2} \times(\mathrm{N}-1)$ matrix. The least-squares estimator of $\boldsymbol{\alpha}^{*}$ is

(A1.5) $\hat{\alpha}^{*}=\left(\mathbf{X}^{* \prime} \mathbf{X}^{*}\right)^{-1} \mathbf{X}^{* \prime} \mathbf{y}$, with $\operatorname{var}\left(\hat{\boldsymbol{\alpha}}^{*}\right)=\sigma^{2}\left(\mathbf{X}^{* \prime} \mathbf{X}^{*}\right)^{-1}$

where $\sigma^{2}$ is the variance of the disturbance term. 


\section{A1.3 Scalar Expressions}

To derive simple, interpretable scalar expressions for (A1.5), we proceed in four steps.

(i) The Moment Matrix

Define $\mathbf{Z}=\mathbf{X}^{* \prime} \mathbf{X}^{*}=\sum_{\mathrm{c}=1}^{\mathrm{N}} \mathbf{X}_{\mathrm{c}}^{* \prime} \mathbf{X}_{\mathrm{c}}^{*}$, which is an $(\mathrm{N}-1) \times(\mathrm{N}-1)$ matrix. Applying (A1.4), this can be expressed as

$$
\mathbf{Z}=\sum_{\mathrm{c}=1}^{\mathrm{N}-1}\left[\mathbf{I}+\mathbf{u}^{\prime}+\mathrm{N}_{\mathrm{c}} \mathbf{\imath}_{\mathrm{c}}^{\prime}\right]+\left[\mathbf{I}+(\mathrm{N}+1) \mathfrak{\mathbf { t }} \mathbf{\prime}^{\prime}\right]=2 \mathrm{~N} \cdot\left(\mathbf{I}+\mathfrak{u}^{\prime}\right)
$$

as $\sum_{\mathrm{c}=1}^{\mathrm{N}-1} \mathrm{Ni}_{\mathrm{c}} \mathbf{t}_{\mathrm{c}}^{\prime}=\mathrm{NI}$. That is, the $(\mathrm{i}, \mathrm{j})^{\text {th }}$ element of $\mathbf{Z}$ is $\mathrm{z}_{\mathrm{ij}}=4 \mathrm{~N}$ for $\mathrm{i}=\mathrm{j}$, and $\mathrm{z}_{\mathrm{ij}}=2 \mathrm{~N}$ for $\mathrm{i} \neq \mathrm{j}$. The inverse of $\mathbf{Z}$ is

(A1.6) $\mathbf{Z}^{-1}=\left(\mathrm{NI}-\mathfrak{\imath \imath}^{\prime}\right) / 2 \mathrm{~N}^{2}$,

so that its $(i, j)^{\text {th }}$ element is $z^{i j}=(N-1) / 2 N^{2}$ for $i=j$, and $z^{i j}=-1 / 2 N^{2}$ for $i \neq j$. It is to be noted that when $\mathrm{N}$ is moderately large, the off-diagonal elements of $\mathbf{Z}^{-1}$ are small numbers and the diagonal element are approximately $(2 \mathrm{~N})^{-1}$.

(ii) The Estimator of $\alpha_{\mathrm{c}}$

The product $\left(\mathbf{X}^{* \prime} \mathbf{X}^{*}\right)^{-1} \mathbf{X}^{* \prime}=\mathbf{Z}^{-1} \mathbf{X}^{* \prime}$ in equation (A1.5) can be written in partitioned form as $\mathbf{Z}^{-1} \mathbf{X}^{* \prime}=\left[\mathbf{Z}^{-1} \mathbf{X}_{1}^{* \prime}, \ldots, \mathbf{Z}^{-1} \mathbf{X}_{\mathrm{N}}^{* \prime}\right]$. As shown in Section A1.5, for $\mathrm{c}=1, \ldots, \mathrm{N}$, we have $\mathbf{Z}^{-1} \mathbf{X}_{\mathrm{c}}^{* \prime}=1 /(2 \mathrm{~N}) \cdot \mathbf{X}_{\mathrm{c},-\mathrm{N}}^{\prime}$, where $\mathbf{X}_{\mathrm{c},-\mathrm{N}}$ is the original matrix $\mathbf{X}_{\mathrm{c}}$ with the last column omitted. Substituting this expression into (A1.5), we have, for $\mathrm{c}=1, \ldots, \mathrm{N}-1$,

(A1.7) $\hat{\alpha}_{c}=\frac{1}{2 \mathrm{~N}} \sum_{\mathrm{d}=1}^{\mathrm{N}}\left(\mathrm{y}_{\mathrm{cd}}-\mathrm{y}_{\mathrm{dc}}\right)=\frac{1}{\mathrm{~N}} \sum_{\mathrm{d}=1}^{\mathrm{N}} \mathrm{y}_{\mathrm{cd}}$,

as $\mathrm{y}_{\mathrm{dc}}=-\mathrm{y}_{\mathrm{cd}}$. For the derivation of result (A1.7), see Section A1.5.

(iii) The Sampling Variance

The sampling variance of $\hat{\alpha}^{*}$ is $\sigma^{2} \mathbf{Z}^{-1}$. As there are $\mathrm{N}^{2}$ observations and N-1 unknown parameters, an unbiased estimator of $\sigma^{2}$ is

(A1.8) $\hat{\sigma}^{2}=\frac{1}{\mathrm{~N}^{2}-(\mathrm{N}-1)} \sum_{\mathrm{c}=1}^{\mathrm{N}} \sum_{\mathrm{d}=1}^{\mathrm{N}} \hat{\varepsilon}_{\mathrm{cd}}^{2}$,

where $\hat{\varepsilon}_{\mathrm{cd}}=\mathrm{y}_{\mathrm{cd}}-\hat{\alpha}_{\mathrm{c}}+\hat{\alpha}_{\mathrm{d}}$ is the residual for the $(\mathrm{c}, \mathrm{d})^{\text {th }}$ observation. Accordingly, we have 


$$
\widehat{\operatorname{var}\left(\hat{\alpha}^{*}\right)}=\hat{\sigma}^{2} \mathbf{Z}^{-1}=\hat{\sigma}^{2}\left(\mathrm{NI}-\mathfrak{\imath \imath} \mathbf{\imath}^{\prime}\right) / 2 \mathrm{~N}^{2}
$$

so that $\overline{\operatorname{var}\left(\hat{\alpha}_{c}^{*}\right)}=\hat{\sigma}^{2}(\mathrm{~N}-1) / 2 \mathrm{~N}^{2}$. This expression is the same for each $\mathrm{c}=1, \ldots, \mathrm{N}-1$.

Define $\mathbf{Y}=\left[\mathrm{y}_{\mathrm{cd}}\right]$, an $\mathrm{N} \times \mathrm{N}$ skew-symmetric matrix. The above approach uses all elements of this matrix in the sense that estimator (A1.7) is the mean of the $\mathrm{c}^{\text {th }}$ row of $\mathbf{Y}$. If, alternatively, only the elements in the upper triangle of $\mathbf{Y}$ are used, expression (A1.7) does not change. But as we now use only $\mathrm{N} \times(\mathrm{N}-1) / 2$ observations, the sum of squared residuals is half of that when all elements of $\mathbf{Y}$ are employed. Thus, after simplifications, the estimator of $\sigma^{2}$ in this case is

$$
\frac{1}{(\mathrm{~N}-2) \times(\mathrm{N}-1)} \sum_{\mathrm{c}=1}^{\mathrm{N}} \sum_{\mathrm{d}=1}^{\mathrm{N}} \hat{\varepsilon}_{\mathrm{cd}}^{2}
$$

which has the same order as (A1.8).

(iv) The Last Country

The estimator of the parameter $\alpha_{\mathrm{N}}$ for country $\mathrm{N}$ is

$$
\hat{\alpha}_{\mathrm{N}}=-\sum_{\mathrm{c}=1}^{\mathrm{N}-1} \hat{\alpha}_{\mathrm{c}}=-\frac{1}{\mathrm{~N}} \sum_{\mathrm{c}=1}^{\mathrm{N}-1} \sum_{\mathrm{d}=1}^{\mathrm{N}} \mathrm{y}_{\mathrm{cd}}=\frac{1}{\mathrm{~N}} \sum_{\mathrm{d}=1}^{\mathrm{N}} \mathrm{y}_{\mathrm{Nd}}
$$

which follows from $\mathfrak{\imath}^{\prime} \mathbf{Y} \mathbf{\imath}=0$. As the estimated covariance matrix of $\hat{\alpha}^{*}$ is $\hat{\sigma}^{2}\left(\mathrm{NI}-\mathfrak{\imath} \mathfrak{\imath}^{\prime}\right) / 2 \mathrm{~N}^{2}$ and $\hat{\alpha}_{N}=-\imath^{\prime} \hat{\alpha}^{*}$, the variance of $\hat{\alpha}_{N}$ is

$$
\widehat{\operatorname{var}\left(\hat{\alpha}_{N}\right)}=\mathbf{l}^{\prime} \overline{\operatorname{var}\left(\hat{\alpha}^{*}\right)} \mathbf{\imath}=\hat{\sigma}^{2}(\mathrm{~N}-1) / 2 \mathrm{~N}^{2}=\widehat{\operatorname{var}\left(\hat{\alpha}_{\mathrm{c}}\right)}, \mathrm{c}=1, \ldots, \mathrm{N}-1 .
$$

The results of this paragraph establish that there is no asymmetry for country N: The estimator of $\alpha_{N}$ has exactly the same form as do those for $\alpha_{c}, c=1, \ldots, N-1$, and the same is true for its sampling variance.

\section{A1.4 Groups of Countries}

This section deals with model (13) of the text, when countries are grouped together. The $\mathrm{N}$ countries are ranked according to income and aggregated into $\mathrm{G}<\mathrm{N}$ groups, $\mathbf{S}_{1}, \ldots, \mathbf{S}_{\mathrm{G}}$, with $\mathrm{m}=\mathrm{N} / \mathrm{G}$ countries in each group. Defining $A_{g}$ as the parameter for group $g, g=1, \ldots, G$, the model becomes $\mathrm{y}_{\mathrm{cd}}=\mathrm{A}_{\mathrm{g}}-\mathrm{A}_{\mathrm{h}}+\zeta_{\mathrm{cd}}, \mathrm{c} \in \mathbf{S}_{\mathrm{g}}, \mathrm{d} \in \mathbf{S}_{\mathrm{h}}$ or

$$
\mathrm{y}_{\mathrm{cd}}=\sum_{\mathrm{g}=1}^{\mathrm{G}} \mathrm{A}_{\mathrm{g}}\left(\delta_{\mathrm{c} \in \mathbf{S}_{\mathrm{g}}}-\delta_{\mathrm{d} \in \mathbf{S}_{\mathrm{g}}}\right)+\zeta_{\mathrm{cd}}
$$


where $\delta_{\mathrm{c} \in \mathbf{S}_{\mathrm{g}}}=1$ if $\mathrm{c} \in \mathbf{S}_{\mathrm{g}}$ and 0 otherwise, and $\zeta_{\mathrm{cd}}$ is a zero-mean disturbance term with $\mathrm{E}\left(\zeta_{\mathrm{cd}}^{2}\right)=\sigma_{\zeta}^{2}$. There are now $\mathrm{G}$ unknown parameters in this model and if both country c and $\mathrm{d}$ are in the same income group, we have $\mathrm{A}_{\mathrm{g}} \delta_{\mathrm{c} \in \mathbf{S}_{\mathrm{g}}}=\mathrm{A}_{\mathrm{g}} \delta_{\mathrm{d} \in \mathbf{S}_{\mathrm{g}}}$ and $\mathrm{y}_{\mathrm{cd}}=\zeta_{\mathrm{cd}}$.

For country $\mathrm{c} \in \mathbf{S}_{\mathrm{g}}$, we start with a formulation similar to (A1.1):

$\left(\mathrm{A} 1.1^{\prime}\right) \quad \mathbf{y}_{\mathrm{c}}=\mathbf{X}_{\mathrm{c}} \mathbf{A}+\zeta_{\mathrm{c}}$,

where $\mathbf{A}$ is a $\mathrm{G} \times 1$ vector, $\mathbf{y}_{\mathrm{c}}$ and $\zeta_{\mathrm{c}}$ are $\mathrm{N} \times 1$ vectors with $\mathbf{A}=\left[\mathrm{A}_{1}, \ldots, \mathrm{A}_{\mathrm{G}}\right]^{\prime}$, $\mathbf{y}_{\mathrm{c}}=\left[\mathrm{y}_{\mathrm{c} 1}, \ldots, \mathrm{y}_{\mathrm{cN}}\right]^{\prime}$ and $\zeta_{\mathrm{c}}=\left[\zeta_{\mathrm{cl}}, \ldots, \zeta_{\mathrm{cN}}\right]^{\prime}$. The term $\mathbf{X}_{\mathrm{c}}$ is an $\mathrm{N} \times \mathrm{G}$ matrix, and in terms of groups, $\mathbf{X}_{\mathrm{c}}$ has a similar form as that defined below equation (A1.1), $-\mathbf{I}+\mathfrak{u t}_{\mathrm{c}}^{\prime}$, but now $\mathbf{I}$ is the $\mathrm{G} \times \mathrm{G}$ identity matrix, $\mathbf{\imath}$ is a $\mathrm{G} \times 1$ unit column vector, and $\mathbf{t}_{\mathrm{c}}$ is a vector of $\mathrm{G}$ elements with the $\mathrm{c}^{\text {th }}$ element unity and zeros elsewhere. Additionally, as the dummy variables for each of the $\mathrm{m}$ members of a group take the same values, the matrix $\mathbf{X}_{\mathrm{c}}$ takes the Kronecker product form $\left(-\mathbf{I}+\mathfrak{u t}_{\mathrm{c}}^{\prime}\right) \otimes \mathbf{i}_{\mathrm{m} \times 1}$, where $\mathbf{t}_{\mathrm{m} \times 1}$ is a $\mathrm{m} \times 1$ unit column vector. Thus, for $\mathrm{c} \in \mathbf{S}_{\mathrm{g}}$, $\mathrm{g}=1, \ldots, \mathrm{G}-1$, the matrices $\mathbf{X}_{\mathrm{c}}$ and $\mathbf{X}_{\mathrm{c}}^{*}$, under the constraint $\sum_{\mathrm{g}=1}^{\mathrm{G}} \mathrm{A}_{\mathrm{g}}=0$, are

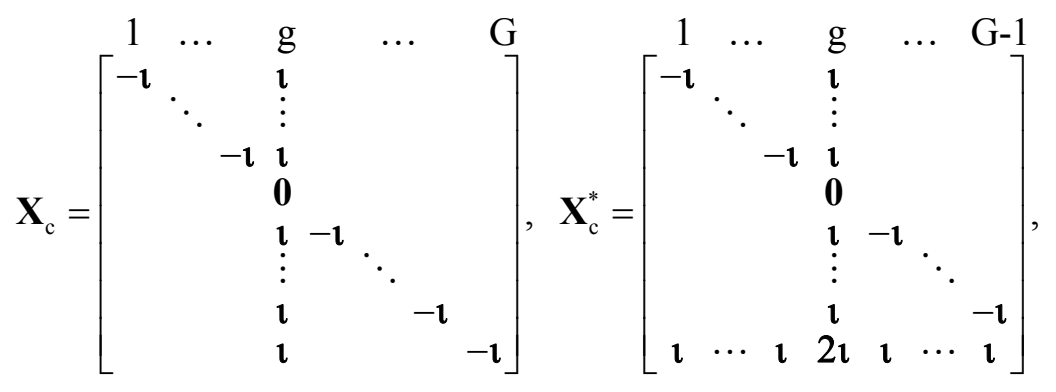

and for country $\mathrm{c}$ in the last group, $\mathrm{c} \in \mathbf{S}_{\mathrm{G}}$,

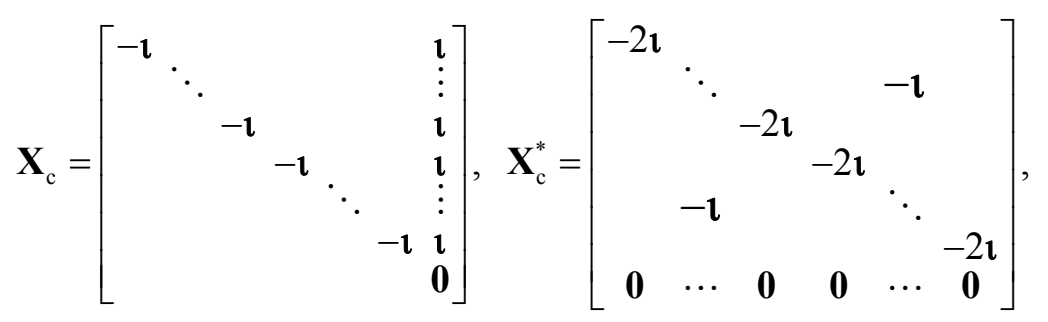

where $\mathbf{l}$ is to be interpreted as $\mathbf{t}_{\mathrm{m} \times 1}$ and $\mathbf{0}$ is an $\mathrm{m} \times 1$ zero vector.

As shown in Section A6, the $(G-1) \times(G-1)$ moment matrix $\mathbf{X}_{\mathrm{c}}^{* \prime} \mathbf{X}_{\mathrm{c}}^{*}$ now takes the form

$\left(\right.$ A1.4 $\left.4^{\prime}\right) \quad \mathbf{X}_{\mathrm{c}}^{* \prime} \mathbf{X}_{\mathrm{c}}^{*}=\mathrm{m} \times\left[\mathbf{I}+\mathfrak{u \imath}^{\prime}+\mathrm{G}_{\left.\mathbf{t}_{\mathrm{c}} \mathbf{\imath}_{\mathrm{c}}^{\prime}\right]}\right]$ when $\mathrm{c} \in \mathbf{S}_{\mathrm{g}}, \mathrm{g}=1, \ldots, \mathrm{G}-1$, 


$$
\mathbf{X}_{\mathrm{c}}^{* \prime} \mathbf{X}_{\mathrm{c}}^{*}=\mathrm{m} \times\left[\mathbf{I}+(\mathrm{G}+1) \mathfrak{\imath \imath}^{\prime}\right] \text { when } \mathrm{c} \in \mathbf{S}_{\mathrm{g}}, \mathrm{g}=\mathrm{G},
$$

where $\mathbf{I}$ is a $(\mathrm{G}-1) \times(\mathrm{G}-1)$ identity matrix, $\mathbf{\imath}$ is a $(\mathrm{G}-1) \times 1$ unit column vector, and $\mathbf{t}_{\mathrm{c}}$ is a vector of $\mathrm{G}-1$ elements with the $\mathrm{c}^{\text {th }}$ element unity and zeros elsewhere. Thus, we have

$$
\mathbf{Z}=\sum_{\mathrm{g}=1}^{\mathrm{G}} \sum_{\mathrm{c} \in \mathbf{S}_{\mathrm{g}}} \mathbf{X}_{\mathrm{c}}^{* \prime} \mathbf{X}_{\mathrm{c}}^{*}=\mathrm{m}^{2} \cdot 2 \mathrm{G}\left(\mathbf{I}+\mathfrak{u \imath}^{\prime}\right) .
$$

The inverse of $\mathbf{Z}$ is

$$
(\text { A1.6 }) \quad \mathbf{Z}^{-1}=\left(\mathrm{GI}-\mathbf{t u}^{\prime}\right) /\left(2 \mathrm{~m}^{2} \mathrm{G}^{2}\right)
$$

and the product $\mathbf{Z}^{-1} \mathbf{X}_{\mathrm{c}}^{* \prime}=1 /\left(2 \mathrm{~m}^{2} \mathrm{G}\right) \cdot \mathbf{X}_{\mathrm{c},-\mathrm{N}}^{\prime}$, where $\mathbf{X}_{\mathrm{c},-\mathrm{N}}$ is the original matrix $\mathbf{X}_{\mathrm{c}}$ with the last column omitted.

As the least-squares estimator of the G-1 parameter vector $\mathrm{A}^{*}$ is $\hat{\mathrm{A}}^{*}=\left(\mathbf{X}^{* \prime} \mathbf{X}^{*}\right)^{-1} \mathbf{X}^{* \prime} \mathbf{y}$. In Section A6, it is shown that for $\mathrm{g}=1, \ldots, \mathrm{G}-1$,

$$
\hat{\mathrm{A}}_{\mathrm{g}}=\frac{1}{2 \mathrm{~m}^{2} \mathrm{G}} \sum_{\mathrm{c} \in \mathbf{S}_{\mathrm{g}}} \sum_{\mathrm{d} \notin \mathbf{S}_{\mathrm{g}}}\left(\mathrm{y}_{\mathrm{cd}}-\mathrm{y}_{\mathrm{dc}}\right)=\frac{1}{\mathrm{Nm}} \sum_{\mathrm{c} \in \mathbf{S}_{\mathrm{g}}} \sum_{\mathrm{d} \notin \mathbf{S}_{\mathrm{g}}} \mathrm{y}_{\mathrm{cd}} .
$$

We also show in Section A6 that this simplifies to

$$
\hat{\mathrm{A}}_{\mathrm{g}}=\frac{1}{\mathrm{~m}} \sum_{\mathrm{c} \in \mathbf{S}_{\mathrm{g}}} \hat{\alpha}_{\mathrm{c}}, \mathrm{g}=1, \cdots, \mathrm{G},
$$

with

$$
\widehat{\operatorname{var}\left(\hat{A}_{g}\right)}=\hat{\sigma}_{\zeta}^{2} \frac{G-1}{2 m^{2} G^{2}}, \quad g=1, \ldots, G
$$

In words, for group $\mathrm{g}$, the LS estimator of $\mathrm{A}_{\mathrm{g}}$ is simply the mean of the estimators for the $\mathrm{m}$ member countries $\hat{\alpha}_{\mathrm{c}}, \mathrm{c} \in \mathbf{S}_{\mathrm{g}}$.

There is a clear parallel relationship between the structures of the individual country case and the groups of countries. This parallel is in part indicated by the primes added to equation numbers of this section that have the same form as their unprimed counterparts of the previous section. Table A1.1 contains a summary of the two cases in a way which highlights the parallels. 


\section{A1.5 Derivations}

In Section A1.1, we stated that for country $\mathrm{c} \neq \mathrm{N}$, the product $\mathbf{X}_{\mathrm{c}}^{* \prime} \mathbf{X}_{\mathrm{c}}^{*}=\mathbf{I}+\mathfrak{u l}^{\prime}+\mathrm{N}_{\mathbf{c}} \mathbf{l}_{\mathrm{c}}^{\prime}$. This can be verified by direct calculation:

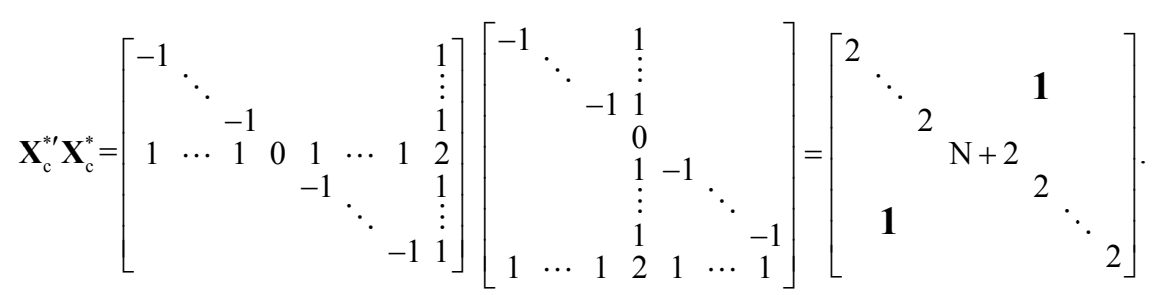

The $\mathrm{c}^{\text {th }}$ diagonal element of the product is $\mathrm{N}+2$, the other diagonals are 2 and all other elements unity. For the $\mathrm{N}^{\text {th }}$ country, we have

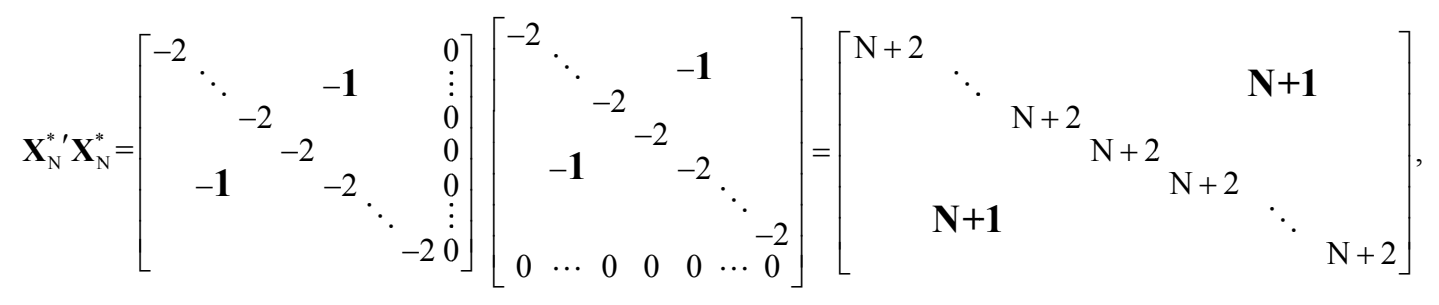

which can be written as $\mathbf{X}_{\mathrm{N}}^{* \prime} \mathbf{X}_{\mathrm{N}}^{*}=\mathbf{I}+(\mathrm{N}+1) \mathfrak{\imath} \mathbf{\imath}^{\prime}$, a matrix with $\mathrm{N}+2$ as the diagonals and $\mathrm{N}+1$ elsewhere, as stated in Section A1.1.

The moment matrix $\mathbf{Z}$ is defined in Section A1.3 as the sum of products of the $\mathrm{N}$ submatrices, $\mathbf{Z}=\sum_{\mathrm{c}=1}^{\mathrm{N}} \mathbf{X}_{\mathrm{c}}^{* \prime} \mathbf{X}_{\mathrm{c}}^{*}$. Using the expressions in (A4), we obtain

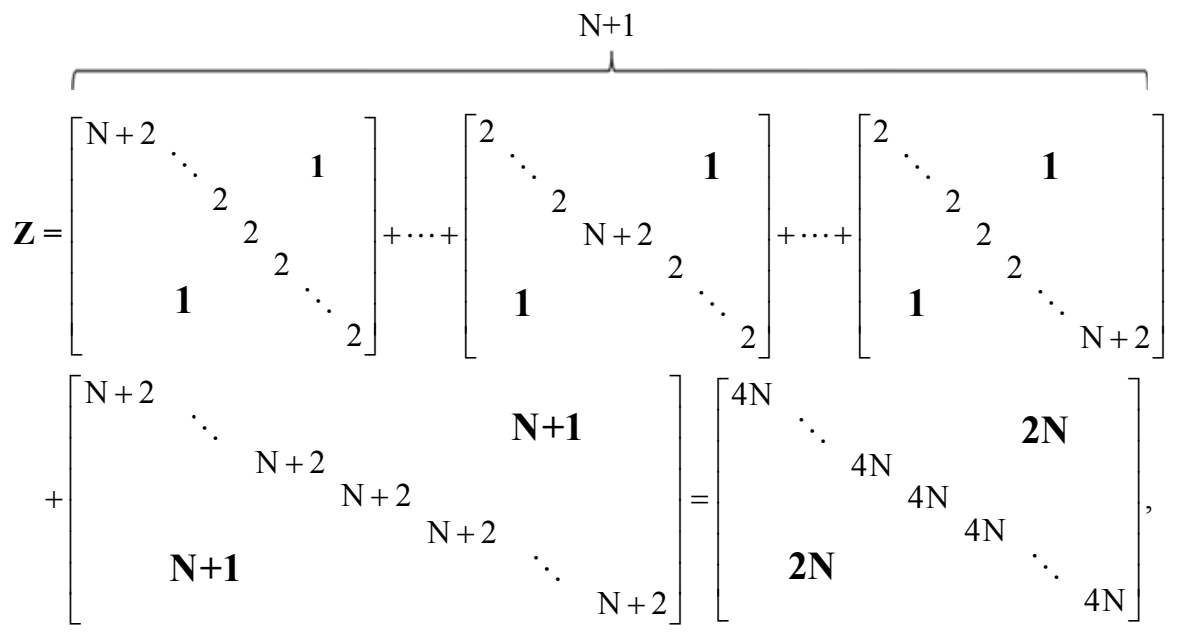

which is of the form $2 \mathrm{~N} \cdot\left(\mathbf{I}+\mathbf{u t}^{\prime}\right)$, as stated in Section A1.3. As noted in Section A1.3, the inverse of $\mathbf{Z}$ is 


$$
\mathbf{Z}^{-1}=\frac{1}{2 \mathrm{~N}^{2}}\left[\begin{array}{ccc}
\mathrm{N}-1 & & \mathbf{- 1} \\
& \ddots & \\
\mathbf{- 1} & & \mathrm{N}-1
\end{array}\right]
$$

Then, for $\mathrm{c}=1, \ldots, \mathrm{N}-1$, we have

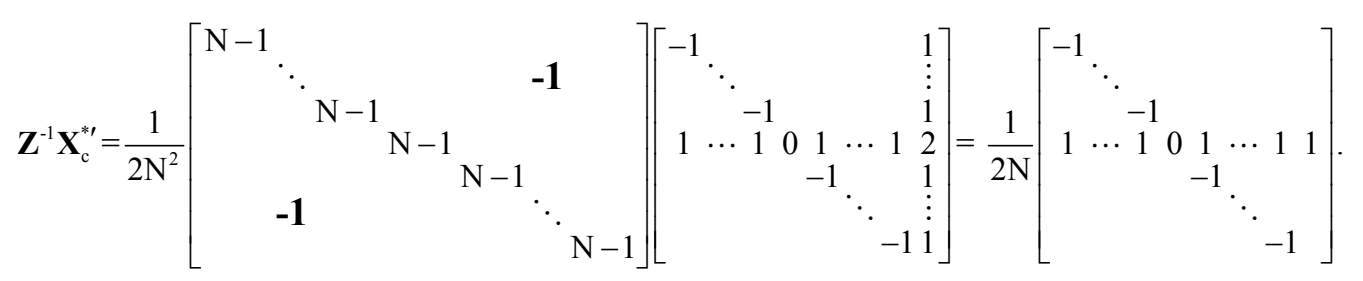

The matrix on the far right is a multiple $1 / 2 \mathrm{~N}$ of the transpose of the original matrix $\mathbf{X}_{\mathrm{c}}$, defined below equation (A1.1) with the last row omitted. For $\mathrm{c}=\mathrm{N}$, we have

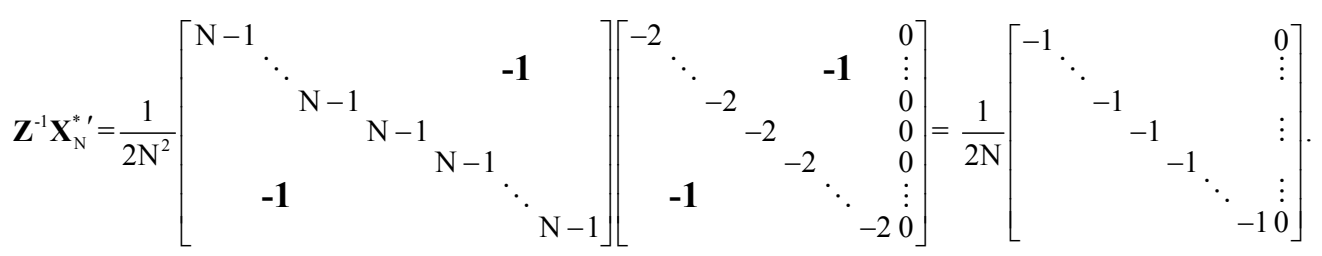

As the above expression is of the same form as $\mathbf{Z}^{-1} \mathbf{X}_{\mathrm{c}}^{* \prime}, \mathrm{c}=1, \ldots, \mathrm{N}-1$, the combined matrix is

$$
\mathbf{Z}^{-1} \mathbf{X}^{* \prime}=\left[\mathbf{Z}^{-1} \mathbf{X}_{1}^{* \prime}, \cdots, \mathbf{Z}^{-1} \mathbf{X}_{\mathrm{N}}^{* \prime}\right]=1 / 2 \mathrm{~N} \cdot \mathbf{X}_{-\mathrm{N}}^{\prime}
$$

where $\mathbf{X}_{-\mathrm{N}}$ is an $\mathrm{N}^{2} \times(\mathrm{N}-1)$ matrix composed of all rows and the first $\mathrm{N}-1$ columns of $\mathbf{X}$. This result is stated in Section A1.3.

Combining equations (A1.5) and (A1.9), $\hat{\alpha}^{*}=1 / 2 \mathrm{~N} \cdot \mathbf{X}_{-\mathrm{N}}^{\prime} \cdot \mathbf{y}$, so the $\mathrm{c}^{\text {th }}$ element of $\hat{\boldsymbol{\alpha}}^{*}$ is

$$
\hat{\alpha}_{\mathrm{c}}=\frac{1}{2 \mathrm{~N}}\left[\begin{array}{c}
\left(\mathbf{X}_{1}\right)_{\mathrm{c}} \\
\vdots \\
\left(\mathbf{X}_{\mathrm{c}}\right)_{\mathrm{c}} \\
\vdots \\
\left(\mathbf{X}_{\mathrm{N}}\right)_{\mathrm{c}}
\end{array}\right]^{\prime}\left[\begin{array}{c}
\mathbf{y}_{\mathrm{1}} \\
\vdots \\
\mathbf{y}_{\mathrm{c}} \\
\vdots \\
\mathbf{y}_{\mathrm{N}}
\end{array}\right]=\frac{1}{2 \mathrm{~N}}\left[\left(\mathbf{X}_{\mathrm{c}}\right)_{\mathrm{c}}^{\prime} \mathbf{y}_{\mathrm{c}}+\sum_{\mathrm{i} \neq \mathrm{c}}\left(\mathbf{X}_{\mathrm{i}}\right)_{\mathrm{c}}^{\prime} \mathbf{y}_{\mathrm{i}}\right], \mathrm{c}=1, \ldots, \mathrm{N}-1
$$

where $(\cdot)_{c}$ denotes the $c^{\text {th }}$ column of matrix inside the brackets. Consider the first part in the square brackets on the far right-hand side of the above expression. As $\left(\mathbf{X}_{\mathrm{c}}\right)_{\mathrm{c}}^{\prime}=[1, \ldots, 1,0,1, \ldots, 1]$, where the $\mathrm{c}^{\text {th }}$ element is zero and the other elements are ones, and $\mathrm{y}_{\mathrm{cc}}=0$, we have $\left(\mathbf{X}_{\mathrm{c}}\right)_{\mathrm{c}}^{\prime} \mathbf{y}_{\mathrm{c}}=\sum_{\mathrm{i}=1}^{\mathrm{N}} \mathrm{y}_{\mathrm{ci}}$. For the second part, when $\mathrm{i} \neq \mathrm{c}$, 
$\left(\mathbf{X}_{\mathrm{i}}\right)_{\mathrm{c}}^{\prime}=[0, \ldots, 0,-1,0, \ldots, 0]$, where only the $\mathrm{c}^{\text {th }}$ element is nonzero, so we have $\left(\mathbf{X}_{\mathrm{i}}\right)_{\mathrm{c}}^{\prime} \mathbf{y}_{\mathrm{i}}=-\mathrm{y}_{\mathrm{ic}}=\mathrm{y}_{\mathrm{ci}}$. Accordingly,

$$
\hat{\alpha}_{c}=\frac{1}{2 N}\left[\sum_{i=1}^{N} y_{c i}+\sum_{i \neq c}\left(-y_{i c}\right)\right]=\frac{1}{2 N} \sum_{i=1}^{N}\left(y_{c i}-y_{i c}\right)=\frac{1}{N} \sum_{i=1}^{N} y_{c i}, c=1, \ldots, N-1,
$$

which is equation (A1.7).

\section{A1.6 $\underline{\text { More Derivations }}$}

In Section A1.4, it was stated that $\mathbf{X}_{\mathrm{c}}^{* \prime} \mathbf{X}_{\mathrm{c}}^{*}=\mathrm{m} \times\left(\mathbf{I}+\mathbf{u \imath}^{\prime}+\mathrm{G}_{\mathrm{c}} \mathbf{c}_{\mathrm{c}}^{\prime}\right)$, when $\mathrm{c} \in \mathbf{S}_{\mathrm{g}}$, $\mathrm{g}=1, \ldots, \mathrm{G}-1$. This result can be confirmed by direct calculation:

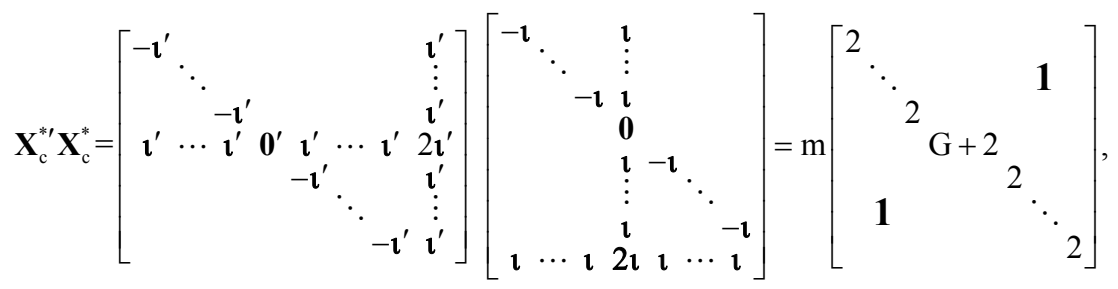

where $\mathbf{l}$ is a $\mathrm{m} \times 1$ unit column vector. When county c belongs to the last group $\mathrm{G}$,

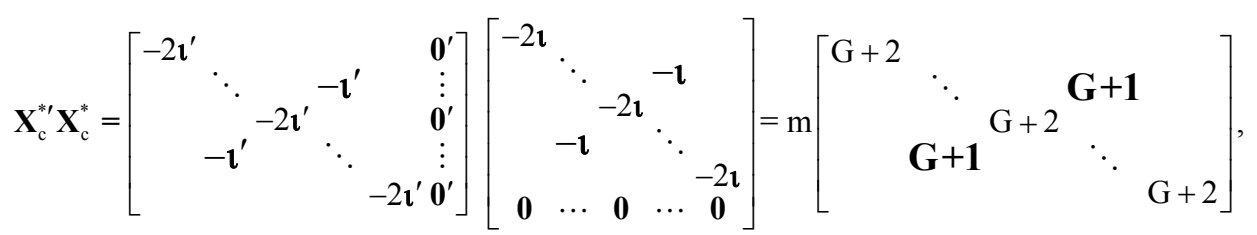

which can be expressed as $m \times\left(\mathbf{I}+(G+1) \mathbf{u}^{\prime}\right)$. The matrix $\mathbf{Z}$ defined in Section A1.4 for groups of countries is

$$
\mathbf{Z}=\mathbf{X}^{* \prime} \mathbf{X}^{*}=\sum_{\mathrm{g}=1}^{\mathrm{G}} \sum_{\mathrm{c} \in \mathbf{S}_{\mathrm{g}}} \mathbf{X}_{\mathrm{c}}^{* \prime} \mathbf{X}_{\mathrm{c}}^{*}
$$

Substituting the above expressions for $\mathbf{X}_{\mathrm{c}}^{* \prime} \mathbf{X}_{\mathrm{c}}^{*}$, which have same format for each country within the same group, we have

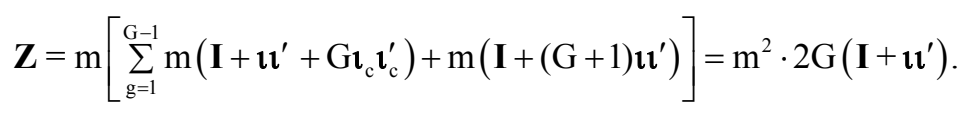

The inverse of $\mathbf{Z}$ is $\left(\mathrm{A} 1.6^{\prime}\right)$, so that

$$
\mathrm{z}^{\mathrm{ij}}=\frac{1}{2 \mathrm{~m}^{2} \mathrm{G}^{2}}\left\{\begin{array}{cc}
\mathrm{G}-1 & \mathrm{i}=\mathrm{j} \\
-1 & \mathrm{i} \neq \mathrm{j}
\end{array} .\right.
$$

Similar to the above derivation for the individual country case, for country c belonging to group $\mathrm{g}, \mathrm{g}=1, \ldots, \mathrm{G}-1$, we have 


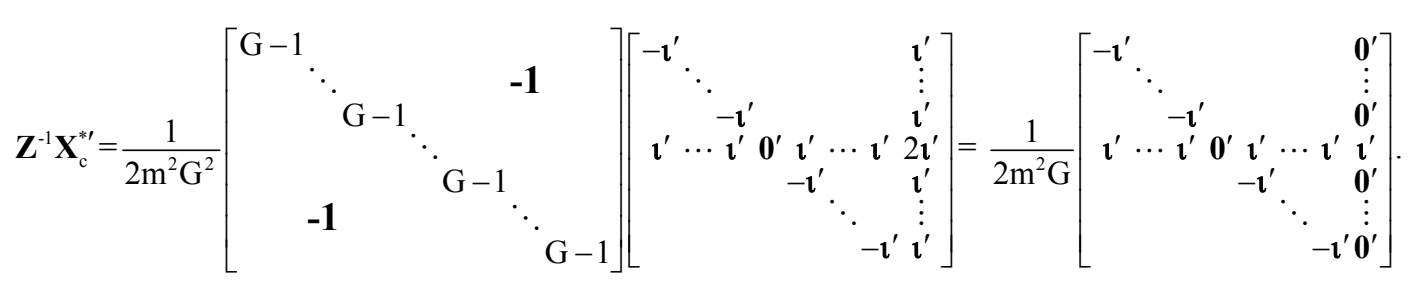

The last matrix is the transpose of the original matrix $\mathbf{X}_{c}$ with the last row omitted. For country in the last group, $\mathrm{c} \in \mathbf{S}_{\mathrm{G}}$, we have

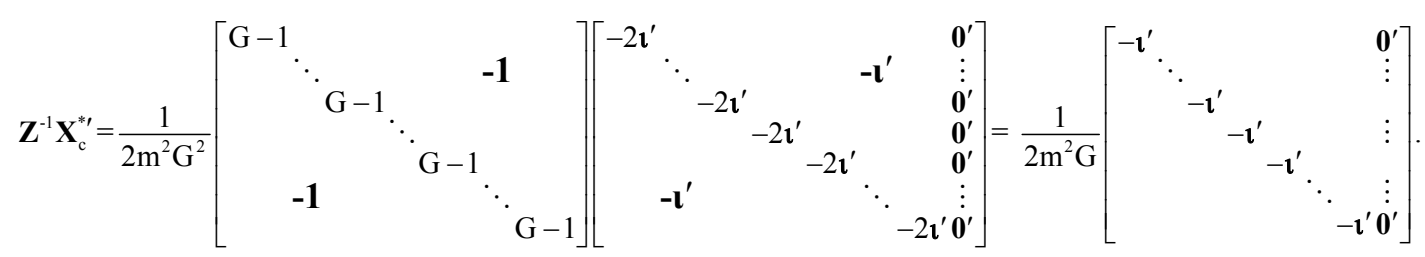

Therefore, the combined matrix $\mathbf{Z}^{-1} \mathbf{X}^{* \prime}=1 /\left(2 \mathrm{~m}^{2} \mathrm{G}\right) \cdot \mathbf{X}_{-\mathrm{N}}^{\prime}$, where $\mathbf{X}_{-\mathrm{N}}$ is composed of all rows and the first $\mathrm{G}-1$ columns of $\mathbf{X}$.

Substituting the above expressions for $\mathbf{Z}^{-1} \mathbf{X}^{* \prime}$ into $\hat{\mathrm{A}}^{*}=\left(\mathbf{X}^{* \prime} \mathbf{X}^{*}\right)^{-1} \mathbf{X}^{* \prime} \mathbf{y}$, we obtain, for $\mathrm{g}=1, \cdots, \mathrm{G}-1$,

$$
\hat{A}_{g}=\frac{1}{2 m^{2} G} \sum_{c \in \mathbf{S}_{g}} \sum_{d \notin \in \mathbf{S}_{g}}\left(y_{c d}-y_{d c}\right)=\frac{1}{m N} \sum_{c \in \mathbf{S}_{g}} \sum_{d \notin \mathbf{S}_{g}} y_{c d}=\frac{1}{m N} \sum_{c \in \mathbf{S}_{g}} \sum_{d=1}^{N} y_{c d}=\frac{1}{m} \sum_{c \in \mathbf{S}_{g}} \hat{\alpha}_{c},
$$

where the last second equality is based on $\sum_{\mathrm{c} \in \mathbf{S}_{\mathrm{g}}} \sum_{\mathrm{d} \in \mathbf{S}_{\mathrm{g}}} \mathrm{y}_{\mathrm{cd}}=0$. The estimated variance of $\hat{\mathrm{A}}^{*}$ is

$$
\widehat{\operatorname{var}\left(\hat{\mathbf{A}}^{*}\right)}=\frac{1}{\mathrm{~N}^{2}-(\mathrm{G}-1)} \sum_{\mathrm{c}=1}^{\mathrm{N}} \sum_{\mathrm{d}=1}^{\mathrm{N}} \hat{\zeta}_{\mathrm{cd}}^{2} \cdot \mathbf{Z}^{-1}=\frac{\hat{\sigma}_{\zeta}^{2}}{2 \mathrm{~m}^{2} \mathrm{G}^{2}}\left(\mathrm{GI}-\mathfrak{u}^{\prime}\right)
$$

where $\hat{\zeta}_{\mathrm{cd}}=\mathrm{y}_{\mathrm{cd}}-\hat{\mathrm{A}}_{\mathrm{g}}+\hat{\mathrm{A}}_{\mathrm{h}}, \mathrm{c} \in \mathbf{S}_{\mathrm{g}}$ and $\mathrm{d} \in \mathbf{S}_{\mathrm{h}}$, and

$$
\hat{\sigma}_{\zeta}^{2}=\frac{1}{\mathrm{~N}^{2}-(\mathrm{G}-1)} \sum_{\mathrm{c}=1 \mathrm{~d}=1}^{\mathrm{N}} \sum_{\mathrm{c}}^{\mathrm{N}} \hat{\zeta}_{\mathrm{d}}^{2}
$$

is the estimated error variance. Thus, in scalar terms,

$$
\widehat{\operatorname{var}\left(\hat{\mathrm{A}}_{\mathrm{g}}^{*}\right)}=\frac{\hat{\sigma}_{\zeta}^{2}}{2 \mathrm{~m}^{2} \mathrm{G}^{2}}(\mathrm{G}-1), \mathrm{g}=1, \ldots, \mathrm{G}-1 .
$$

Since $\sum_{\mathrm{c}=1}^{\mathrm{N}} \sum_{\mathrm{d}=1}^{\mathrm{N}} \mathrm{y}_{\mathrm{cd}}=0$, the estimated parameter for group $\mathrm{G}$ is

$$
\hat{\mathrm{A}}_{\mathrm{G}}=-\sum_{\mathrm{g}=1}^{\mathrm{G}-1} \hat{\mathrm{A}}_{\mathrm{g}}=-\frac{1}{\mathrm{Nm}} \sum_{\mathrm{c} \notin \mathbf{S}_{\mathrm{G}}} \sum_{\mathrm{d}=1}^{\mathrm{N}} \mathrm{y}_{\mathrm{cd}}=\frac{1}{\mathrm{Nm}} \sum_{\mathrm{c} \in \mathbf{S}_{\mathrm{G}}} \sum_{\mathrm{d}=1}^{\mathrm{N}} \mathrm{y}_{\mathrm{cd}} \text {. }
$$

The sampling variance of $\hat{\mathrm{A}}_{\mathrm{G}}=-\mathbf{l}^{\prime} \hat{\mathrm{A}}^{*}$ is then given as

$$
\widehat{\operatorname{var}\left(\hat{\mathrm{A}}_{\mathrm{G}}\right)}=\mathfrak{\imath}^{\prime} \operatorname{\operatorname {var}(\hat {\mathrm {A}}^{*})} \mathfrak{\imath}=\hat{\sigma}_{\zeta}^{2} \frac{(\mathrm{G}-1)}{2 \mathrm{~m}^{2} \mathrm{G}^{2}}=\widehat{\operatorname{var}\left(\hat{\mathrm{A}}_{\mathrm{g}}\right)}, \mathrm{g}=1, \ldots, \mathrm{G}-1 .
$$


Similar to the individual country case, we conclude that there is no asymmetry for group G: The estimator of $A_{G}$ has exactly the same form as do those for $A_{g}, g=1, \ldots, G-1$, and the same is true for its variance. 


\section{Appendix A2}

\section{INCOME SENSITIVITIES}

This appendix analyses the income dependence of the volume of, the price of and spending on quality. We start with the multilateral approach and then proceed to the bilateral case.

\section{A2.1 The Multilateral Approach}

Consider model (11) for quality index between countries $\mathrm{c}$ and $\mathrm{d}$,

$$
\mathrm{y}_{\eta \mathrm{q}}^{\mathrm{cd}}=\alpha_{\mathrm{c}}-\alpha_{\mathrm{d}}+\varepsilon_{\mathrm{cd}} \text {, }
$$

where $\alpha_{\mathrm{c}}$ is the factor for country c, and $\varepsilon_{\mathrm{cd}}$ is the disturbance term with zero mean and standard deviation $\sigma$. This model compresses the $\mathrm{N}^{2}$ values $\mathrm{y}_{\eta q}^{\mathrm{cd}}, \mathrm{c}, \mathrm{d}=1, \ldots, \mathrm{N}$ into $\mathrm{N}$ parameters $\alpha_{c}, c=1, \ldots, N$. As shown previously, the estimate of $\alpha_{c}$ is the mean of quality

indexes over countries, $\hat{\alpha}_{\mathrm{c}}=\sum_{\mathrm{d}=1}^{\mathrm{N}} \mathrm{y}_{\eta \mathrm{q}}^{\mathrm{cd}} / \mathrm{N}$. The estimate of $\alpha_{\mathrm{c}}$ for the 132 countries are listed in Table 4 and Panel A of Figure A2.1 is a scatter of these estimates against income. In view of the strong visual evidence of the dependence of $\hat{\alpha}_{c}$ on income, suppose that $\hat{\alpha}_{c}$ is linearly dependent on real income $\log \mathrm{Q}_{\mathrm{c}}$,

(A2.1) $\hat{\alpha}_{\mathrm{c}}=\beta+\gamma_{\alpha} \log \mathrm{Q}_{\mathrm{c}}+\mu_{\mathrm{c}}$,

where $\beta$ is the intercept, $\gamma_{\alpha}$ is the slope, interpreted as the income elasticity of quality, and $\mu_{\mathrm{c}}$ is the disturbance term with zero mean and standard deviation $\sigma_{\alpha}$.

The least-squares estimator of the slope is

$$
\hat{\gamma}_{\alpha}=\frac{\sum_{\mathrm{c}=1}^{\mathrm{N}} \hat{\alpha}_{\mathrm{c}} \log \mathrm{Q}_{\mathrm{c}}}{\sum_{\mathrm{c}=1}^{\mathrm{N}}\left(\log \mathrm{Q}_{\mathrm{c}}\right)^{2}-\mathrm{N}\left(\sum_{\mathrm{c}=1}^{\mathrm{N}} \log \mathrm{Q}_{\mathrm{c}} / \mathrm{N}\right)^{2}} .
$$

As $\hat{\alpha}_{\mathrm{c}}=\sum_{\mathrm{d}=1}^{\mathrm{N}} \mathrm{y}_{\eta \mathrm{q}}^{\mathrm{cd}} / \mathrm{N}$, this can be expressed as

(A2.2) $\hat{\gamma}_{\alpha}=\frac{1}{\mathrm{~N}} \cdot \frac{\sum_{\mathrm{d}=1}^{\mathrm{N}} \sum_{\mathrm{c}=1}^{\mathrm{N}} \mathrm{y}_{\eta q}^{\mathrm{cd}} \log \mathrm{Q}_{\mathrm{c}}}{\sum_{\mathrm{c}=1}^{\mathrm{N}}\left(\log \mathrm{Q}_{\mathrm{c}}\right)^{2}-\mathrm{N}\left(\sum_{\mathrm{c}=1}^{\mathrm{N}} \log \mathrm{Q}_{\mathrm{c}} / \mathrm{N}\right)^{2}}$.

The variance of $\hat{\gamma}_{\alpha}$ is

$$
\operatorname{var}\left(\hat{\gamma}_{\alpha}\right)=\frac{\sigma_{\alpha}^{2}}{\sum_{\mathrm{c}=1}^{\mathrm{N}}\left(\log \mathrm{Q}_{\mathrm{c}}\right)^{2}-\mathrm{N}\left(\sum_{\mathrm{c}=1}^{\mathrm{N}} \log \mathrm{Q}_{\mathrm{c}} / \mathrm{N}\right)^{2}},
$$


where $\sigma_{\alpha}$ is the standard deviation of the disturbance term in model (A2.1), which can be estimated unbiasedly by $\hat{\sigma}_{\alpha}^{2}=\sum_{c=1}^{\mathrm{N}}\left(\hat{\mu}_{\mathrm{c}}\right)^{2} /(\mathrm{N}-2)$, where $\hat{\mu}_{\mathrm{c}}=\hat{\alpha}_{\mathrm{c}}-\hat{\beta}+\hat{\gamma}_{\alpha} \log \mathrm{Q}_{\mathrm{c}}$ is the leastsquares residual from model (A2.1). Therefore, the estimated value of $\operatorname{var}\left(\hat{\gamma}_{\alpha}\right)$ is

(A2.3) $\widehat{\operatorname{var}}\left(\hat{\gamma}_{\alpha}\right)=\frac{\sum_{\mathrm{c}=1}^{\mathrm{N}}\left(\hat{\mu}_{\mathrm{c}}\right)^{2} /(\mathrm{N}-2)}{\sum_{\mathrm{c}=1}^{\mathrm{N}}\left(\log \mathrm{Q}_{\mathrm{c}}\right)^{2}-\mathrm{N}\left(\sum_{\mathrm{c}=1}^{\mathrm{N}} \log \mathrm{Q}_{\mathrm{c}} / \mathrm{N}\right)^{2}}$

Panel A of Figure A2.1 reveals that $\hat{\gamma}_{\alpha}=0.065$ with standard error 0.003 . Thus, the income elasticity of quality is estimated to be about 0.07 and this estimate is highly significant. The two other panels of Figure A2.1 show that the income elasticity of the price of quality is 0.01 , while that of spending is 0.08 ; both estimates are significant. It is to be noted that the excess of the spending elasticity over the price elasticity is the income elasticity of quality: $0.07=0.08-0.01$. Thus, these estimates satisfy the aggregation constraint.

\section{A2.2 The Bilateral Approach}

We return to model (11), $\mathrm{y}_{\eta q}^{\mathrm{cd}}=\alpha_{\mathrm{c}}-\alpha_{\mathrm{d}}+\varepsilon_{\mathrm{cd}}$, and consider another version of equation (A2.1) that is expressed in terms of the unknown parameter $\alpha_{c}$ rather than its estimate $\hat{\alpha}_{c}$ :

$$
\alpha_{c}=\beta+\gamma_{\alpha} \log Q_{c}+\mu_{c}^{\prime}
$$

where $\mu_{\mathrm{c}}^{\prime}=\mu_{\mathrm{c}}+\left(\alpha_{\mathrm{c}}-\hat{\alpha}_{\mathrm{c}}\right)$ is a new disturbance term with zero mean. Substituting the righthand side of (A2.1') for $\alpha_{c}$ in model (11) gives

$(\mathrm{A} 2.4) \quad \mathrm{y}_{\eta \mathrm{q}}^{\mathrm{cd}}=\gamma_{\alpha} \log \left(\mathrm{Q}_{\mathrm{c}} / \mathrm{Q}_{\mathrm{d}}\right)+\zeta_{\mathrm{cd}}^{\prime}$

where $\zeta_{c d}^{\prime}=\mu_{c}^{\prime}-\mu_{d}^{\prime}+\varepsilon_{c d}$ is a composite disturbance term. Model (A2.4) implies that the quality difference between two countries is proportional to their relative income $\log \left(Q_{c} / Q_{d}\right)$. It is to be noted that this model retains the three basic consistency properties:

(ii) Mirror symmetry, $\mathrm{y}_{\eta \mathrm{q}}^{\mathrm{cd}}=-\mathrm{y}_{\eta \mathrm{q}}^{\mathrm{dc}}$.

(iii) Income the only determinant, $\mathrm{y}_{\eta \mathrm{q}}^{\mathrm{cd}}=0$, if $\mathrm{Q}_{\mathrm{c}}=\mathrm{Q}_{\mathrm{d}}$ for $\mathrm{c} \neq \mathrm{d}$.

Note that the intercept in equation $\left(\mathrm{A} 2.1^{\prime}\right), \beta$, is the same for all countries. What if this were replaced with a country-specific term, $\beta_{c}$ ? In this case model (A2.4) becomes $\mathrm{y}_{\eta \mathrm{q}}^{\mathrm{cd}}=\beta_{\mathrm{c}}-\beta_{\mathrm{d}}+\gamma_{\alpha} \log \left(\mathrm{Q}_{\mathrm{c}} / \mathrm{Q}_{\mathrm{d}}\right)+\zeta_{\mathrm{cd}}^{\prime}$. This satisfies property (i) and (ii) above, but (iii) requires 
that $\beta_{\mathrm{c}}=\beta_{\mathrm{d}}$, that is, the intercept must be independent of countries. This is the justification for using the common intercept specification.

Suppose we start with equation (A2.4) and do not know that its slope coefficient is equal to that of (A2.1), $\gamma_{\alpha}$. In this situation, we have

$\left(\mathrm{A} 2.4^{\prime}\right) \quad \mathrm{y}_{\eta \mathrm{q}}^{\mathrm{cd}}=\gamma_{\mathrm{y}} \log \left(\mathrm{Q}_{\mathrm{c}} / \mathrm{Q}_{\mathrm{d}}\right)+\zeta_{\mathrm{cd}}$

where $\gamma_{\mathrm{y}}$ is the new slope and $\zeta_{\mathrm{cd}}$ is a disturbance term with zero mean and standard deviation $\sigma_{\mathrm{y}}$. Using the $\mathrm{N}^{2}$ observations on equation $\left(\mathrm{A} 2.4^{\prime}\right)$ for $\mathrm{c}, \mathrm{d}=1, \ldots, \mathrm{N}$, the least-squares estimator of $\gamma_{\mathrm{y}}$ is

$$
\hat{\gamma}_{\mathrm{y}}=\frac{\sum_{\mathrm{d}=1}^{\mathrm{N}} \sum_{\mathrm{c}=1}^{\mathrm{N}} \mathrm{y}_{\eta \mathrm{q}}^{\mathrm{cd}} \log \left(\mathrm{Q}_{\mathrm{c}} / \mathrm{Q}_{\mathrm{d}}\right)}{\sum_{\mathrm{d}=1}^{\mathrm{N}} \sum_{\mathrm{c}=1}^{\mathrm{N}}\left(\log \left(\mathrm{Q}_{\mathrm{c}} / \mathrm{Q}_{\mathrm{d}}\right)\right)^{2}-\mathrm{N}\left(\sum_{\mathrm{d}=1}^{\mathrm{N}} \sum_{\mathrm{c}=1}^{\mathrm{N}} \log \left(\mathrm{Q}_{\mathrm{c}} / \mathrm{Q}_{\mathrm{d}}\right) / \mathrm{N}\right)^{2}}
$$

The numerator of the above expression for $\hat{\gamma}_{\mathrm{y}}$, which is equivalent to $\sum_{\mathrm{d}=1}^{\mathrm{N}} \sum_{\mathrm{c}=1}^{\mathrm{N}} \mathrm{y}_{\eta \mathrm{q}}^{\mathrm{cd}}\left(\log \mathrm{Q}_{\mathrm{c}}-\log \mathrm{Q}_{\mathrm{d}}\right), \quad$ can $\quad$ be $\quad$ simplified $\quad$ to $2 \sum_{\mathrm{d}=1}^{\mathrm{N}} \sum_{\mathrm{c}=1}^{\mathrm{N}} \mathrm{y}_{\eta q}^{\mathrm{cd}} \log \mathrm{Q}_{\mathrm{c}} \quad$ as $\sum_{\mathrm{d}=1}^{\mathrm{N}} \sum_{\mathrm{c}=1}^{\mathrm{N}} \mathrm{y}_{\eta q}^{\mathrm{cd}} \log \mathrm{Q}_{\mathrm{c}}=\sum_{\mathrm{d}=1}^{\mathrm{N}} \sum_{\mathrm{c}=1}^{\mathrm{N}} \mathrm{y}_{\eta q}^{\mathrm{dc}} \log \mathrm{Q}_{\mathrm{d}}$ and $\mathrm{y}_{\eta q}^{\mathrm{cd}}=-\mathrm{y}_{\eta q}^{\mathrm{dc}}$. Consider the first term of the denominator,

$$
\begin{aligned}
& \sum_{\mathrm{d}=1}^{\mathrm{N}} \sum_{\mathrm{c}=1}^{\mathrm{N}}\left(\log \left(\mathrm{Q}_{\mathrm{c}} / \mathrm{Q}_{\mathrm{d}}\right)\right)^{2} \\
= & \sum_{\mathrm{d}=1}^{\mathrm{N}} \sum_{\mathrm{c}=1}^{\mathrm{N}}\left[\left(\log \mathrm{Q}_{\mathrm{c}}\right)^{2}+\left(\log \mathrm{Q}_{\mathrm{d}}\right)^{2}-2\left(\log \mathrm{Q}_{\mathrm{c}} \log \mathrm{Q}_{\mathrm{d}}\right)\right] \\
= & 2 \mathrm{~N} \sum_{\mathrm{c}=1}^{\mathrm{N}}\left(\log \mathrm{Q}_{\mathrm{c}}\right)^{2}-2 \sum_{\mathrm{d}=1}^{\mathrm{N}} \log \mathrm{Q}_{\mathrm{d}} \sum_{\mathrm{c}=1}^{\mathrm{N}} \log \mathrm{Q}_{\mathrm{c}} \\
= & 2 \mathrm{~N} \sum_{\mathrm{c}=1}^{\mathrm{N}}\left(\log \mathrm{Q}_{\mathrm{c}}\right)^{2}-2\left(\sum_{\mathrm{c}=1}^{\mathrm{N}} \log \mathrm{Q}_{\mathrm{c}}\right)^{2} \\
= & 2 \mathrm{~N}\left[\sum_{\mathrm{c}=1}^{\mathrm{N}}\left(\log \mathrm{Q}_{\mathrm{c}}\right)^{2}-\mathrm{N}\left(\sum_{\mathrm{c}=1}^{\mathrm{N}} \log \mathrm{Q}_{\mathrm{c}} / \mathrm{N}\right)^{2}\right] .
\end{aligned}
$$

The second term of the denominator is 0 as $\sum_{d=1}^{N} \sum_{c=1}^{N} \log \left(Q_{c} / Q_{d}\right)=0$. Therefore, $\hat{\gamma}_{y}$ can be simplified to

(A2.5) $\hat{\gamma}_{\mathrm{y}}=\frac{\sum_{\mathrm{d}=1}^{\mathrm{N}} \sum_{\mathrm{c}=1}^{\mathrm{N}} \mathrm{y}_{\eta q}^{\mathrm{cd}} \log \mathrm{Q}_{\mathrm{c}}}{\mathrm{N}\left[\sum_{\mathrm{c}=1}^{\mathrm{N}}\left(\log \mathrm{Q}_{\mathrm{c}}\right)^{2}-\mathrm{N}\left(\sum_{\mathrm{c}=1}^{\mathrm{N}} \log \mathrm{Q}_{\mathrm{c}} / \mathrm{N}\right)^{2}\right]}$.

Comparing (A2.5) with (A2.2), we have $\hat{\gamma}_{\mathrm{y}}=\hat{\gamma}_{\alpha}$. This shows that even although we use the $\mathrm{N}^{2}$ observations to estimate equation $\left(\mathrm{A} 2.4^{\prime}\right)$, we obtain exactly the same slope coefficient as if we estimate equation (A2.1) with $\mathrm{N}$ observations. Thus, equation (A2.4) is equivalent to $\left(\mathrm{A} 2.4^{\prime}\right)$, and $\zeta_{\mathrm{cd}}=\zeta_{\mathrm{cd}}^{\prime}$

The variance of $\hat{\gamma}_{\mathrm{y}}$ is 


$$
\operatorname{var}\left(\hat{\gamma}_{\mathrm{y}}\right)=\frac{\sigma_{\mathrm{y}}^{2}}{2 \mathrm{~N}\left[\sum_{\mathrm{c}=1}^{\mathrm{N}}\left(\log \mathrm{Q}_{\mathrm{c}}\right)^{2}-\mathrm{N}\left(\sum_{\mathrm{c}=1}^{\mathrm{N}} \log \mathrm{Q}_{\mathrm{c}} / \mathrm{N}\right)^{2}\right]},
$$

where $\sigma_{\mathrm{y}}$ is the standard deviation of the disturbance term in model (A2.4'), which can be estimated by $\hat{\sigma}_{\mathrm{y}}^{2}=\sum_{\mathrm{d}=1}^{\mathrm{N}} \sum_{\mathrm{c}=1}^{\mathrm{N}}\left(\hat{\zeta}_{\mathrm{cd}}\right)^{2} /\left(\mathrm{N}^{2}-1\right)$, with $\hat{\zeta}_{\mathrm{cd}}$ the corresponding residual. Thus, the estimate of $\operatorname{var}\left(\hat{\gamma}_{\mathrm{y}}\right)$ is

(A2.6) $\widehat{\operatorname{var}}\left(\hat{\gamma}_{\mathrm{y}}\right)=\frac{\sum_{\mathrm{d}=1}^{\mathrm{N}} \sum_{\mathrm{c}=1}^{\mathrm{N}}\left(\hat{\zeta}_{\mathrm{cd}}\right)^{2} /\left(\mathrm{N}^{2}-1\right)}{2 \mathrm{~N}\left[\sum_{\mathrm{c}=1}^{\mathrm{N}}\left(\log \mathrm{Q}_{\mathrm{c}}\right)^{2}-\mathrm{N}\left(\sum_{\mathrm{c}=1}^{\mathrm{N}} \log \mathrm{Q}_{\mathrm{c}} / \mathrm{N}\right)^{2}\right]}$

Figure 2.2 gives the scatters of quality, prices and spending against income in the bilateral case. The estimated slope coefficients are the same as before (for reasons discussed above), but the standard errors are now much smaller, a result that is analysed in the next section.

\section{A2.3 A Comparison of Precision}

To estimate model (A2.1), we use N=132 observations, while for model (A2.4) there are $\mathrm{N}^{2}=132^{2}$ observations. Although the least-square estimates of the slope coefficients of the two models coincide (as shown above), as the number of observation differs, it is appropriate to compare their precision.

To compare the two variances, (A2.3) and (A2.6), we consider their ratio:

(A2.7) $\frac{\widehat{\operatorname{var}}\left(\hat{\gamma}_{\alpha}\right)}{\widehat{\operatorname{var}}\left(\hat{\gamma}_{\mathrm{y}}\right)}=2 \mathrm{~N} \cdot \frac{\hat{\sigma}_{\alpha}^{2}}{\hat{\sigma}_{\mathrm{y}}^{2}}=2 \mathrm{~N} \cdot \frac{\sum_{\mathrm{c}=1}^{\mathrm{N}}\left(\hat{\mu}_{\mathrm{c}}\right)^{2} /(\mathrm{N}-2)}{\sum_{\mathrm{d}=1}^{\mathrm{N}} \sum_{\mathrm{c}=1}^{\mathrm{N}}\left(\hat{\zeta}_{\mathrm{cd}}\right)^{2} /\left(\mathrm{N}^{2}-1\right)}$.

As discussed below model (A2.4), the composite disturbance $\zeta_{\mathrm{cd}}^{\prime}=\mu_{\mathrm{c}}^{\prime}-\mu_{\mathrm{d}}^{\prime}+\varepsilon_{\mathrm{cd}}$, while below (A2.5) we established that $\zeta_{c d}=\zeta_{c d}^{\prime}$. Thus, for the corresponding residuals, we have $\hat{\zeta}_{c d}=\hat{\mu}_{c}-\hat{\mu}_{d}+\hat{\varepsilon}_{c d}$, so that the sum of squares is given by

$$
\begin{aligned}
\sum_{\mathrm{d}=1}^{\mathrm{N}} \sum_{\mathrm{c}=1}^{\mathrm{N}}\left(\hat{\zeta}_{\mathrm{cd}}\right)^{2} & =\sum_{\mathrm{d}=1}^{\mathrm{N}} \sum_{\mathrm{c}=1}^{\mathrm{N}}\left[\left(\hat{\varepsilon}_{\mathrm{cd}}\right)^{2}+\left(\hat{\mu}_{\mathrm{c}}\right)^{2}+\left(\hat{\mu}_{\mathrm{d}}\right)^{2}-2 \hat{\mu}_{\mathrm{c}} \hat{\mu}_{\mathrm{d}}+2 \hat{\mu}_{\mathrm{c}} \hat{\varepsilon}_{\mathrm{cd}}-2 \hat{\mu}_{\mathrm{d}} \hat{\varepsilon}_{\mathrm{cd}}\right] \\
& =\sum_{\mathrm{d}=1}^{\mathrm{N}} \sum_{\mathrm{c}=1}^{\mathrm{N}}\left(\hat{\varepsilon}_{\mathrm{cd}}\right)^{2}+\mathrm{N} \sum_{\mathrm{c}=1}^{\mathrm{N}}\left(\hat{\mu}_{\mathrm{c}}\right)^{2}+\mathrm{N} \sum_{\mathrm{d}=1}^{\mathrm{N}}\left(\hat{\mu}_{\mathrm{d}}\right)^{2}-2 \sum_{\mathrm{d}=1}^{\mathrm{N}} \hat{\mu}_{\mathrm{d}} \sum_{\mathrm{c}=1}^{\mathrm{N}} \hat{\mu}_{\mathrm{c}}+2 \sum_{\mathrm{d}=1}^{\mathrm{N}} \sum_{\mathrm{c}=1}^{\mathrm{N}} \hat{\mu}_{\mathrm{c}} \hat{\varepsilon}_{\mathrm{cd}}+2 \sum_{\mathrm{c}=1}^{\mathrm{N}} \sum_{\mathrm{d}=1}^{\mathrm{N}} \hat{\mu}_{\mathrm{d}} \hat{\varepsilon}_{\mathrm{dc}} \\
& =\sum_{\mathrm{d}=1}^{\mathrm{N}} \sum_{\mathrm{c}=1}^{\mathrm{N}}\left(\hat{\varepsilon}_{\mathrm{cd}}\right)^{2}+2 \mathrm{~N} \cdot \sum_{\mathrm{c}=1}^{\mathrm{N}}\left(\hat{\mu}_{\mathrm{c}}\right)^{2}-2\left(\sum_{\mathrm{c}=1}^{\mathrm{N}} \hat{\mu}_{\mathrm{c}}\right)^{2}+4 \sum_{\mathrm{c}=1}^{\mathrm{N}} \hat{\mu}_{\mathrm{c}} \sum_{\mathrm{d}=1}^{\mathrm{N}} \hat{\varepsilon}_{\mathrm{cd}} \\
& =\sum_{\mathrm{d}=1}^{\mathrm{N}} \sum_{\mathrm{c}=1}^{\mathrm{N}}\left(\hat{\varepsilon}_{\mathrm{cd}}\right)^{2}+2 \mathrm{~N} \cdot \sum_{\mathrm{c}=1}^{\mathrm{N}}\left(\hat{\mu}_{\mathrm{c}}\right)^{2},
\end{aligned}
$$


where the last equality follows from $\sum_{\mathrm{c}=1}^{\mathrm{N}} \hat{\mu}_{\mathrm{c}}=0$ and $\sum_{\mathrm{d}=1}^{\mathrm{N}} \hat{\varepsilon}_{\mathrm{cd}}=0$. Dividing this sum of squares by the degrees of freedom, $\mathrm{N}^{2}-1$, gives

$$
\frac{\sum_{d=1}^{N} \sum_{c=1}^{N}\left(\hat{\zeta}_{c d}\right)^{2}}{N^{2}-1}=\frac{\sum_{d=1}^{N} \sum_{c=1}^{N}\left(\hat{\varepsilon}_{c d}\right)^{2}}{N^{2}-1}+\frac{2 N \cdot \sum_{c=1}^{N}\left(\hat{\mu}_{c}\right)^{2}}{N^{2}-1} \text {. }
$$

The left-hand side of equation (A2.8) is the estimated variance of the disturbance term $\zeta_{c d}$ of model (A2.4'), $\hat{\sigma}_{\mathrm{y}}^{2}$. The first term on the right of (A2.8) is an estimate of the variance of $\varepsilon_{\mathrm{cd}}$

of the original model considered at the start of Section A2.1, $\hat{\sigma}^{2}$. As $2 \mathrm{~N} /\left(\mathrm{N}^{2}-1\right) \approx 2 /(\mathrm{N}-2)$, the second term on the right-hand side of the above is approximately twice the estimated variance of model (A2.1), 2 $\hat{\sigma}_{\alpha}^{2}$. Accordingly, we have

(A2.9) $\hat{\sigma}_{\mathrm{y}}^{2} \approx \hat{\sigma}^{2}+2 \hat{\sigma}_{\alpha}^{2}$

Substituting approximation (A2.9) into equation (A2.7), we have

$$
\frac{\widehat{\operatorname{var}}\left(\hat{\gamma}_{\alpha}\right)}{\widehat{\operatorname{var}}\left(\hat{\gamma}_{\mathrm{y}}\right)} \approx \frac{\mathrm{N}}{1+\hat{\sigma}^{2} / 2 \hat{\sigma}_{\alpha}^{2}},
$$

which shows that the ratio on the right is less than N. Table A2.1 explores these issues numerically by using the estimated variances obtained from our $\mathrm{N}=132$ countries. As can be seen from rows 2 and 4 of column 2 (which refers to quality), the standard deviation of the residuals from model (A2.1) is about half that of those from (A2.4') -- 4 versus 8 percent. Row 6 shows that the estimate of slope in the bilateral model is much more precise than that in the multilateral model. Finally, row 7 shows that (A2.9) is an accurate approximation. The last two columns of the table give the results for prices and spending, and the same pattern emerges.

\section{A2.4 The Dependence of the Income Elasticity on Income}

In model (A2.1), $\hat{\alpha}_{c}$ is linearly dependent on real income $\log Q_{c}$, and the slope $\gamma_{\alpha}$ is assumed to be constant for all countries. That is, the income elasticity of quality is invariant for all income levels. As quality could be considered to become increasingly important as income grows, in this section we investigate the validity of this assumption.

If the elasticity $\gamma_{\alpha}$ is different for the rich from the poor, model (A2.1) could then be reformulated as

$$
\hat{\alpha}_{c}=\beta_{r}+\gamma_{\alpha, r} \log Q_{c}+\varepsilon_{c}, \quad c \in S_{r} ; \quad \hat{\alpha}_{c}=\beta_{p}+\gamma_{\alpha, p} \log Q_{c}+\varepsilon_{c}, \quad c \in S_{p},
$$


where $\beta_{\mathrm{r}}$ is the intercept and $\gamma_{\alpha, \mathrm{r}}$ is the slope for the group of rich countries, denoted by $\mathrm{S}_{\mathrm{r}}$; and $\beta_{\mathrm{r}}$ and $\gamma_{\alpha, \mathrm{r}}$ are those for the poor group $\mathrm{S}_{\mathrm{p}}$. We use the Quandt-Andrews unknown breakpoint test to identify the country that divides up the world into the rich and the poor. This involves ranking countries by income and then examining all possible divisions into the two groups.

As shown in column 2 of Table A2.2, for quality this approach yields as the "marginal" country Bulgaria, country number 51, whose income is 26 percent of that in the US. That is, the rich group consists of countries 1 to 50 and other countries belong to the poor group. The same country, Bulgaria, is identified as the richest county in the poor group for spending (column 4), while it is Nigeria in the case of prices (column 3). But as the p-values in the three cases are reasonable high, there is not strong evidence of that the elasticities differ with income. Nevertheless, as the p-value for prices is greater than the other two p-values for quality and spending, in what follows, we take Bulgaria as the marginal country in all three cases.

The results for the rich and the poor groups are given in Figure A2.3. Panel A shows that the estimated income elasticity of quality for the rich is 0.12 , which is indeed larger than that for the poor (0.06). The elasticities for prices and spending are also larger for the rich than the poor. In going from Figure A2.1 to Figure A2.3, the $\mathrm{R}^{2}$ values increase, as they should. But the increase is only modest, which re-enforces the finding that there is only weak evidence in favour of variable income elasticities. 
TABLE A1.1

\section{SUMMARY OF STOCHASTIC QUALITY FORMULATION}

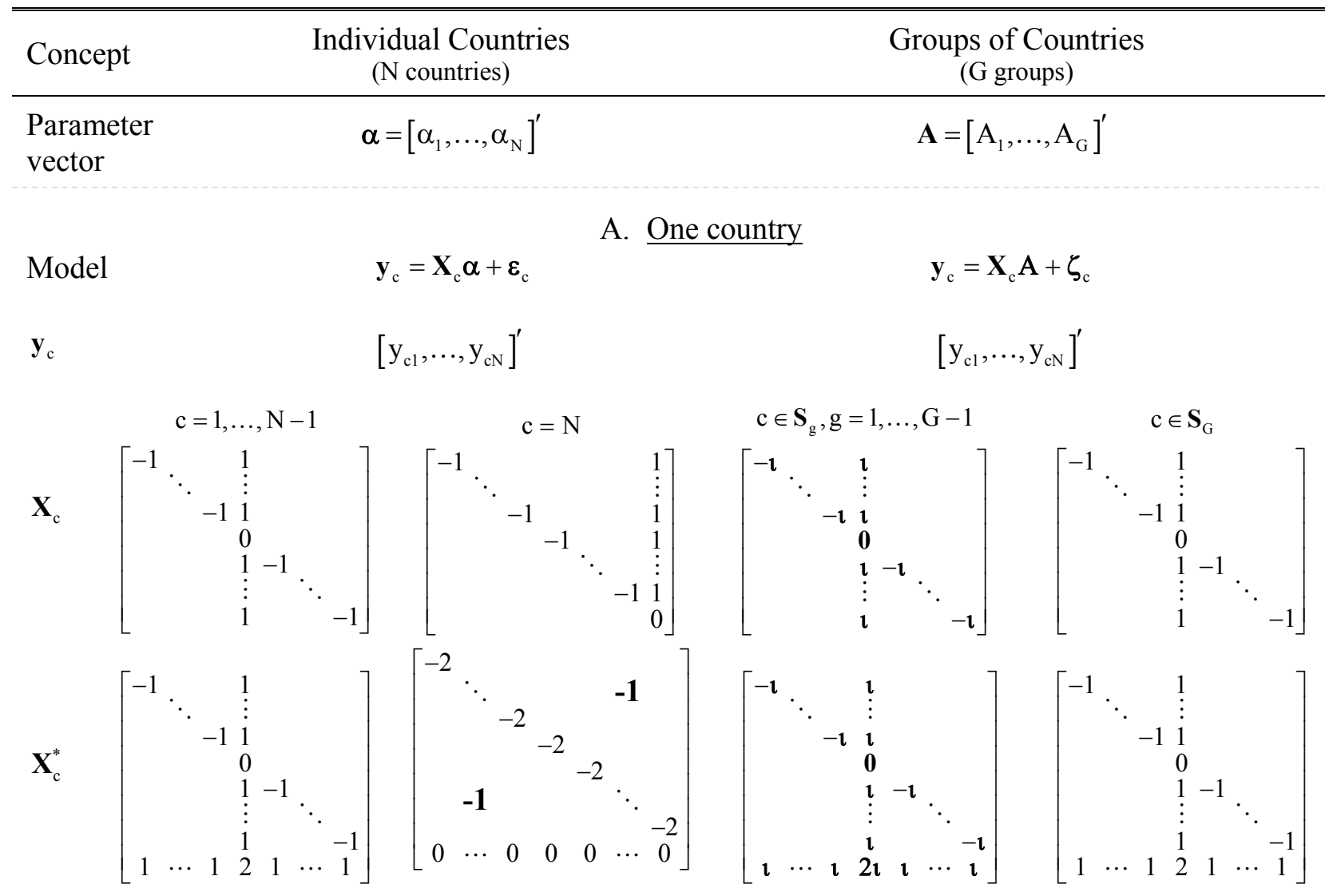

B. All countries combined
Model
$\mathbf{y}=\mathbf{X} \boldsymbol{\alpha}+\varepsilon$
$\mathbf{y}=\mathbf{X A}+\zeta$
$\mathbf{y}$
$\left[\mathbf{y}_{1}^{\prime}, \ldots, \mathbf{y}_{\mathrm{N}}^{\prime}\right]^{\prime}$
$\left[\mathbf{y}_{1}^{\prime}, \ldots, \mathbf{y}_{\mathrm{N}}^{\prime}\right]^{\prime}$
$\mathbf{X}^{*}$

$$
\left[\mathbf{X}_{1}^{* \prime}, \ldots, \mathbf{X}_{\mathrm{N}}^{*}\right]^{\prime}
$$$$
\left[\mathbf{X}_{1}^{* \prime}, \ldots, \mathbf{X}_{\mathrm{N}}^{* \prime}\right]^{\prime}
$$
$\mathbf{X}^{* \prime} \mathbf{X}^{*}$
$2 \mathrm{~N} \cdot\left(\mathbf{I}+\mathfrak{\imath l}^{\prime}\right)$
$\mathrm{m}^{2} \cdot 2 \mathrm{G}\left(\mathbf{I}+\mathfrak{u}^{\prime}\right)$
$\left(\mathbf{X}^{* \prime} \mathbf{X}^{*}\right)^{-1}$
$\left(\mathrm{NI}-\mathfrak{u}^{\prime}\right) / 2 \mathrm{~N}^{2}$
$1 / \mathrm{m}^{2} \cdot\left(\mathrm{GI}-\mathfrak{u}^{\prime}\right) /\left(2 \mathrm{G}^{2}\right)$
$\left(\mathbf{X}^{* \prime} \mathbf{X}^{*}\right)^{-1} \mathbf{X}^{* \prime} \mathbf{y}$
$\hat{\alpha}_{\mathrm{c}}=\frac{1}{\mathrm{~N}} \sum_{\mathrm{d}=1}^{\mathrm{N}} \mathrm{y}_{\mathrm{cd}}$
$\hat{\mathrm{A}}_{\mathrm{g}}=\frac{1}{\mathrm{~m}} \sum_{\mathrm{c} \in \mathbf{S}_{\mathrm{g}}} \hat{\alpha}_{\mathrm{c}}, \mathrm{m}=\mathrm{N} / \mathrm{G}$
$\hat{\phi}^{2} \operatorname{diag}\left(\mathbf{X}^{* \prime} \mathbf{X}^{*}\right)^{-1}$
$\hat{\sigma}^{2} \cdot(\mathrm{N}-1) /\left(2 \mathrm{~N}^{2}\right)$
$\hat{\sigma}_{\zeta}^{2} / \mathrm{m}^{2} \cdot(\mathrm{G}-1) /\left(2 \mathrm{G}^{2}\right)$

Note: $\mathbf{l}$ is a unit vector of length $\mathrm{m}$ in panel $\mathrm{A}$ and $\mathrm{N}-1$ and $\mathrm{G}-1$ in the second and third columns of panel $\mathrm{B}$, respectively. The term $\hat{\phi}^{2}$ in the last entry of the first column is the estimate of the variance of the disturbance term. This becomes $\hat{\sigma}^{2}$ and $\hat{\sigma}_{\zeta}^{2}$ in the corresponding elements of the second and third columns. 
TABLE A2.1

COMPARISON OF VARIANCES

\begin{tabular}{|c|c|c|c|}
\hline $\begin{array}{l}\text { Variance } \\
\text { (1) }\end{array}$ & $\begin{array}{l}\text { Quality } \\
\text { (2) }\end{array}$ & $\begin{array}{c}\text { Prices } \\
(3)\end{array}$ & $\begin{array}{c}\text { Spending } \\
\text { (4) }\end{array}$ \\
\hline \multicolumn{4}{|c|}{ I . Multilateral model (11): } \\
\hline \multicolumn{4}{|c|}{$\mathrm{y}_{\eta \mathrm{q}}^{\mathrm{cd}}=\alpha_{\mathrm{c}}-\alpha_{\mathrm{d}}+\varepsilon_{\mathrm{cd}}$} \\
\hline 1. $\hat{\sigma}^{2}$ & $5.9639^{2}$ & $3.3207^{2}$ & $3.2993^{2}$ \\
\hline \multicolumn{4}{|c|}{$\hat{\alpha}_{c}=\beta+\gamma_{\alpha} \log Q_{c}+\mu_{c}$} \\
\hline 2. $\hat{\sigma}_{\alpha}^{2}$ & $4.0609^{2}$ & $1.6425^{2}$ & $4.0892^{2}$ \\
\hline 3. $\operatorname{var}\left(\hat{\gamma}_{\alpha}\right)$ & $0.2993^{2}$ & $0.1211^{2}$ & $0.3014^{2}$ \\
\hline \multicolumn{4}{|c|}{ III. Income-dependent bilateral model (A2.4') : } \\
\hline \multicolumn{4}{|c|}{$\mathrm{y}_{\eta \mathrm{q}}^{\mathrm{cd}}=\gamma_{\mathrm{y}} \log \left(\mathrm{Q}_{\mathrm{c}} / \mathrm{Q}_{\mathrm{d}}\right)+\zeta_{\mathrm{cd}}$} \\
\hline 4. $\hat{\sigma}_{y}^{2}$ & $8.2484^{2}$ & $4.0374^{2}$ & $6.6328^{2}$ \\
\hline 5. $\operatorname{var}\left(\hat{\gamma}_{\mathrm{y}}\right)$ & $0.0373^{2}$ & $0.0182^{2}$ & $0.0300^{2}$ \\
\hline \multicolumn{4}{|c|}{ IV. $\underline{\text { Comparison }}$} \\
\hline 6. $\operatorname{var}\left(\hat{\gamma}_{\alpha}\right) / \operatorname{var}\left(\hat{\gamma}_{\mathrm{y}}\right)$ & 64.3866 & 44.2737 & 100.9355 \\
\hline 7. $\left(\hat{\sigma}^{2}+2 \hat{\sigma}_{\alpha}^{2}\right) / \hat{\sigma}_{\mathrm{y}}^{2}$ & 1.0076 & 1.0075 & 1.0076 \\
\hline
\end{tabular}

Note: All entries except those in the last two rows are to be divided by 10,000 .

TABLE A2.2

BREAKPOINT TEST FOR QUALITY, PRICES AND SPENDING

\begin{tabular}{lccc}
\hline \hline Concept & Quality & Prices & Spending \\
$(1)$ & $(2)$ & $(3)$ & $(4)$ \\
\hline Break point & 51. Bulgaria & 112. Nigeria & 51. Bulgaria \\
Maximum Wald F-statistic & 7.7375 & 6.8403 & 9.7271 \\
p-value & 0.3285 & 0.4385 & 0.1607 \\
\hline
\end{tabular}


FIGURE A2.1

THE DEPENDENCE OF QUALITY, PRICES AND SPENDING INDEXES: THE MULTILATRERAL CASE
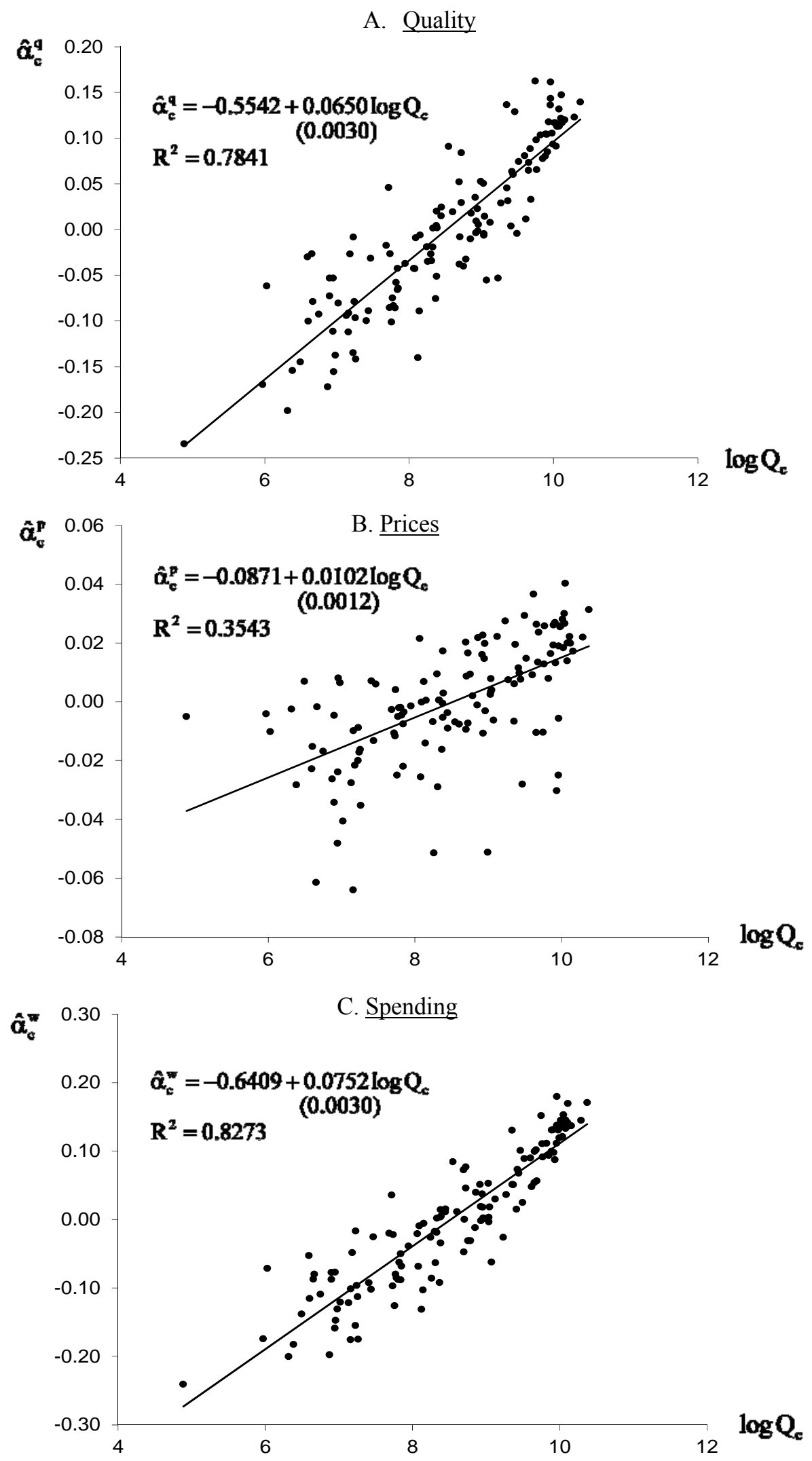

Note: Standard errors are in parentheses. 
FIGURE A2.2

THE DEPENDENCE OF QUALITY, PRICES AND SPENDING INDEXES: THE BILATERAL CASE
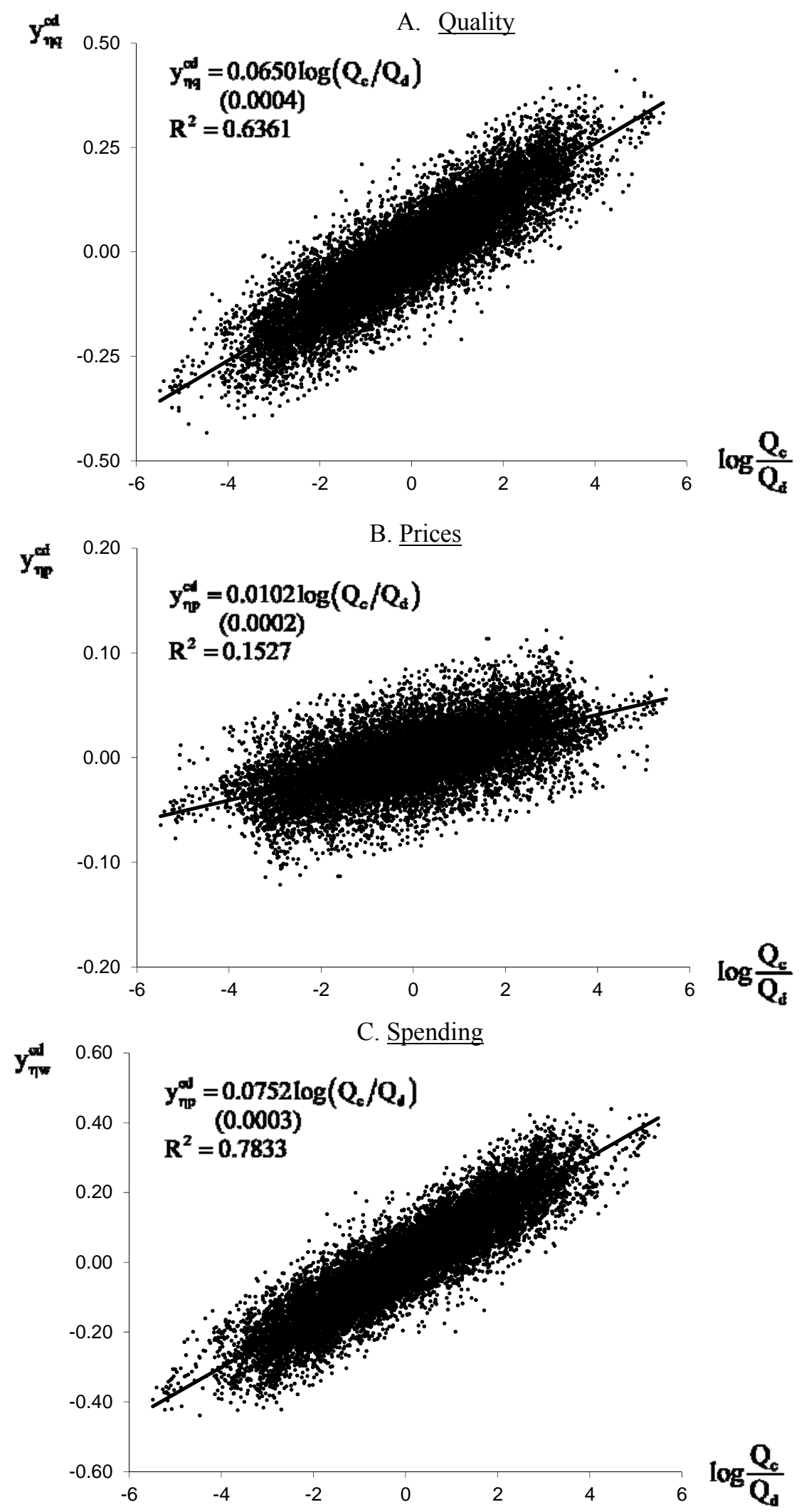

Note: Standard errors are in parentheses. 
FIGURE A2.3

VARIABLE INCOME ELASTICITIES
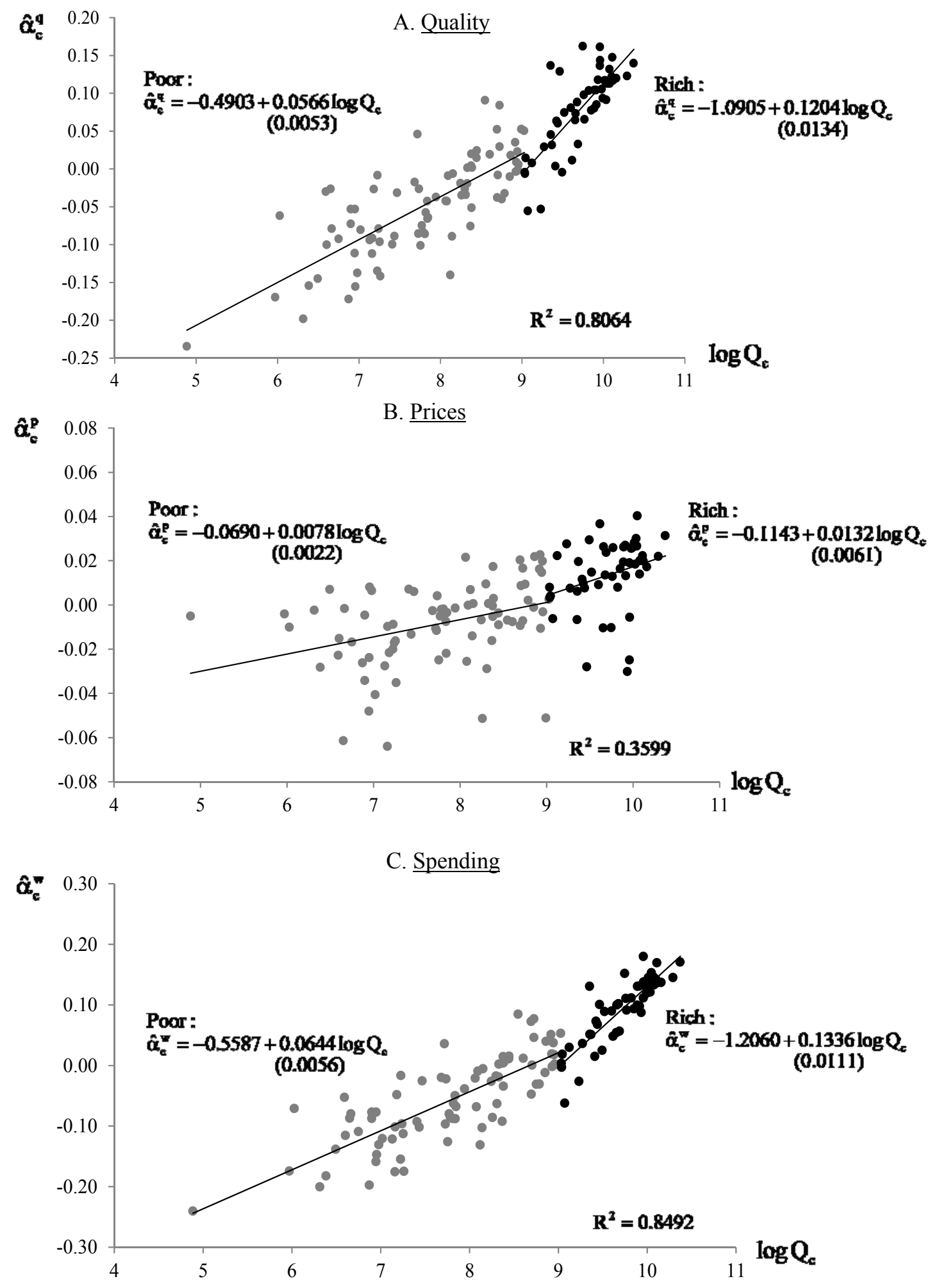

Notes: 1. Standard errors are in parentheses.

2. The $R^{2}$ values refer to all 132 countries. 
ECONOMICS DISCUSSION PAPERS

2009

\begin{tabular}{|c|c|c|}
\hline $\begin{array}{l}\text { DP } \\
\text { NUMBER }\end{array}$ & AUTHORS & TITLE \\
\hline 09.01 & Le, A.T. & $\begin{array}{l}\text { ENTRY INTO UNIVERSITY: ARE THE CHILDREN OF } \\
\text { IMMIGRANTS DISADVANTAGED? }\end{array}$ \\
\hline 09.02 & $\mathrm{Wu}, \mathrm{Y}$. & CHINA'S CAPITAL STOCK SERIES BY REGION AND SECTOR \\
\hline 09.03 & Chen, M.H. & $\begin{array}{l}\text { UNDERSTANDING WORLD COMMODITY PRICES RETURNS, } \\
\text { VOLATILITY AND DIVERSIFACATION }\end{array}$ \\
\hline 09.04 & Velagic, R. & UWA DISCUSSION PAPERS IN ECONOMICS: THE FIRST 650 \\
\hline 09.05 & McLure, M. & $\begin{array}{l}\text { ROYALTIES FOR REGIONS: ACCOUNTABILITY AND } \\
\text { SUSTAINABILITY }\end{array}$ \\
\hline 09.06 & Chen, A. and Groenewold, N. & $\begin{array}{l}\text { REDUCING REGIONAL DISPARITIES IN CHINA: AN } \\
\text { EVALUATION OF ALTERNATIVE POLICIES }\end{array}$ \\
\hline 09.07 & Groenewold, N. and Hagger, A. & $\begin{array}{l}\text { THE REGIONAL ECONOMIC EFFECTS OF IMMIGRATION: } \\
\text { SIMULATION RESULTS FROM A SMALL CGE MODEL. }\end{array}$ \\
\hline 09.08 & Clements, K. and Chen, D. & AFFLUENCE AND FOOD: SIMPLE WAY TO INFER INCOMES \\
\hline 09.09 & Clements, K. and Maesepp, M. & A SELF-REFLECTIVE INVERSE DEMAND SYSTEM \\
\hline 09.10 & Jones, C. & $\begin{array}{l}\text { MEASURING WESTERN AUSTRALIAN HOUSE PRICES: } \\
\text { METHODS AND IMPLICATIONS }\end{array}$ \\
\hline 09.11 & Siddique, M.A.B. & $\begin{array}{l}\text { WESTERN AUSTRALIA-JAPAN MINING CO-OPERATION: AN } \\
\text { HISTORICAL OVERVIEW }\end{array}$ \\
\hline 09.12 & Weber, E.J. & $\begin{array}{l}\text { PRE-INDUSTRIAL BIMETALLISM: THE INDEX COIN } \\
\text { HYPTHESIS }\end{array}$ \\
\hline 09.13 & McLure, M. & $\begin{array}{l}\text { PARETO AND PIGOU ON OPHELIMITY, UTILITY AND } \\
\text { WELFARE: IMPLICATIONS FOR PUBLIC FINANCE }\end{array}$ \\
\hline 09.14 & Weber, E.J. & $\begin{array}{l}\text { WILFRED EDWARD GRAHAM SALTER: THE MERITS OF A } \\
\text { CLASSICAL ECONOMIC EDUCATION }\end{array}$ \\
\hline 09.15 & Tyers, R. and Huang, L. & $\begin{array}{l}\text { COMBATING CHINA'S EXPORT CONTRACTION: FISCAL } \\
\text { EXPANSION OR ACCELERATED INDUSTRIAL REFORM }\end{array}$ \\
\hline 09.16 & $\begin{array}{l}\text { Zweifel, P., Plaff, D. and } \\
\text { Kühn, J. }\end{array}$ & $\begin{array}{l}\text { IS REGULATING THE SOLVENCY OF BANKS COUNTER- } \\
\text { PRODUCTIVE? }\end{array}$ \\
\hline 09.17 & Clements, $\mathrm{K}$. & THE PHD CONFERENCE REACHES ADULTHOOD \\
\hline 09.18 & McLure, M. & $\begin{array}{l}\text { THIRTY YEARS OF ECONOMICS: UWA AND THE WA } \\
\text { BRANCH OF THE ECONOMIC SOCIETY FROM } 1963 \text { TO } 1992\end{array}$ \\
\hline 09.19 & Harris, R.G. and Robertson, P. & $\begin{array}{l}\text { TRADE, WAGES AND SKILL ACCUMULATION IN THE } \\
\text { EMERGING GIANTS }\end{array}$ \\
\hline 09.20 & $\begin{array}{l}\text { Peng, J., Cui, J., Qin, F. and } \\
\text { Groenewold, N. }\end{array}$ & STOCK PRICES AND THE MACRO ECONOMY IN CHINA \\
\hline 09.21 & Chen, A. and Groenewold, N. & $\begin{array}{l}\text { REGIONAL EQUALITY AND NATIONAL DEVELOPMENT IN } \\
\text { CHINA: IS THERE A TRADE-OFF? }\end{array}$ \\
\hline
\end{tabular}




\section{ECONOMICS DISCUSSION PAPERS}

2010

\begin{tabular}{|c|c|c|}
\hline $\begin{array}{l}\text { DP } \\
\text { NUMBER }\end{array}$ & AUTHORS & TITLE \\
\hline 10.01 & Hendry, D.F. & $\begin{array}{l}\text { RESEARCH AND THE ACADEMIC: A TALE OF } \\
\text { TWO CULTURES }\end{array}$ \\
\hline 10.02 & McLure, M., Turkington, D. and Weber, E.J. & A CONVERSATION WITH ARNOLD ZELLNER \\
\hline 10.03 & $\begin{array}{l}\text { Butler, D.J., Burbank, V.K. and } \\
\text { Chisholm, J.S. }\end{array}$ & $\begin{array}{l}\text { THE FRAMES BEHIND THE GAMES: PLAYER'S } \\
\text { PERCEPTIONS OF PRISONER'S DILEMMA, } \\
\text { CHICKEN, DICTATOR, AND ULTIMATUM GAMES }\end{array}$ \\
\hline 10.04 & Harris, R.G., Robertson, P.E. and Xu, J.Y. & $\begin{array}{l}\text { THE INTERNATIONAL EFFECTS OF CHINA'S } \\
\text { GROWTH, TRADE AND EDUCATION BOOMS }\end{array}$ \\
\hline 10.05 & Clements, K.W., Mongey, S. and Si, J. & $\begin{array}{l}\text { THE DYNAMICS OF NEW RESOURCE PROJECTS } \\
\text { A PROGRESS REPORT }\end{array}$ \\
\hline 10.06 & Costello, G., Fraser, P. and Groenewold, N. & $\begin{array}{l}\text { HOUSE PRICES, NON-FUNDAMENTAL } \\
\text { COMPONENTS AND INTERSTATE SPILLOVERS: } \\
\text { THE AUSTRALIAN EXPERIENCE }\end{array}$ \\
\hline 10.07 & Clements, $\mathrm{K}$. & $\begin{array}{l}\text { REPORT OF THE } 2009 \text { PHD CONFERENCE IN } \\
\text { ECONOMICS AND BUSINESS }\end{array}$ \\
\hline 10.08 & Robertson, P.E. & $\begin{array}{l}\text { INVESTMENT LED GROWTH IN INDIA: HINDU } \\
\text { FACT OR MYTHOLOGY? }\end{array}$ \\
\hline 10.09 & Fu, D., Wu, Y. and Tang, Y. & $\begin{array}{l}\text { THE EFFECTS OF OWNERSHIP STRUCTURE AND } \\
\text { INDUSTRY CHARACTERISTICS ON EXPORT } \\
\text { PERFORMANCE }\end{array}$ \\
\hline 10.10 & $\mathrm{Wu}, \mathrm{Y}$. & $\begin{array}{l}\text { INNOVATION AND ECONOMIC GROWTH IN } \\
\text { CHINA }\end{array}$ \\
\hline 10.11 & Stephens, B.J. & $\begin{array}{l}\text { THE DETERMINANTS OF LABOUR FORCE } \\
\text { STATUS AMONG INDIGENOUS AUSTRALIANS }\end{array}$ \\
\hline 10.12 & Davies, M. & $\begin{array}{l}\text { FINANCING THE BURRA BURRA MINES, SOUTH } \\
\text { AUSTRALIA: LIQUIDITY PROBLEMS AND } \\
\text { RESOLUTIONS }\end{array}$ \\
\hline 10.13 & Tyers, R. and Zhang, Y. & APPRECIATING THE RENMINBI \\
\hline 10.14 & Clements, K.W., Lan, Y. and Seah, S.P. & $\begin{array}{l}\text { THE BIG MAC INDEX TWO DECADES ON } \\
\text { AN EVALUATION OF BURGERNOMICS }\end{array}$ \\
\hline 10.15 & Robertson, P.E. and Xu, J.Y. & $\begin{array}{l}\text { IN CHINA'S WAKE: } \\
\text { HAS ASIA GAINED FROM CHINA'S GROWTH? }\end{array}$ \\
\hline 10.16 & Clements, K.W. and Izan, H.Y. & $\begin{array}{l}\text { THE PAY PARITY MATRIX: A TOOL FOR } \\
\text { ANALYSING THE STRUCTURE OF PAY }\end{array}$ \\
\hline 10.17 & Gao, G. & WORLD FOOD DEMAND \\
\hline 10.18 & $\mathrm{Wu}, \mathrm{Y}$ & $\begin{array}{l}\text { INDIGENOUS INNOVATION IN CHINA: } \\
\text { IMPLICATIONS FOR SUSTAINABLE GROWTH }\end{array}$ \\
\hline 10.19 & Robertson, P.E. & DECIPHERING THE HINDU GROWTH EPIC \\
\hline 10.20 & Stevens, G. & $\begin{array}{l}\text { RESERVE BANK OF AUSTRALIA-THE ROLE OF } \\
\text { FINANCE }\end{array}$ \\
\hline 10.21 & Widmer, P.K., Zweifel, P. and Farsi, M. & $\begin{array}{l}\text { ACCOUNTING FOR HETEROGENEITY IN THE } \\
\text { MEASUREMENT OF HOSPITAL PERFORMANCE }\end{array}$ \\
\hline
\end{tabular}




\begin{tabular}{|l|l|l|}
\hline 10.22 & McLure, $\mathrm{M}$. & $\begin{array}{l}\text { ASSESSMENTS OF A. C. PIGOU'S FELLOWSHIP } \\
\text { THESES }\end{array}$ \\
\hline 10.23 & Poon, A.R. & $\begin{array}{l}\text { THE ECONOMICS OF NONLINEAR PRICING: } \\
\text { EVIDENCE FROM AIRFARES AND GROCERY } \\
\text { PRICES }\end{array}$ \\
\hline 10.24 & Halperin, D. & $\begin{array}{l}\text { FORECASTING METALS RETURNS: A BAYESIAN } \\
\text { DECISION THEORETIC APPROACH }\end{array}$ \\
\hline 10.25 & Clements, K.W. and Si. J. & $\begin{array}{l}\text { THE INVESTMENT PROJECT PIPELINE: COST } \\
\text { ESCALATION, LEAD-TIME, SUCCESS, FAILURE } \\
\text { AND SPEED }\end{array}$ \\
\hline 10.26 & Chen, A., Groenewold, N. and Hagger, A.J. & $\begin{array}{l}\text { THE REGIONAL ECONOMIC EFFECTS OF A } \\
\text { REDUCTION IN CARBON EMISSIONS }\end{array}$ \\
\hline 10.27 & $\begin{array}{l}\text { Siddique, A., Selvanathan, E.A. and } \\
\text { Selvanathan, S. }\end{array}$ & $\begin{array}{l}\text { REMITTANCES AND ECONOMIC GROWTH: } \\
\text { EMPIRICAL EVIDENCE FROM BANGLADESH, } \\
\text { INDIA AND SRI LANKA }\end{array}$ \\
\hline
\end{tabular}




\section{ECONOMICS DISCUSSION PAPERS}

2011

\begin{tabular}{|c|c|c|}
\hline $\begin{array}{l}\text { DP } \\
\text { NUMBER }\end{array}$ & AUTHORS & TITLE \\
\hline 11.01 & Robertson, P.E. & $\begin{array}{l}\text { DEEP IMPACT: CHINA AND THE WORLD } \\
\text { ECONOMY }\end{array}$ \\
\hline 11.02 & Kang, C. and Lee, S.H. & $\begin{array}{l}\text { BEING KNOWLEDGEABLE OR SOCIABLE? } \\
\text { DIFFERENCES IN RELATIVE IMPORTANCE OF } \\
\text { COGNITIVE AND NON-COGNITIVE SKILLS }\end{array}$ \\
\hline 11.03 & Turkington, D. & DIFFERENT CONCEPTS OF MATRIX CALCULUS \\
\hline 11.04 & Golley, J. and Tyers, R. & $\begin{array}{l}\text { CONTRASTING GIANTS: DEMOGRAPHIC CHANGE } \\
\text { AND ECONOMIC PERFORMANCE IN CHINA AND } \\
\text { INDIA }\end{array}$ \\
\hline 11.05 & Collins, J., Baer, B. and Weber, E.J. & $\begin{array}{l}\text { ECONOMIC GROWTH AND EVOLUTION: } \\
\text { PARENTAL PREFERENCE FOR QUALITY AND } \\
\text { QUANTITY OF OFFSPRING }\end{array}$ \\
\hline 11.06 & Turkington, D. & $\begin{array}{l}\text { ON THE DIFFERENTIATION OF THE LOG } \\
\text { LIKELIHOOD FUNCTION USING MATRIX } \\
\text { CALCULUS }\end{array}$ \\
\hline 11.07 & Groenewold, N. and Paterson, J.E.H. & $\begin{array}{l}\text { STOCK PRICES AND EXCHANGE RATES IN } \\
\text { AUSTRALIA: ARE COMMODITY PRICES THE } \\
\text { MISSING LINK? }\end{array}$ \\
\hline 11.08 & Chen, A. and Groenewold, N. & $\begin{array}{l}\text { REDUCING REGIONAL DISPARITIES IN CHINA: IS } \\
\text { INVESTMENT ALLOCATION POLICY EFFECTIVE? }\end{array}$ \\
\hline 11.09 & Williams, A., Birch, E. and Hancock, P. & $\begin{array}{l}\text { THE IMPACT OF ON-LINE LECTURE RECORDINGS } \\
\text { ON STUDENT PERFORMANCE }\end{array}$ \\
\hline 11.10 & Pawley, J. and Weber, E.J. & $\begin{array}{l}\text { INVESTMENT AND TECHNICAL PROGRESS IN THE } \\
\text { G7 COUNTRIES AND AUSTRALIA }\end{array}$ \\
\hline 11.11 & Tyers, R. & $\begin{array}{l}\text { AN ELEMENTAL MACROECONOMIC MODEL FOR } \\
\text { APPLIED ANALYSIS AT UNDERGRADUATE LEVEL }\end{array}$ \\
\hline 11.12 & Clements, K.W. and Gao, G. & QUALITY, QUANTITY, SPENDING AND PRICES \\
\hline 11.13 & Tyers, R. and Zhang, Y. & $\begin{array}{l}\text { JAPAN'S ECONOMIC RECOVERY: INSIGHTS FROM } \\
\text { MULTI-REGION DYNAMICS }\end{array}$ \\
\hline 11.14 & McLure, M. & A. C. PIGOU'S REJECTION OF PARETO'S LAW \\
\hline 11.15 & Kristoffersen, I. & $\begin{array}{l}\text { THE SUBJECTIVE WELLBEING SCALE: HOW } \\
\text { REASONABLE IS THE CARDINALITY } \\
\text { ASSUMPTION? }\end{array}$ \\
\hline 11.16 & Clements, K.W., Izan, H.Y. and Lan, Y. & VOLATILITY AND STOCK PRICE INDEXES \\
\hline 11.17 & Parkinson, M. & $\begin{array}{l}\text { SHANN MEMORIAL LECTURE 2011: SUSTAINABLE } \\
\text { WELLBEING - AN ECONOMIC FUTURE FOR } \\
\text { AUSTRALIA }\end{array}$ \\
\hline
\end{tabular}

